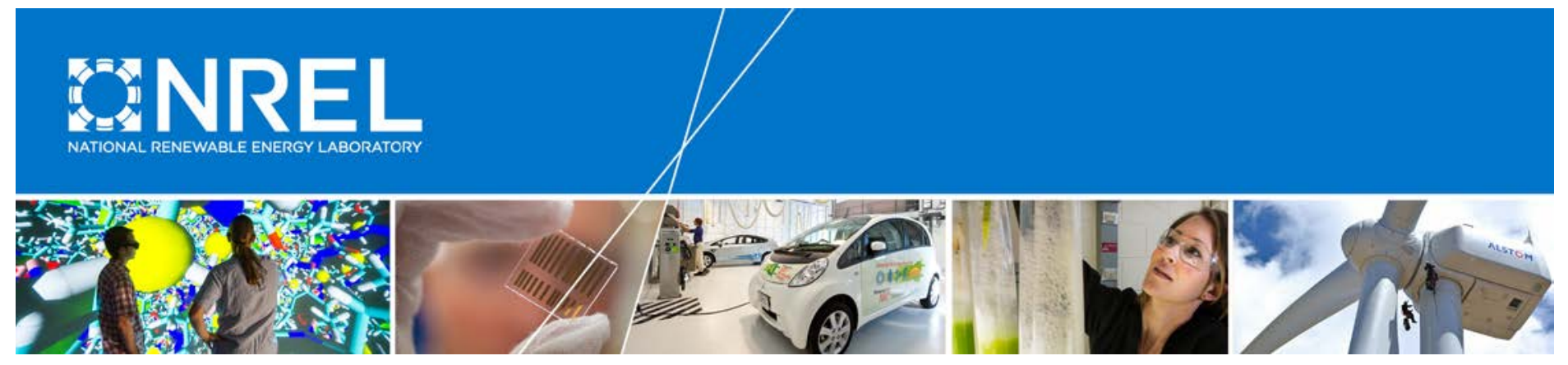

\title{
Wind Plant Preconstruction Energy Estimates: Current Practice and Opportunities
}

Andrew Clifton, Aaron Smith, and Michael Fields National Renewable Energy Laboratory

NREL is a national laboratory of the U.S. Department of Energy Office of Energy Efficiency \& Renewable Energy Operated by the Alliance for Sustainable Energy, LLC

This report is available at no cost from the National Renewable Energy Laboratory (NREL) at www.nrel.gov/publications.

Technical Report

NREL/TP-5000-64735

April 2016

Contract No. DE-AC36-08GO28308 


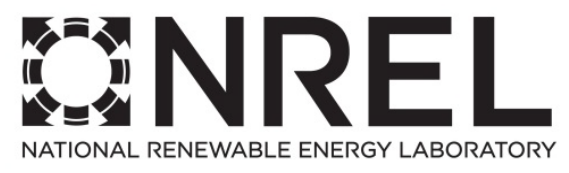

\section{Wind Plant Preconstruction Energy Estimates: Current Practice and Opportunities}

Andrew Clifton, Aaron Smith, and Michael Fields National Renewable Energy Laboratory

Prepared under Task No. WE15.3B02

NREL is a national laboratory of the U.S. Department of Energy Office of Energy Efficiency \& Renewable Energy Operated by the Alliance for Sustainable Energy, LLC

This report is available at no cost from the National Renewable Energy Laboratory (NREL) at www.nrel.gov/publications.

National Renewable Energy Laboratory 15013 Denver West Parkway Golden, CO 80401 303-275-3000 • www.nrel.gov
Technical Report

NREL/TP-5000-64735

April 2016

Contract No. DE-AC36-08GO28308 


\section{NOTICE}

This report was prepared as an account of work sponsored by an agency of the United States government. Neither the United States government nor any agency thereof, nor any of their employees, makes any warranty, express or implied, or assumes any legal liability or responsibility for the accuracy, completeness, or usefulness of any information, apparatus, product, or process disclosed, or represents that its use would not infringe privately owned rights. Reference herein to any specific commercial product, process, or service by trade name, trademark, manufacturer, or otherwise does not necessarily constitute or imply its endorsement, recommendation, or favoring by the United States government or any agency thereof. The views and opinions of authors expressed herein do not necessarily state or reflect those of the United States government or any agency thereof.

This report is available at no cost from the National Renewable Energy Laboratory (NREL) at www.nrel.gov/publications.

Available electronically at SciTech Connect http:/www.osti.gov/scitech

Available for a processing fee to U.S. Department of Energy and its contractors, in paper, from:

U.S. Department of Energy

Office of Scientific and Technical Information

P.O. Box 62

Oak Ridge, TN 37831-0062

OSTI http://www.osti.gov

Phone: 865.576.8401

Fax: 865.576.5728

Email: reports@osti.gov

Available for sale to the public, in paper, from:

U.S. Department of Commerce

National Technical Information Service

5301 Shawnee Road

Alexandria, VA 22312

NTIS http://www.ntis.gov

Phone: 800.553 .6847 or 703.605 .6000

Fax: 703.605.6900

Email: orders@ntis.gov 


\section{Acknowledgments}

This work was supported by the U.S. Department of Energy under Contract No. DE-AC3608GO28308 with the National Renewable Energy Laboratory. Funding for the work was provided by the DOE Office of Energy Efficiency and Renewable Energy, Wind and Water Power Technologies Office. 


\section{List of Acronyms}

$\begin{array}{ll}\mathrm{GWh} / \mathrm{yr} & \text { gigawatt-hour per year } \\ \mathrm{IE} & \begin{array}{l}\text { independent engineer } \\ \text { IEC }\end{array} \\ \mathrm{kW} & \text { International Electrotechnical Commission } \\ \text { kCOE } & \text { kilowatt } \\ \mathrm{m} / \mathrm{s} & \text { levelized cost of energy } \\ \mathrm{MCP} & \text { meters per second } \\ \mathrm{MW} & \text { measure-correlate-predict } \\ \text { O\&M } & \text { megawatt } \\ \text { OEM } & \text { operation and maintenance } \\ & \text { original equipment manufacturer }\end{array}$




\section{Executive Summary}

Understanding the amount of energy that will be harvested by a wind power plant each year and the variability of that energy is essential to assessing and potentially improving the financial viability of that power plant.

The preconstruction energy estimate process predicts the amount of energy — with uncertainty estimates - that a wind power plant will deliver to the point of revenue. This report describes the preconstruction energy estimate process from a technical perspective and seeks to provide insight into the financial implications associated with each step. The main outcome from the process is the net energy estimate, which includes its probability distribution (Figure ES1).

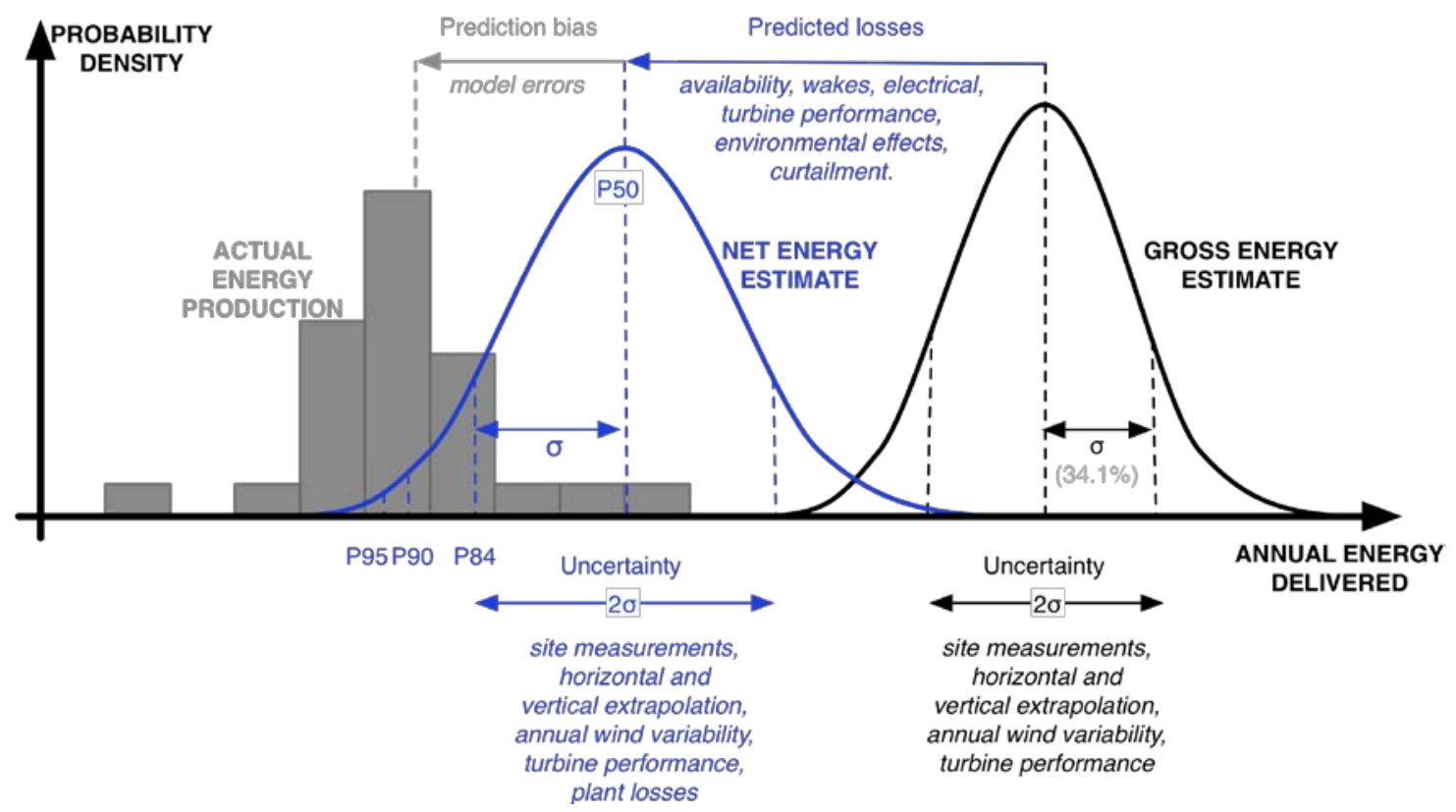

Figure ES1. The net energy estimate is a key part of the preconstruction energy estimate

The preconstruction energy estimate only includes the gross and net energy estimates together with information about losses and uncertainties. Actual energy production data are shown for illustration only.

The net energy estimate is used by the developer to judge the financial viability of a wind power plant, and it is included as part of its financing package. Reducing uncertainty in energy reduces the cost of financing the power plant, and it may open wind energy to alternative funding sources. Reducing predicted losses through plant optimization or improved operational strategies increases the potential revenue from the plant and so reduces the cost of electricity.

The estimate is expressed as a probability distribution of energy in different periods that are important to various project stakeholders. These timescales are typically 1 year, 10 years, and 20 years, and the uncertainties are expressed as $P x$ values. For example, the 1-year $P 50$ value is the amount of energy that has a $50 \%$ probability of being exceeded in any single year during the project's life. Likewise, the 10-year $P 95$ is the amount of energy that has a $95 \%$ probability of being exceeded in any 10 years of the project's life. These data are essential inputs to financial models, and they are used by stakeholders to size their capital contributions and evaluate the degrees of exposure to risk related to production uncertainty. 
The preconstruction energy estimate process is similar throughout most of the wind industry in the United States and Europe (Figure ES2). Although this document focuses on land-based wind power plants, the same processes are used offshore.

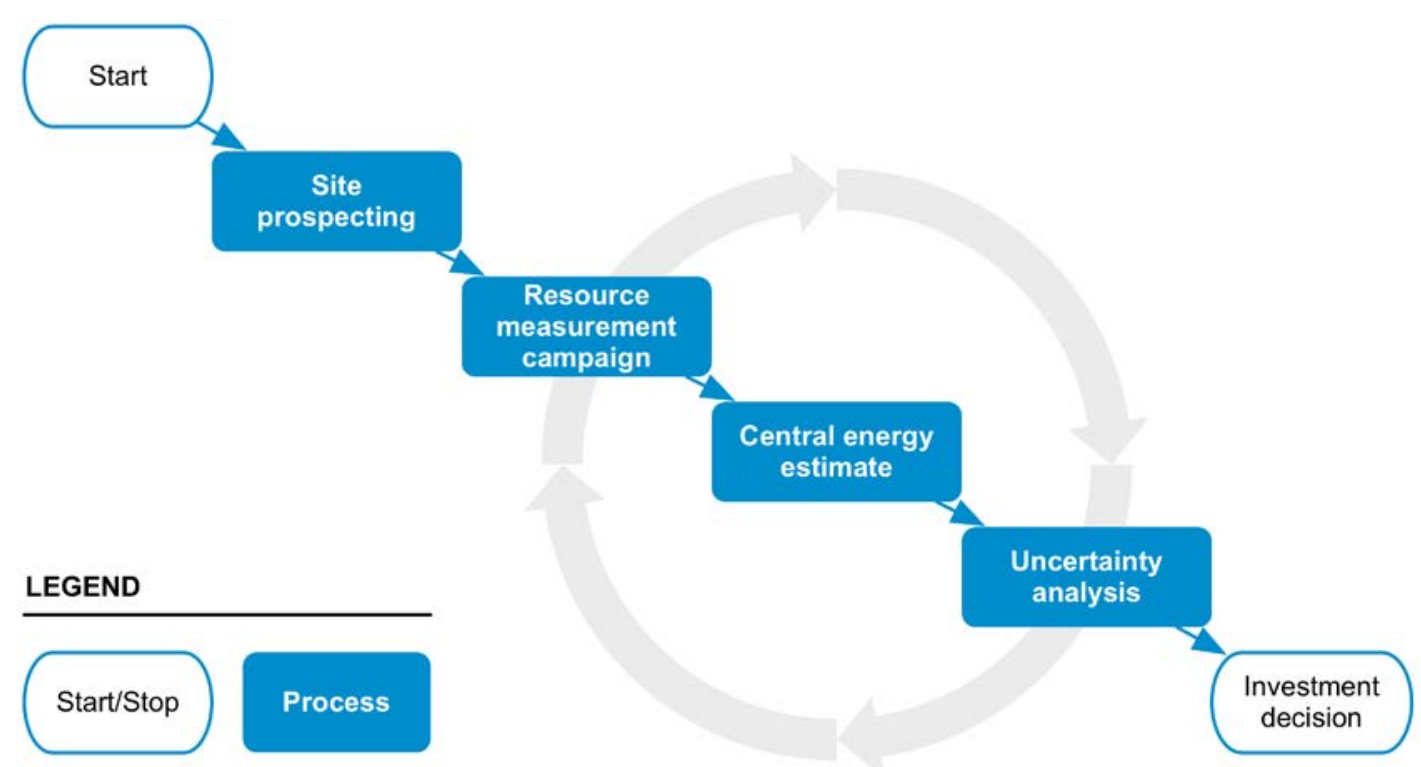

Figure ES2. Main technical activities in a wind power plant's energy estimate process

The main steps include:

- Site prospecting: finding a potential site using country- or state-level resource maps and securing land

- Resource measurement campaign: measuring wind and other conditions on the site for several years

- Central energy estimate, including:

○ Long-term resource correction: calculating the long-term on-site wind climate from local and off-site data

- Horizontal and vertical extrapolation: filling gaps between measurement points and estimating wind speed at hub heights and across the rotor

- Turbine selection: choosing appropriate wind turbines for the site's wind speed and turbulence

- Site optimization: establishing the best layout for a particular goal and quantifying the energy capture $(P 50)$ based on that layout and turbines

- Loss estimation: calculating how much energy will be lost in electrical lines and through turbine downtime, wakes, and other factors.

- Uncertainty analysis: quantifying the uncertainty of each step in the estimate, which is then used to derive $P 95$ and $P 99$ values for different timescales. 
The central energy estimate and uncertainty estimate are revised in an iterative fashion as more project data become available and different commercial scenarios are considered.

Although some approaches to preconstruction energy prediction process are similar, there is no standard process or terminology at the present time of publication. Therefore, an international group has proposed a new International Electrotechnical Commission (IEC) standard to address this issue, provisionally called IEC 61400-15: Assessment of Wind Resource, Energy Yield, and Site Suitability Input Conditions for Wind Power Plants.

The chief controls on wind plant energy losses are the site's layout, wind conditions, and operations. Losses can be reduced through a variety of approaches such as site planning, use of turbine- and plant-level controls, and engagement with balancing authorities. Better loss estimates would reduce the bias compared to actual performance, which would make wind more comparable to thermal generation and increase the confidence of financiers to invest in wind energy. Figure ES3 and Figure ES4 present summaries of loss and uncertainty values in the literature according to the categories proposed by the IEC 61400-15 working group. These are not fleet-wide values because this data is not available.

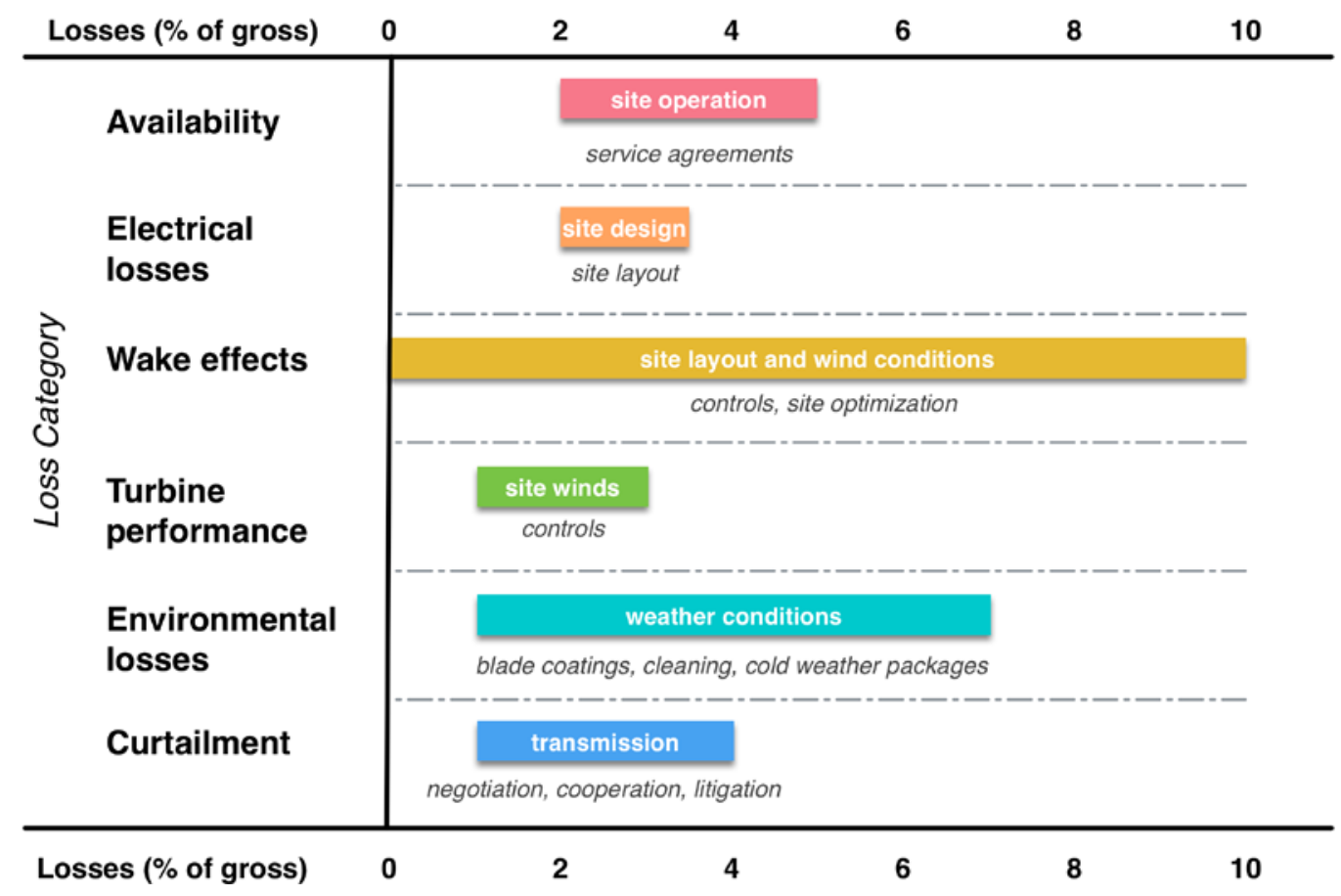

Figure ES3. Sources of wind plant energy losses

Controlling factors are identified in the bars; mitigation actions are shown below each bar. Values apply to wind power plants designed and built in 2010-2015 and are based on the literature survey in Section 4.

Uncertainties associated with site layout, measurements, and turbine model are under the project's control and can be mitigated; for example, using more instruments at more points around a site, up to and beyond hub heights, would directly reduce uncertainty. In comparison, uncertainties associated with wind conditions and climate variability are largely dictated by the project location, and they are largely out of the project's control. 


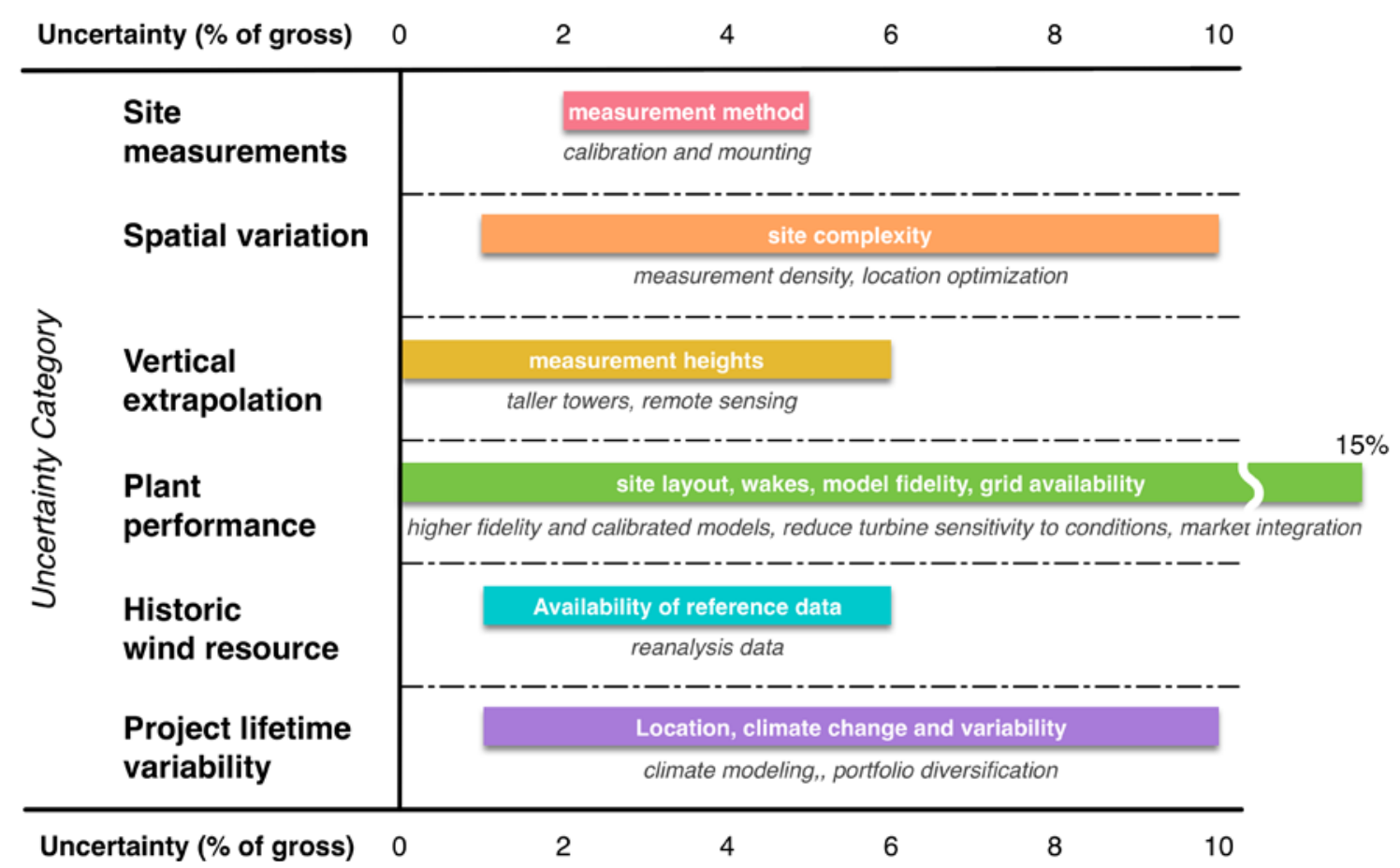

Figure ES4. Sources of uncertainty in a wind plant energy estimate

Controlling factors are identified in the bars; mitigation actions are shown below each bar. Values apply to wind power plants designed and built in 2010-2015 and are based on the literature survey in Section 4.

Many wind flow, wake, or turbine performance models do not include relevant physics. Compared to baseline models, higher-fidelity models require more information (or assumptions) to run, but they may be more accurate or reduce uncertainty.

The accuracy of preconstruction energy estimates could be improved by addressing the prediction of gross energy production, losses, and uncertainties. Actions to achieve this include:

- Evidence to drive investigations: create a database representing a wide range of developers, turbines, and geographic areas that includes pre- and postconstruction energy estimates with standardized reporting of losses and uncertainties.

- Improved measurement and modeling techniques: develop better site measurement tools, including remote sensing, more accurate wind turbine power curve methods, faster and more accurate wind flow and wake models, better long-term wind resource prediction tools including climate variability, and better curtailment models.

- Improved modeling and reporting of uncertainty: create more accurate and evidencebased uncertainty models-potentially based on time-based energy prediction approachesas well as the use of risk-assessments to identify, report, and potentially mitigate lowprobability but high-impact technical risks to the wind power plant's performance.

Improvements to the preconstruction energy estimate would potentially open the path to new wind power plant financing and increase the deployment of wind energy in the United States and abroad. 


\section{Table of Contents}

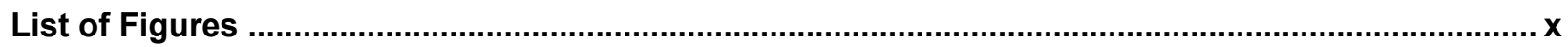

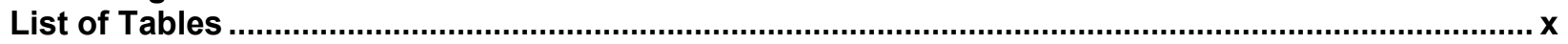

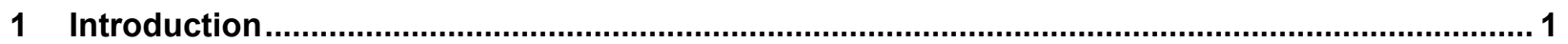

1.1 What Is a Preconstruction Energy Estimate? ............................................................... 1

1.2 Who Is Involved in the Preconstruction Energy Estimate? .................................................. 2

1.3 How Is The Preconstruction Energy Estimate Used?...............................................

2 Key Parts of the Preconstruction Energy Estimate .............................................................. 5

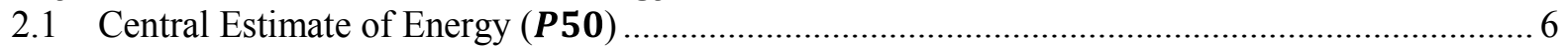

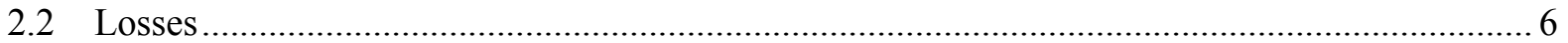

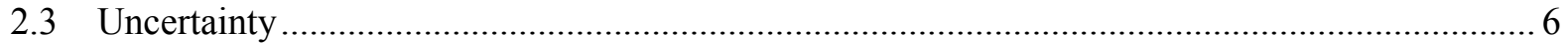

2.4 Prediction Bias .................................................................................................. 7

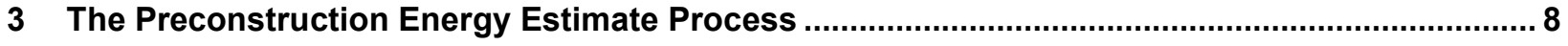

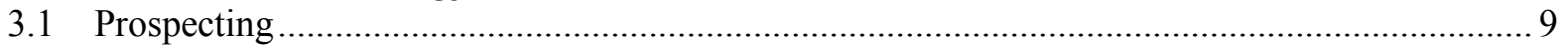

3.2 Resource Measurement Campaign .......................................................................... 11

3.3 Central Estimate of Energy $(P 50)$............................................................................ 13

3.3.1 Data Processing and Long-Term Resource Correction ........................................... 14

3.3.2 Horizontal and Vertical Extrapolation ............................................................. 16

3.3.3 Turbine Selection .................................................................................... 18

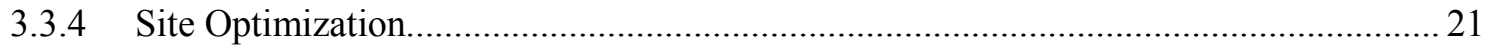

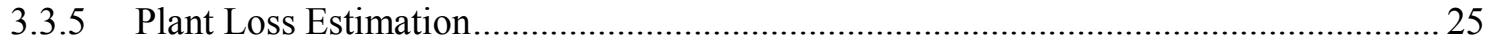

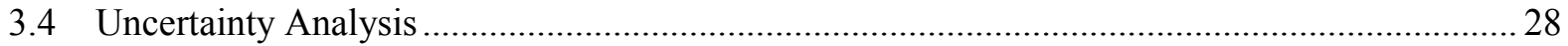

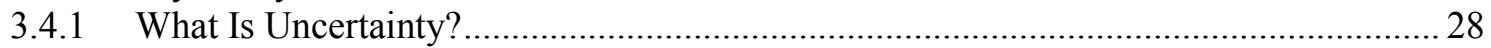

3.4.2 Measurement Uncertainty ........................................................................... 28

3.4.3 Model Uncertainty................................................................................... 30

3.4.4 Project Total Uncertainty ........................................................................... 31

3.4.5 Establishing P-factors from Uncertainties....................................................... 31

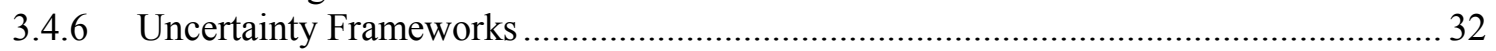

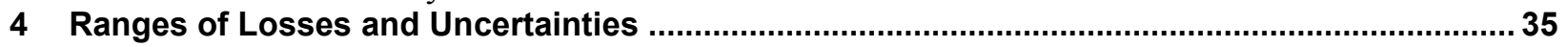

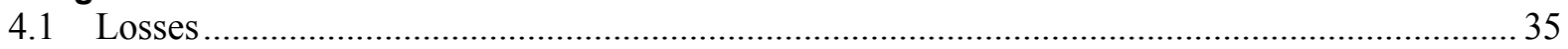

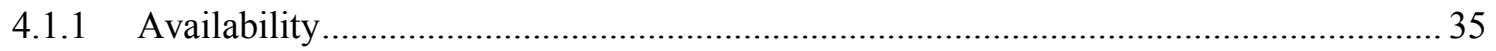

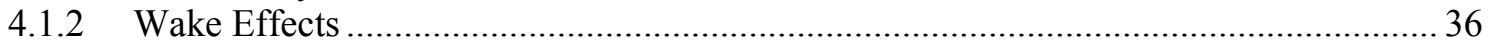

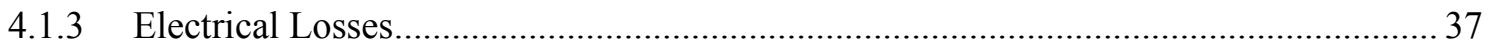

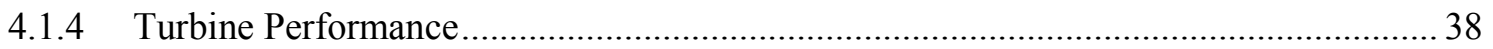

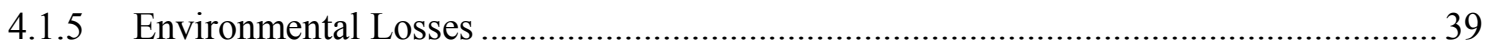

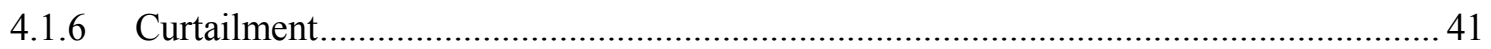

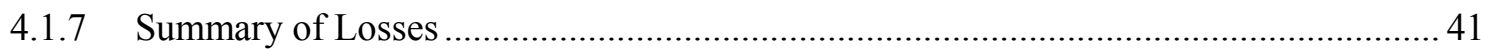

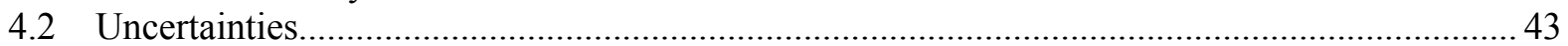

4.2.1 Site Measurements .................................................................................. 43

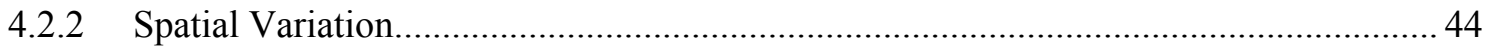

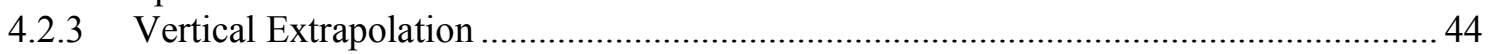

4.2.4 Plant Performance .................................................................................... 45

4.2.5 Historic Wind Resource .............................................................................. 46

4.2.6 Project Lifetime Variability ........................................................................ 47

4.2.7 Summary of Uncertainties........................................................................ 47

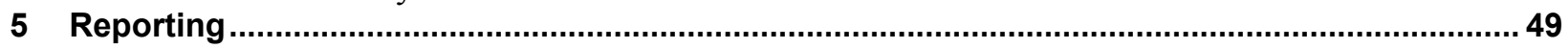

5.1 Site Description ............................................................................................ 49

5.2 Wind Resource Characteristics ............................................................................... 50

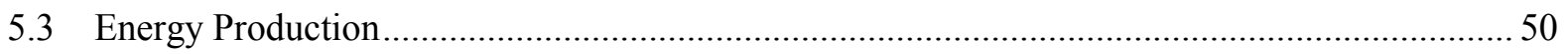

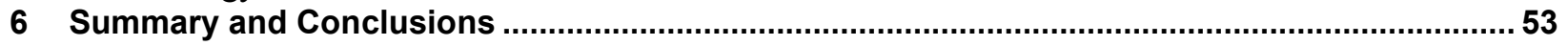

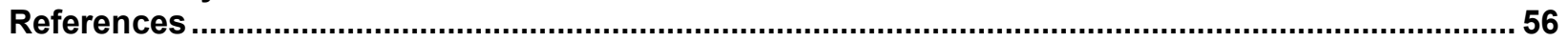




\section{List of Figures}

Figure ES1. The net energy estimate is a key part of the preconstruction energy estimate......................... $\mathrm{v}$

Figure ES2. Main technical activities in a wind power plant's energy estimate process........................... vi

Figure ES3. Sources of wind plant energy losses ............................................................................... vii

Figure ES4. Sources of uncertainty in a wind plant energy estimate....................................................viii

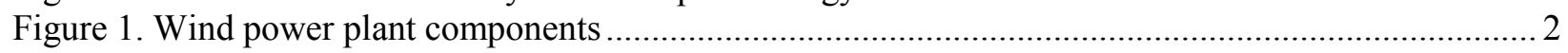

Figure 2. Elements of the preconstruction energy estimate ........................................................ 5

Figure 3. High-level technical activities to develop an energy estimate for a new wind power plant.......... 8

Figure 4. Process of creating a wind plant's central energy estimate ....................................................... 14

Figure 5. Binned wind speed for a single turbine together with the turbine power curve ......................... 20

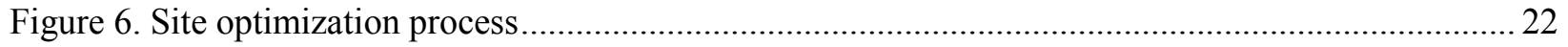

Figure 7. Loss categories proposed by the IEC 61400-15 working group ............................................ 26

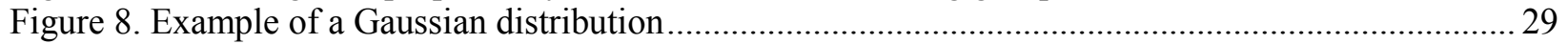

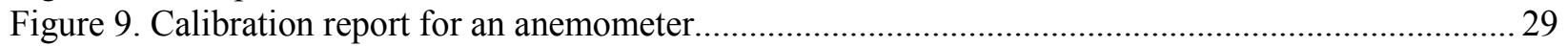

Figure 10. Example of the relationship between the mean and standard deviation and Pxx .................... 31

Figure 11. Uncertainty categories proposed by the IEC 61400-15 working group ................................ 32

Figure 12. When uncertainties in the preconstruction energy estimate are created ................................. 33

Figure 13. Range of energy losses in a wind plant's preconstruction energy estimate.............................53

Figure 14. Range of energy uncertainties in a wind plant's preconstruction energy estimate....................54

All figures created by NREL.

\section{List of Tables}

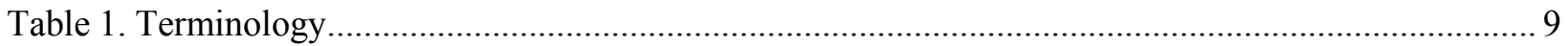

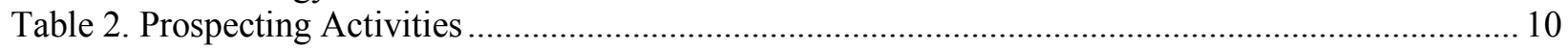

Table 3. Resource Measurement Campaign Activities ....................................................................... 12

Table 4. Data Processing and Long-Term Resource Correction Activities ........................................... 15

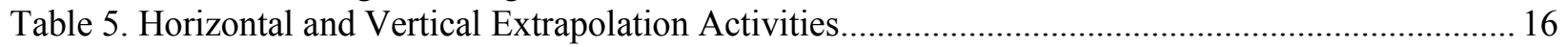

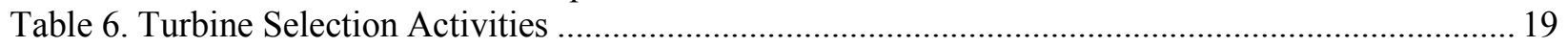

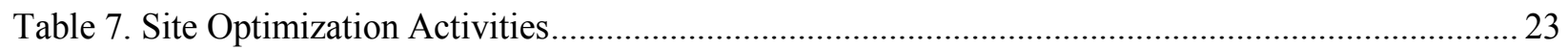

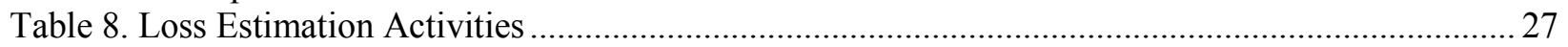

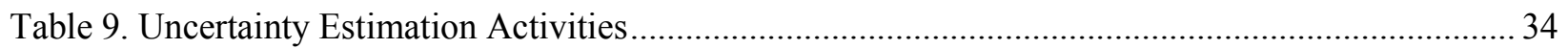

Table 10. Summary of Losses in a Wind Plant......................................................................................... 42

Table 11. Summary of Uncertainties in Wind Plant Preconstruction Energy Estimates .......................... 48

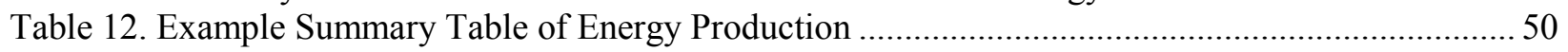

Table 13. Example Summary Energy Production and Capacity Factor Distribution ................................. 51

Table 14. Example Summary of Loss Using Proposed IEC 61400-15 Categories.................................... 51

Table 15. Example Summary of Uncertainty Using Proposed IEC 61400-15 Categories......................... 52

Table 16. Example 12-by-24 Table of Energy Production .................................................................... 52 


\section{Introduction}

Commercial-scale wind projects are large, complex, and capital intensive, with capital expenditures for a typical 200-megawatt (MW) land-based wind project ranging between $\$ 280$ million and $\$ 500$ million (Wiser and Bollinger 2014). Offshore wind projects tend to be larger than land-based projects and more expensive on a dollar-per-kilowatt basis. A typical 400-MW offshore wind project in Europe would require capital expenditures from \$1.6 billion to $\$ 2.4$ billion (Hamilton et al. 2014).

Like any other large-scale energy project, decisions to invest in wind projects are built on expectations about the future that are subject to some amount of uncertainty, which can impact the profitability of the venture. In a wind energy project, project sponsors take steps during the development phase to understand capital expenditures, operational expenditures, and net annual energy production based on the characteristics at a given project site. These are evaluated against the price at which energy and other attributes can be sold into the market to value the opportunity associated with the investment. This primer focuses on communicating the methodology that the wind industry uses to predict the net energy delivery from prospective wind projects, including current status, uncertainties, and linkages to financial decision-making. This prediction is called the preconstruction energy estimate.

This section provides an introduction to the preconstruction energy estimate, including the various stakeholders and how they use it. Section 2 describes key parts of the preconstruction energy estimate. Section 3 describes the high-level process that is common to most of the wind energy community. Section 4 presents recently published estimates of losses and uncertainty. Section 5 describes the preconstruction energy yield analysis report that will be generated. Section 6 summarizes the process and discusses opportunities to better estimate energy assessment losses and uncertainties.

\subsection{What is a Preconstruction Energy Estimate?}

The amount of energy delivered by a wind power plant varies each year. This variability arises because of natural fluctuations in the wind resource and because of changes in the wind power plant's ability to capture and deliver that energy. This variability leads to a fluctuating income for the wind power plant and investors. Because of this, it is essential to quantify both the mean energy and the variability of the energy as accurately as possible before the wind power plant is built. This is done using the preconstruction energy estimate, which quantifies the likely distribution of energy that a wind power plant will produce during different periods of its investment life.

A preconstruction energy estimate is an estimate of the energy delivered to the point of revenue metering (Figure 1) during each year that the plant is in operation. This estimate is the potential amount of energy that could be generated by the wind project given the site's wind resource and turbine power curve minus plant losses due to the effect of wakes on downwind turbines, turbine performance, environmental factors, technical availability, curtailment, and electrical losses. 


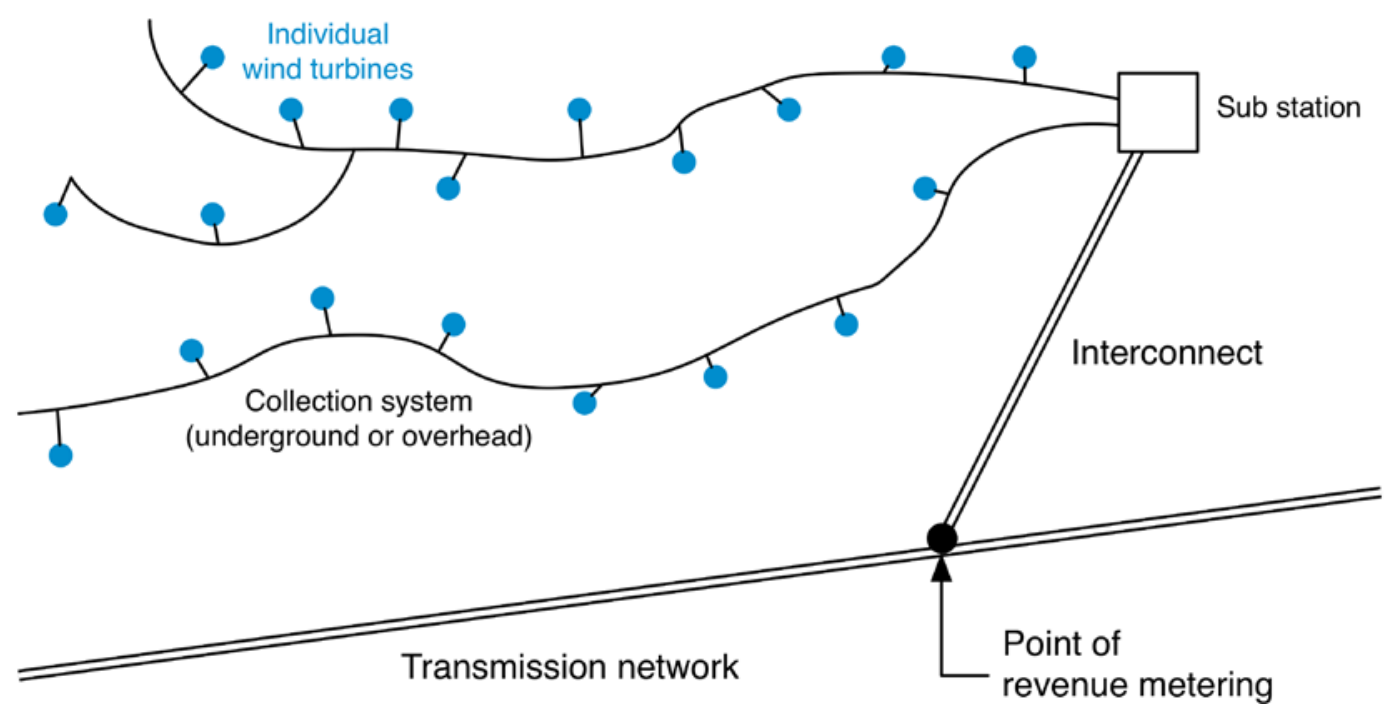

Figure 1. Wind power plant components

Typically, the preconstruction estimate is produced directly by the project sponsor or by one or more independent engineers, and it leverages their experiences of other wind power plants.

\subsection{Who is Involved in the Preconstruction Energy Estimate?}

A preconstruction energy estimate involves many different parties, including:

- The project sponsor, also referred to as the developer: the entity that leads the development of the wind project and arranges the financial structure. The engineering capability of the project sponsor varies: some sponsors having significant in-house wind power plant development capabilities, and others subcontract much of the engineering.

- Independent engineer (IE): an organization that provides engineering services to the project sponsor and has no financial stake in the project.

- Turbine original equipment manufacturer (OEM): the organization that provides the turbines to the project.

\subsection{How is the Preconstruction Energy Estimate Used?}

Financial stakeholders use the information in the preconstruction energy estimate to value the future cash flows that a project could generate during its operational lifetime. The preconstruction energy estimate also provides insight into the amount of uncertainty surrounding cash flow. 
Wind project sponsors use a number of different financial structures to obtain the investment required to build wind projects. Harper, Karcher, and Bolinger (2007) provide an overview of the most common financial structures in the U.S. market that are used to attract investors, manage risk exposure, and allocate the value of tax benefits. ${ }^{1}$ The main financial stakeholders are as follows:

- The sponsor may choose to continue participating in an ownership role throughout the project's life cycle or may choose to divest part or all of its interest. Equity provided by the sponsor is generally unsecured and represents the first dollar lost if revenue is less than predicted.

- Tax investors invest upfront capital in wind projects primarily in exchange for claims on the future tax credits that will be generated by the project, which are referred to as tax equity. Examples include large banks, insurance companies, or other corporations that have large federal income tax liabilities. Tax investors typically invest with a time horizon that corresponds to the availability of the tax benefits and structure their investments so that they are protected in the event of financial distress.

- Debt investors provide commercial debt to a project either to a sponsor at the corporate level or directly to the project. Project-level debt, also referred to as nonrecourse debt, is a claim on the future cash flows of a project and is secured by the assets of the project. In the event of default, the debt provider can seize the project assets but cannot recover any other compensation from the borrower. For this reason, nonrecourse debt is generally structured conservatively and has a prioritized claim on cash flows generated by the project. Because debt has a first lien on project assets and is prioritized over the claim of tax investors, wind project capital structures in the United States rarely include both nonrecourse debt and tax equity investors.

The preconstruction energy estimate provides key information that management and/or credit boards at these financial stakeholders use to make informed decisions about whether or not they will invest in a given project. If a financial stakeholder chooses to proceed with an investment, the information in the preconstruction energy estimate provides data that can be used to identify the appropriate price and volume that the investor is willing to contribute to the overall financing package.

\footnotetext{
${ }^{1}$ Tax benefits represent credits against future federal income tax liabilities that result from accelerated depreciation of tangible assets as well as federal incentives such as the Production Tax Credit and Investment Tax Credit. These benefits provide significant value to wind projects, but generally they cannot be monetized efficiently (i.e., in the year that they are generated) by wind project sponsors because the sponsors lack sufficient income tax liability.
} 
Each of these investor types has specific criteria that they use to evaluate wind projects, including time horizons and risk appetites. For example, a sponsor that plans on maintaining an ownership during the entire life of a project will often evaluate project returns based on a 20 -year $P 90$ energy estimate. A tax equity investor investing to monetize a Production Tax Credit-based revenue stream will use a 10 -year $P 95$ value that corresponds to the 10 -year term during which the Production Tax Credit is valid. A debt investor will generally size their investment based on a 1-year, $P 99$ value to ensure that the project will not default on debt obligations in any given year and thus reduces their risk to an event that might send the project into financial distress. ${ }^{2}$

If the preconstruction energy estimate leads to the identification of significant sources of risk and uncertainty (e.g., high-probability curtailment) or suggests that there is a probability that future revenues may be too low to support the required level of investment, the sponsor may choose to modify, abandon, or put the project on hold for future consideration. If an attractive wind resource exists, the developer is often able to successfully mitigate risks and uncertainties by modifying the plant layout, selecting different turbines, strengthening contractual protections, or collecting additional data albeit at additional cost.

\footnotetext{
${ }^{2}$ The examples above describe only probability values and time horizons that each class of investor generally uses to evaluate the revenue potential of wind projects. Different organizations may use criteria that may be more or less conservative; however, the values described are thought to be broadly representative. Many other commercial terms and conditions can be built into the financing structure to protect investors from repayment risk including reserve funds, minimum return thresholds, cash sweeps, etc.
} 


\section{Key Parts of the Preconstruction Energy Estimate}

The preconstruction energy estimate documents the process by which the industry estimates the expected distribution of the net amount of energy delivered to the point of revenue metering per year during a range of timescales. The estimate includes the gross energy estimate, an estimate of losses, and a prediction of the net amount of energy delivered to the point of revenue metering. Each of these estimates is reported as uncertain values so that the final net energy estimate can be expressed as a range of probabilities (Figure 2).

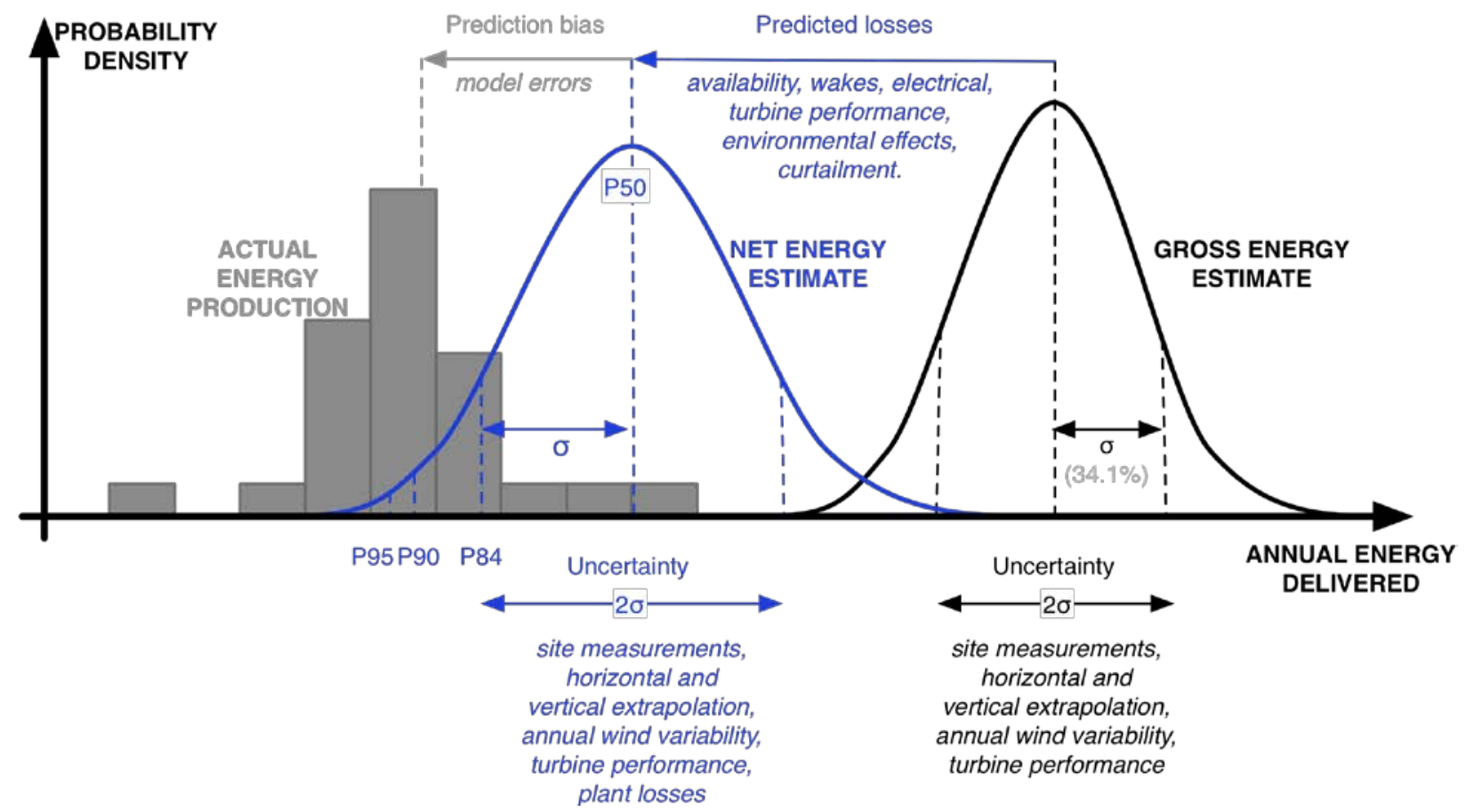

Figure 2. Elements of the preconstruction energy estimate

The preconstruction energy estimate includes central estimates of the gross and net energy estimates and information about losses and uncertainties. Actual energy production data are for illustration only.

The expected distribution of energy in any one year from a wind power plant is the major output from a preconstruction energy estimate. The distribution shown on the right of Figure 2 represents the gross energy production estimate, which is calculated based on the site's characteristics (e.g., wind speed distribution, terrain, layout) and the wind turbine's power curve. The gross energy estimate is reported as a central estimate with uncertainty information or as a probability distribution. The uncertainty is introduced by site measurements, the vertical extrapolation method, the accuracy of the historical wind resource record, the variability in the wind resource from one year to another (interannual variability), and other terms described later in this document.

The estimate of net energy is the gross estimate minus losses such as wakes, turbine performance, environmental factors, technical availability, curtailment, and other factors. The net energy estimate is always lower than the gross energy estimate. The uncertainty of the net energy estimate is greater than the uncertainty of the gross estimate because each of the expected loss types is subject to uncertainty. The reported uncertainty of the central estimate of the net energy 
estimate is usually one standard deviation. Because uncertainties are often assumed to be normally distributed they show a bell-shaped distribution wherein the area bounded by one standard deviation on either side of the $P 50$ value includes approximately $68 \%$ of events. In this case, the uncertainty estimate therefore brackets the energy that would be produced in 13 years by a wind power plant that has a 20-year investment life cycle. The $P 90$ and $P 95$ values are also shown; these are the amounts of energy that are expected to be exceeded in at least 18 years or 19 years, respectively, of the wind power plant's life cycle.

Key terms are described in the subsections below.

\subsection{Central Estimate of Energy (P50)}

The main outcome of the preconstruction energy estimate is the amount of energy delivered to the point of revenue metering that has a 50\% likelihood of being exceeded during timescales of any one year, 10 years, or the investment life of the plant. This is the $P 50$ value for energy, and it is a key wind power plant characteristic. This estimate is also known as the annual energy production.

The methods used to create the central estimate of energy are described in Section 3.3.

\subsection{Losses}

Losses are amounts of energy that are potentially available to the wind power plant but cannot be harvested for technical or other reasons, and they are the difference between gross and net energy. Losses can result from wakes, turbine response, availability, electrical transmission, curtailment, and other factors. If loss estimates are not accurate, the P50 estimate will be wrong.

Typical methods used to estimate losses are described in Section 3.3.5. Recent loss estimates are summarized in Section 4.1.

\subsection{Uncertainty}

Uncertainties arise from random errors from observations or models used to create the central energy estimate. For example, random errors in wind measurement can occur because an individual anemometer does not measure the "true" wind speed that would be measured by a theoretically perfect instrument that did not modify the flow and had an instantaneous response to gusts or slowdown. Real-world anemometers measure wind speeds that are affected by turbulence and inflow angle, and their performance may be impacted by wear and tear. Likewise, random errors can arise in models of wind turbine performance or wake propagation and electrical losses. These and other measurement and model uncertainties contribute to the distribution of the energy estimate wherein the width of the distribution (Figure 2) and the Pxx estimate for energy are a function of the cumulative uncertainty of all of the parts of the preconstruction energy estimate process.

Typical approaches to estimating energy uncertainty are described in Section 3.4. Recent uncertainty budgets are summarized in Section 4.2. 


\subsection{Prediction Bias}

The actual energy produced by a wind power plant may differ from the preconstruction energy estimates. This difference may arise from wind speeds that are lower or higher than expected, curtailment, or other factors, and the differences may vary from one year to another. The magnitude of the difference between the preconstruction distribution and the actual distribution, after removing variation due to external factors such as low wind speeds or curtailment, is the prediction bias due to modeling. The leftmost distribution in Figure 2 shows a scenario in which actual energy production is lower than the predicted value (referred to as underperformance). During the lifetime of the plant, the difference in production should be as small as possible to maximize the accuracy of preconstruction revenue projections and thus minimize the risk exposure for financial investors.

Causes of prediction bias are discussed throughout this document. 


\section{The Preconstruction Energy Estimate Process}

The process of predicting the energy from a wind power plant project before it is built is quite well defined when viewed from a high level (Figure 3).

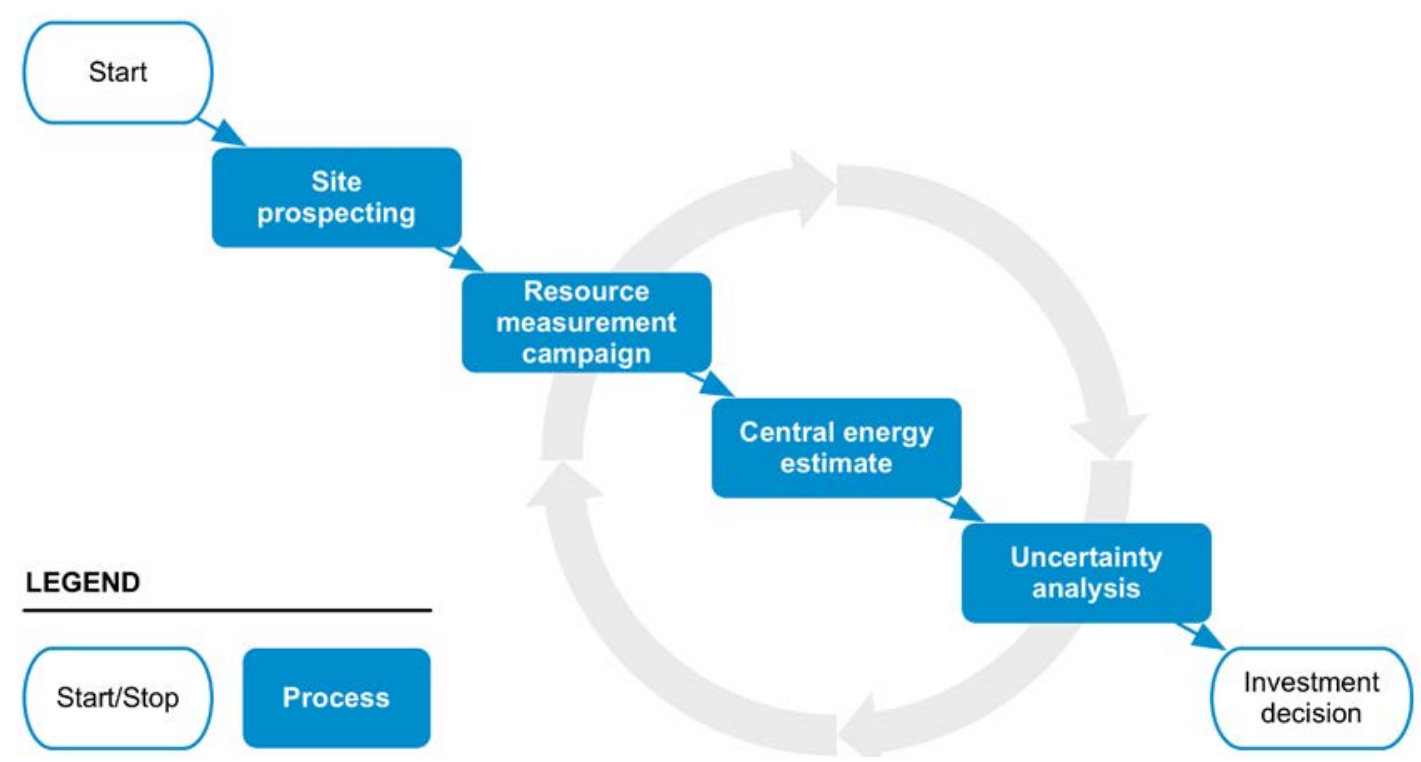

Figure 3. High-level technical activities to develop an energy estimate for a new wind power plant

This process has been used to develop most of the wind power plants throughout the world, and it includes the following steps:

- Site prospecting: use national or state-level wind maps and data to identify target areas.

- Resource measurement campaign: measure wind resources at multiple points on the site using a combination of meteorological (met) towers and remote sensing.

- Central estimate ( $P 50)$ process: estimate the energy delivered by the wind project to the point of revenue metering. This iterative process will be repeated during the development process to reflect additional data and maturing plant design and includes:

- Data processing and long-term resource correction: identify and remove or correct poor data. Predict long-term wind resource characteristics.

- Horizontal and vertical extrapolation: estimate wind characteristics across the site at turbine locations and up to hub heights or across the rotor plane.

○ Turbine selection: select a turbine model (or models) suited to the site's wind characteristics and temperature, seismic, and other site-specific conditions.

- Site optimization: evaluate a range of site layout options within the limits of standard construction methods and turbine load limitations with an objective of maximizing energy capture or minimizing the levelized cost of energy (LCOE).

- Energy production estimates: quantify the energy produced by each turbine and estimate losses from each turbine and the whole plant at a range of timescales.

- Uncertainty analysis: quantify the uncertainty in the energy production estimates. 
Although the high-level process is similar from one project to another (Tegen 2015), each sponsor or IE takes a slightly different approach to the details. The preconstruction energy estimate is produced by different entities and at different levels of fidelity as the plant design matures. An initial estimate at the site-prospecting stage may be quite coarse, and subsequent layouts are generated that incorporate improved wind resource, turbine data, and plant layout to inform optimized plant design. Budgets increase substantially throughout this process, and management usually has a direct role in approving further action at key stage gates.

A common format is used in this report to describe the activities in each stage (Table 1).

Table 1. Terminology

\begin{tabular}{ll}
\hline Activity & Smallest identifiable blocks of work that are carried out \\
Desired outcome & Goal of the activity \\
Method & How the activity is carried out \\
Uncertainties & Probable sources of spread in the outcome from the activity
\end{tabular}

\subsection{Prospecting}

Prospecting is the process of identifying a geographical location where the project sponsor can expect to find a viable wind resource and there is market demand and transmission capability that suggest favorable conditions for wind plant development. Although prospecting is not part of the process of estimating a wind plant's energy production, it is an important part of a wind plant's development process, and it leads to the identification of the target area for development. Also, information obtained in the prospecting process can directly impact the resource measurement campaign (Figure 3).

The sponsor also generally reviews internal and publicly available data sources to identify any fatal flaws or potential barriers that could result in delays or extra costs, including environmental sensitivities (e.g., protected species), radar issues, local regulations, political environments, and public attitudes toward wind (Table 2). In most cases, the process would define the approximate boundaries of the development, meaning that landowners could be contacted and the process of arranging leases could be started. 
Table 2. Prospecting Activities

\begin{tabular}{|c|c|c|c|}
\hline Activity & Desired Outcome & Method & Uncertainties \\
\hline $\begin{array}{l}\text { Prospect } \\
\text { wind }\end{array}$ & $\begin{array}{l}\text { Identify counties or } \\
\text { survey townships that } \\
\text { may have a viable wind } \\
\text { resource. }\end{array}$ & $\begin{array}{l}\text { Perform a geographic } \\
\text { information system-based } \\
\text { terrain analysis. } \\
\text { Use data from reanalysis or } \\
\text { weather models aggregated } \\
\text { during } 20-30 \text { years. These } \\
\text { are often obtained from a } \\
\text { third party. }\end{array}$ & $\begin{array}{l}\text { Wind resource maps have } \\
\text { minimal validation. }\end{array}$ \\
\hline $\begin{array}{l}\text { Prospect } \\
\text { transmission }\end{array}$ & $\begin{array}{l}\text { Identify locations that } \\
\text { have transmission } \\
\text { capacity on an annual or } \\
\text { seasonal basis. }\end{array}$ & Perform a desktop study. & $\begin{array}{l}\text { Limited data are available. } \\
\text { An historic availability of } \\
\text { transmission does not } \\
\text { guarantee future capacity. }\end{array}$ \\
\hline $\begin{array}{l}\text { Conduct } \\
\text { high-level } \\
\text { feasibility } \\
\text { study }\end{array}$ & $\begin{array}{l}\text { Identify major permitting, } \\
\text { environmental, land-use, } \\
\text { or logistical challenges to } \\
\text { project delivery. }\end{array}$ & $\begin{array}{l}\text { Perform a desktop study } \\
\text { with publicly available data. }\end{array}$ & $\begin{array}{l}\text { Data may be limited, } \\
\text { inaccurate, or out of date. }\end{array}$ \\
\hline
\end{tabular}

Expenses and time required at this stage of the project's development are relatively limited. Tegen (2015) interviewed developers and determined that prospecting for successful projects amounts to approximately $\$ 0.25 / \mathrm{kW}-\$ 0.5 / \mathrm{kW}$. Larger sponsors typically have a corporate budget for site prospecting and do not attribute site prospecting costs to individual wind projects; instead, these costs are factored into the calculations for required rates of return or development fees in the entire project portfolio.

Development costs can be reduced if a possible wind farm's location can be rejected quickly without spending money on a wind resource measurement campaign for a marginal site. This rapid decision making is possible if the data that are used for wind prospecting are of high accuracy. High-quality wind data can be combined with information about environmentally sensitive areas, competing land use, slope angles, and roads and thus simplify the prospecting process. In some countries, governments support prospecting by underwriting wind model development and disseminating wind maps. Countries that have followed this approach include the United States, the United Kingdom, Switzerland, Denmark, Germany, and Canada. Similarly, extensive public energy production data sets from operating wind projects in Germany enable relatively simple site prospecting. Several private companies offer high-resolution model-derived wind data that are marketed for site prospecting. Wind maps are also sometimes produced as part of an aid package for a country because they can reduce barriers to investment but require skills that might not be found there. (See wind maps for Gujarat by Draxl, Purkayastha, and Parker [2014]).

The availability of transmission can be a major barrier to the development of a wind power plant. Transmission is often limited in potential areas for wind plant development. New transmission lines can be time consuming and expensive to develop, and often they require legislative action and a planning horizon that can span more than 10 years from initiation to commissioning. 
Active research worldwide is improving the prospecting process. Researchers from academia, industries, and governments are investigating how wind resource maps can be improved through better foundational weather models. Also, geographic information systems are increasingly used as a platform to identify development sites and rapidly estimate overall capital costs. For example, a geographic information systems tool can be used to combine wind resource and terrain data to estimate the potential energy production at a site and the costs of integrating a wind plant into the transmission system. Improved resource prospecting could decrease the risk of spending money on sites that are later found to be uneconomical to develop, potentially reducing the cost of early-stage development capital.

\subsection{Resource Measurement Campaign}

The resource measurement campaign takes place after the approximate site location has been identified. At this time, the project sponsor is relatively confident that there may be a wind resource, but the sponsor lacks information required to make an accurate financial assessment. The aim of the campaign is to obtain enough data to estimate with confidence the long-term wind resource at the site and enable follow-on wind field modeling and financial modeling.

A wind resource measurement campaign requires deploying measurement equipment on or near the site to obtain the data that are required to estimate the long-term wind resource (Table 3 ). Brower et al. (2010) provides an excellent overview of the practicalities of the resource measurement campaign. Because a land lease is usually required to deploy meteorological equipment, most project developers tend to obtain options on the project land at this time to ensure that the site can be developed if a suitable resource is found.

The resource assessment campaign is capital intensive, requiring between $\$ 50,000-\$ 100,000$ per tower or remote sensing device, and it incurs significant ongoing costs for labor and equipment for installation, monitoring, maintenance, and documentation of the towers or remote sensing devices. Not all potential wind farms move to construction so the costs of the unsuccessful resource campaigns contribute to the developer's overhead; therefore, most developers try to minimize the initial costs of the resource assessment campaign. A common approach is to use temporary $60-\mathrm{m}$ towers to minimize costs and permitting challenges and move to more expensive measurement equipment aimed at reducing uncertainty only after an initial estimate of the project viability has been made. 
Table 3. Resource Measurement Campaign Activities

\begin{tabular}{|c|c|c|c|}
\hline Activity & Desired Outcome & Methods & Uncertainties \\
\hline $\begin{array}{l}\text { Design } \\
\text { campaign }\end{array}$ & $\begin{array}{l}\text { Ensure: } \\
\text { High data availability } \\
\text { Low wind resource } \\
\text { uncertainty } \\
\text { Within available } \\
\text { budget } \\
\text { Measurements that } \\
\text { enable flow modeling, } \\
\text { wake modeling, } \\
\text { mechanical loads } \\
\text { analysis, and power } \\
\text { curve development. }\end{array}$ & $\begin{array}{l}\text { Identify key atmospheric } \\
\text { parameters that need to } \\
\text { be measured (e.g., wind } \\
\text { speed and direction, } \\
\text { turbulence, air pressure, } \\
\text { temperature, humidity). } \\
\text { Use flow modeling to } \\
\text { identify potential areas } \\
\text { of complex flow. } \\
\text { Perform instrument } \\
\text { costing and selection. }\end{array}$ & $\begin{array}{l}\text { Model limitations are not always } \\
\text { known. } \\
\text { Instrument performance may be } \\
\text { overstated by vendors. } \\
\text { There is a lack of standard } \\
\text { methods to quantify resource } \\
\text { campaign uncertainty. } \\
\text { The activity does not provide data } \\
\text { required for wind power plant } \\
\text { optimization. }\end{array}$ \\
\hline $\begin{array}{l}\text { Take initial } \\
\text { measurements }\end{array}$ & $\begin{array}{l}\text { Obtain resource } \\
\text { characterization data, } \\
\text { including: } \\
\text { Wind speed and } \\
\text { direction } \\
\text { Turbulence } \\
\text { Wind shear } \\
\text { Temperature } \\
\text { Pressure. } \\
\text { Enable a go/no-go } \\
\text { decision. }\end{array}$ & $\begin{array}{l}\text { Use } 1 \text { year of } \\
\text { measurements from } \\
\text { hub-height met tower at } \\
\text { locations with clean flow } \\
\text { and instrumented with } \\
\text { cup anemometers and } \\
\text { wind vanes recorded at } \\
1 \mathrm{~Hz} \text {. }\end{array}$ & $\begin{array}{l}\text { The measurement period may not } \\
\text { be representative of the long-term } \\
\text { conditions. } \\
\text { Data may be missing due to } \\
\text { equipment failure or icing. } \\
\text { Towers may not reach the likely } \\
\text { hub heights. } \\
\text { Temperature does not map } \\
\text { directly to the risk of turbine icing. } \\
\text { The measurement campaign } \\
\text { does not address all atmospheric } \\
\text { quantities needed for modeling, } \\
\text { power curve definition, etc. }\end{array}$ \\
\hline $\begin{array}{l}\text { Take } \\
\text { measurements } \\
\text { to reduce } \\
\text { uncertainty }\end{array}$ & $\begin{array}{l}\text { Reduce uncertainty in } \\
\text { resource data. }\end{array}$ & $\begin{array}{l}\text { Use an extended period } \\
\text { of measurement. } \\
\text { Use remote sensing to } \\
\text { check vertical and } \\
\text { horizontal extrapolation. } \\
\text { Use remote sensing or } \\
\text { towers to make } \\
\text { measurements at areas } \\
\text { of high-flow model } \\
\text { uncertainty. }\end{array}$ & $\begin{array}{l}\text { The remote sensing uncertainty } \\
\text { compared to towers is increased } \\
\text { in complex flow situations. } \\
\text { Remote sensing does not remove } \\
\text { all uncertainty in horizontal } \\
\text { extrapolation. }\end{array}$ \\
\hline
\end{tabular}

Results from the wind resource measurement campaign are important in deciding whether a wind plant is viable in the development location. Together with information about the availability of transmission and land leases, the wind resource is one of the key metrics for assessing wind plant viability. The wind measurement campaign is especially crucial to understanding a wind power plant's future performance because the output data provides the quantitative basis for the plant's design and optimization as well as the wind turbine OEM site-suitability analysis. Further, because the wind measurement campaign lasts for at least 1 year and possibly longer, it is very important to design the campaign correctly from the start; delays due to data gaps or high uncertainties can cause significant delays in a project's schedule and ultimately increase the project's costs. 
Research in the area of wind resource measurement has recently focused on the use of remote sensing to measure winds on the project site (Wagner et al. 2011). Remote sensing is attractive because it can provide data directly at typical wind turbine hub heights $(80 \mathrm{~m}-100 \mathrm{~m})$ or at many points across the site, allowing many different uses. Remote sensing measurements can supplement tower measurements (Lackner et al. 2010) or be used from the outset, removing the need to extrapolate wind speeds at hub heights from data collected at a lower height. Remote sensing or taller towers can also enable estimates of the rotor-equivalent wind speed. The rotor equivalent wind speed is the area's average wind speed across the entire rotor disk, and it is thought to be more accurate than the hub-height wind speed in predicting turbine power in unusual or high-magnitude wind shear conditions (Wagner et al. 2011).

The use of remote sensing for wind resource measurement has been supported by significant international collaborations. Examples of this include the International Electrotechnical Commission (IEC), which created standards for the acquisition of data using remote sensing as part of the proposed new IEC Standard 61400-12-1 for power performance testing of wind turbines.

The International Energy Agency Implementing Agreement for Co-operation in the Research, Development and Deployment of Wind Energy Systems (IEA Wind) is a vehicle for member countries to exchange information on the planning and execution of national, large-scale wind system projects and undertake cooperative research and development projects called Tasks or Annexes. IEA Wind Task 32, "Wind Lidar" has developed recommended practices for the use of remote sensing for wind measurements (Clifton, Elliott, and Courtney 2013), and for the use of lidar in complex terrain (Clifton et al. 2016).

\subsection{Central Estimate of Energy (P50)}

After a potentially suitable wind power plant site has been identified and the wind resource measurement campaign has started, the project sponsor usually starts to develop estimates of the energy that the wind plant can produce. These estimates typically take the form of $P 50$ values for energy capture and losses delivered to the point of revenue metering during a variety of timescales, including any one year, during the first 10 years, and during the entire investment lifetime of the plant. Because the $P 50$ is very important, this step of the preconstruction energy estimation process is likely to be repeated several times during the development phase as more data become available, leading to refined estimates and reduced uncertainty.

Like the overall development process, the process of creating the central energy estimate of a wind farm is common to most wind projects. The major steps are shown in Figure 4 and discussed in this section. 


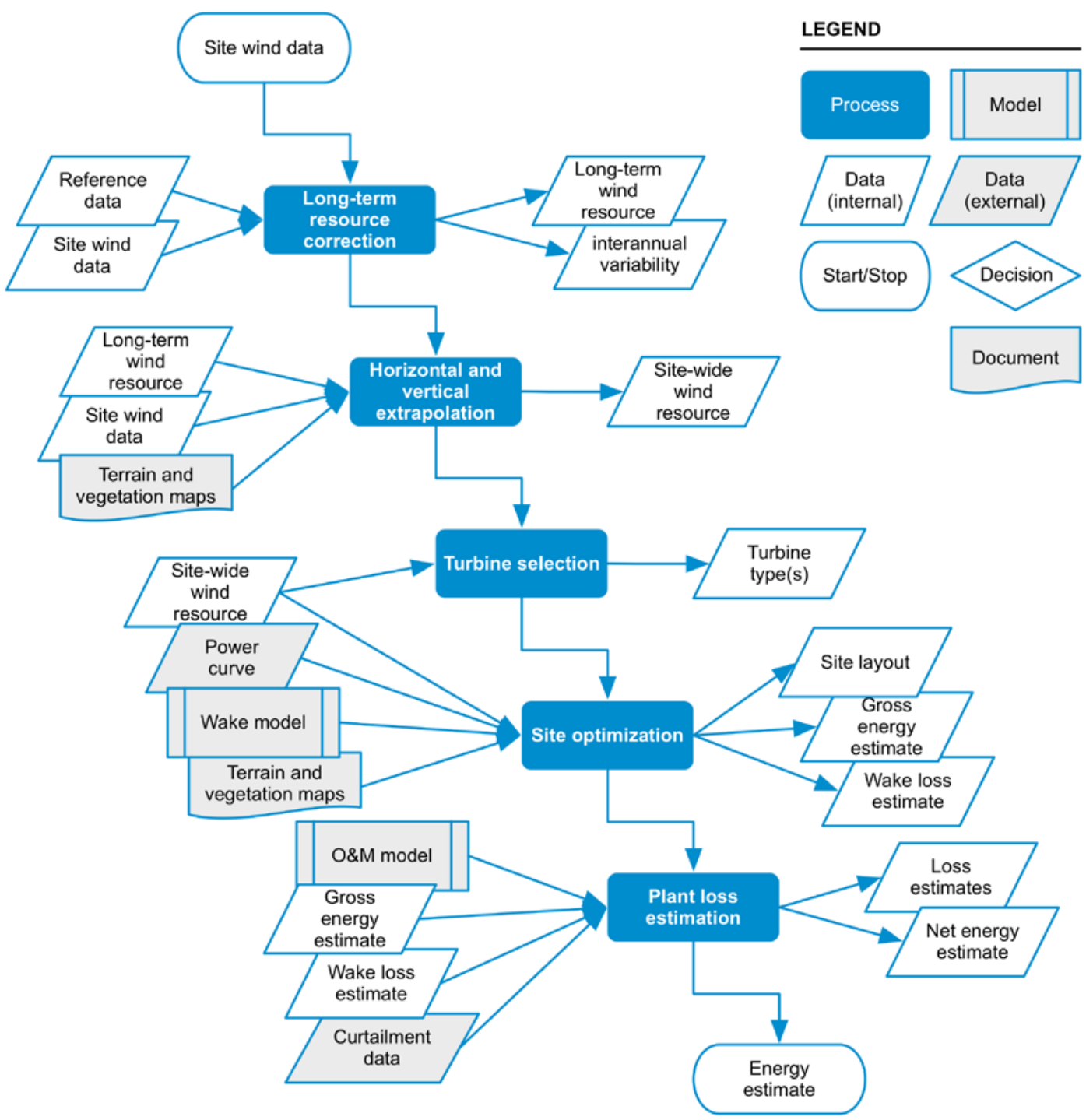

Figure 4. Process of creating a wind plant's central energy estimate

\subsubsection{Data Processing and Long-Term Resource Correction}

The economics of modern wind projects are typically evaluated based on an assumed business case of between 20 years -25 years. To understand the long-term wind resource available at a project site, a process known as measure-correlate-predict (MCP) is used to correct short-term measurement data to a longer-term historical perspective. MCP is the process of using the data measured at a wind site together with other long-term, "reference" measurements to predict the long-term wind resource at the site (Table 4). The reference measurements are typically from 10 years-30 years in duration and could be from an airport weather station, a well-maintained surface station, or from a numerical weather prediction model. Note that although a weather station might have been operating for a long period, those data should be treated with caution. For example, changes in vegetation height, surrounding buildings, poor instrument maintenance records, or changes in the instrument type, location, or data logging may cause inconsistencies in the data set that would introduce a bias in the wind resource estimate. 
Table 4. Data Processing and Long-Term Resource Correction Activities

\begin{tabular}{|c|c|c|c|}
\hline Activity & Desired Outcome & Method & Uncertainties \\
\hline $\begin{array}{l}\text { Select reference } \\
\text { sites }\end{array}$ & $\begin{array}{l}\text { Obtain list of suitable } \\
\text { long-term reference } \\
\text { sites. }\end{array}$ & $\begin{array}{l}\text { Perform a desktop study to } \\
\text { identify reference sites that } \\
\text { highly correlate to the } \\
\text { development site. }\end{array}$ & $\begin{array}{l}\text { Poor instrument } \\
\text { maintenance or record } \\
\text { keeping reduces the } \\
\text { quality of the data. }\end{array}$ \\
\hline $\begin{array}{l}\text { Correlate between } \\
\text { reference site and } \\
\text { development site }\end{array}$ & $\begin{array}{l}\text { Relationship between } \\
\text { reference site and } \\
\text { development site. }\end{array}$ & $\begin{array}{l}\text { Apply some form of } \\
\text { regression- or joint- } \\
\text { probability-based } \\
\text { correlation of site data to } \\
\text { long-term wind data. }\end{array}$ & $\begin{array}{l}\text { Data from the reference } \\
\text { site may not be } \\
\text { representative of the long- } \\
\text { term wind climate in that } \\
\text { area. }\end{array}$ \\
\hline $\begin{array}{l}\text { Predict long-term } \\
\text { wind resource }\end{array}$ & $\begin{array}{l}\text { Correct site data to } \\
\text { long-term record. }\end{array}$ & $\begin{array}{l}\text { Develop and apply } \\
\text { correction factors to } \\
\text { estimate bounds for wind } \\
\text { resource throughout } \\
\text { project lifetime. }\end{array}$ & $\begin{array}{l}\text { The prediction may be } \\
\text { using incorrect correction } \\
\text { factors. }\end{array}$ \\
\hline $\begin{array}{l}\text { Estimate } \\
\text { interannual } \\
\text { variability }\end{array}$ & $\begin{array}{l}\text { Quantify wind } \\
\text { resource variability. }\end{array}$ & $\begin{array}{l}\text { Use long-term data record } \\
\text { to estimate variability. } \\
\text { Apply regional wind speed } \\
\text { variability factors. }\end{array}$ & $\begin{array}{l}\text { There is a lack of long- } \\
\text { term data records for } \\
\text { comparison. } \\
\text { There is a lack of } \\
\text { information about } \\
\text { susceptibility to climate } \\
\text { variation. }\end{array}$ \\
\hline
\end{tabular}

$\mathrm{MCP}$, which can also be considered the process of long-term resource correction, is a complex process that is not clearly defined in an existing recommended practice or standard. A summary of current methods is provided in Carta, Velázquez, and Cabrera (2013). Typically, each IE has their own approach to correcting resource data to the longer term. This approach will vary markedly depending on the terrain and local weather conditions. For example, in complex terrain (e.g., forests, rolling countryside, or mountainous regions), correlations between the reference site and the development site may drop rapidly with distance; but in flat terrain, the correlations may be much higher across the same distance. Where weather conditions are highly heterogeneous (e.g., in coastal or mountainous regions), a similar effect may be seen. These considerations have made it very challenging for the wind industry to develop standard methods for MCP that can be readily compared.

Research into long-term resource correction has investigated several opportunities for more nuanced methods of correction. For example, multivariate regression (e.g., using wind speed, direction, temperature, and pressure to predict the wind speed at the development site) has been found to help in some areas. Similarly, data from meteorological reanalysis models has been used in place of reference stations, and it may enable wind turbine deployments in places that do not have established meteorological infrastructure, particularly offshore (Sempreviva, Barthelmie, and Pryor 2008). The use of reanalysis data is also helpful when reference stations are in different wind climates from wind development sites, such as when reference sites are in valleys and development sites are along ridgelines. This approach is sometimes described as the "synthetic reference" approach. 


\subsubsection{Horizontal and Vertical Extrapolation}

The corrected long-term wind data that are obtained from the MCP process are only directly relevant to locations where data were measured. These data therefore need to be extrapolated across the whole site, and to the likely height of the turbine hub. These steps are known as horizontal and vertical extrapolation (Table 5). Vertical extrapolation is only required if the resource measurement campaign did not include measurements at the turbine hub height.

Table 5. Horizontal and Vertical Extrapolation Activities

\begin{tabular}{|c|c|c|c|}
\hline Activity & Desired Outcome & Method & Uncertainties \\
\hline \multirow{2}{*}{$\begin{array}{l}\text { Perform vertical } \\
\text { extrapolation } \\
\text { using shear }\end{array}$} & \multirow{2}{*}{$\begin{array}{l}\text { Measure wind } \\
\text { speeds at turbine } \\
\text { hub heights. }\end{array}$} & \multirow{2}{*}{$\begin{array}{l}\text { Use power law to extrapolate } \\
\text { from measured wind speeds } \\
\text { to the height of interest. }\end{array}$} & $\begin{array}{l}\text { Wind speed profiles may not } \\
\text { follow the power law. }\end{array}$ \\
\hline & & & $\begin{array}{l}\text { The method introduces } \\
\text { unknown levels of } \\
\text { uncertainty in the predicted } \\
\text { wind speed. }\end{array}$ \\
\hline \multirow{2}{*}{$\begin{array}{l}\text { Perform vertical } \\
\text { scaling using } \\
\text { remote sensing } \\
\text { data }^{a}\end{array}$} & \multirow[t]{2}{*}{$\begin{array}{l}\text { Measure wind } \\
\text { speeds at turbine } \\
\text { hub heights. }\end{array}$} & \multirow{2}{*}{$\begin{array}{l}\text { Use remote sensing to scale } \\
\text { the wind speed data from the } \\
\text { tower for wind speeds } \\
\text { measured above a tower. }\end{array}$} & $\begin{array}{l}\text { This method has a lower } \\
\text { uncertainty than shear } \\
\text { extrapolation. }\end{array}$ \\
\hline & & & $\begin{array}{l}\text { Some remote sensing } \\
\text { devices can be inaccurate in } \\
\text { certain conditions. }\end{array}$ \\
\hline \multirow{3}{*}{$\begin{array}{l}\text { Perform } \\
\text { horizontal } \\
\text { extrapolation } \\
\text { using flow } \\
\text { modeling }\end{array}$} & \multirow{3}{*}{$\begin{array}{l}\text { Consider wind } \\
\text { speed scaling } \\
\text { factors for all points } \\
\text { throughout the site. }\end{array}$} & \multirow{2}{*}{$\begin{array}{l}\text { Use computational fluid } \\
\text { dynamics simulations, } \\
\text { applying models of varying } \\
\text { levels of complexity and } \\
\text { capturing different physical } \\
\text { processes. }\end{array}$} & $\begin{array}{l}\text { Simple flow models exhibit } \\
\text { large errors due to effects of } \\
\text { atmospheric stability. }\end{array}$ \\
\hline & & & $\begin{array}{l}\text { Complex flow models require } \\
\text { significant user expertise. }\end{array}$ \\
\hline & & $\begin{array}{l}\text { processes. } \\
\text { This is usually carried out for } \\
\text { certain wind directions and to } \\
\text { scale measured data. }\end{array}$ & $\begin{array}{l}\text { There is large variation in } \\
\text { results for the same input. }\end{array}$ \\
\hline
\end{tabular}

${ }^{a}$ These are different ways to arrive at the same outcome.

The vertical extrapolation of wind speed data from one height to another is extremely challenging. The use of logarithmic or power laws (Stull 1988) to scale data requires assumptions to be made about the homogeneity of the boundary layer. In simple approaches, winds may be extrapolated vertically by assuming a constant shear exponent or by using measured shear and assuming that these hold throughout the boundary layer. Although these models may be reasonable during the middle of the day (when the boundary layer is deep), they fail during the day-to-night transition because the boundary layer shape may be rapidly changing and at night because the boundary layer can be relatively shallow. These boundary layer effects can result in large changes in boundary layer wind profiles right at the height of $80 \mathrm{~m}-100 \mathrm{~m}$ above ground at which turbines operate (Wagner et al. 2011; Wharton and Lundquist 2012). The effect of these changes in boundary layer shape on the extrapolation depends on the method used to scale the measurements: for example, every 10-minute data record could be scaled using a fit to a wind profile, or each hour of a month could be scaled, or all wind speeds could be scaled by a single global scaling factor, and so on. Each method makes certain assumptions and has different sensitivities to wind conditions, potentially leading to errors in the vertical extrapolation 
at certain times of the day or under certain wind conditions. These errors give rise to uncertainty and possibly biased extrapolations.

Flow modeling for horizontal extrapolation of winds is an essential part of this stage of the energy assessment process. Flow models that are used to estimate winds on a wind farm scale can be categorized in terms of the flow physics that they model. In order of the relative complexity of the physics that are modeled, these categories include:

- Linear flow models: model flow over terrain and changing land cover, using simple models for the speed up of wind over terrain or change of wind speed with surface roughness, but ignore the effects of buoyancy on flow-e.g., the Wind Atlas Analysis and Application Program (WAsP, Troen and Petersen 1989) and the Continuum Wind Flow Model (Walls 2015)

- Reynolds-averaged Navier-Stokes models: model fluid flow by solving the Navier-Stokes equations for the pressure, momentum, and energy of fluids, with some approximations to enable the representation of time-averaged turbulence. These are often known generically as computational fluid dynamics (CFD) models by the wind energy industry. ${ }^{3}$ This approach can better capture more complicated conditions, including complex terrain or unsteady processes - e.g., WAsP CFD and Ventos (Abiven, Palma, and Brady 2011)

- Large eddy simulation (LES) models: resolve larger turbulent eddies but are limited to vertical extents of a few kilometers at a resolution of $1 \mathrm{~m}-100 \mathrm{~m}-\mathrm{e} . \mathrm{g}$., the Simulator fOr Wind Farm Applications (SOWFA) toolbox (Churchfield et al. 2012)

- Mesoscale models: designed to model weather processes that happen throughout scales from hundreds to thousands of kilometers at a resolution of around $1 \mathrm{~km}-\mathrm{e} . \mathrm{g}$., the Weather Research and Forecasting model (WRF).

A significant challenge with flow modeling is that there is not yet a community-wide best practice that specifies which model types are best for which applications or how to configure them to obtain the best results for any given site. This challenge arises from the rapid pace of change in the wind energy flow modeling community (partly forced by a desire to reduce the cost of flow modeling), the rapid increase in the availability of computing power, and a lack of previous industry-wide comparison exercises. These factors make it very difficult to identify a best practice that will be valid for more than a few months.

Several international comparison exercises have been carried out or are in process which aim to quantify the accuracy and uncertainty of these models. These include the Comparative Resource and Energy Yield Assessment Procedures held by the European Wind Energy Association in 2011 and 2013 and a similar exercise held by the American Wind Energy Association in 2013. IEA Wind Task 31, called "Wakebench," is an international collaboration to test flow models against a wide variety of case studies (Sanz Rodrigo et al. 2014; Moriarty et al. 2014). Vendors have also conducted numerous studies to demonstrate the capability of their tools. Results from the comparisons suggest that as site complexity increases (either through the addition of forested areas or in complex terrain) or thermal effects become important (such as in areas that

${ }^{3}$ Strictly, all four categories listed here contain computational fluid dynamics models in that they all use numerical models of fluid flow; the four categories represent different levels of fidelity. 
experience strong diurnal ground heating and cooling cycles), results from flow modeling become worse with respect to observations.

Efforts are also ongoing to improve mesoscale flow modeling through improved physical models. These include the U.S. Department of Energy's Atmosphere to Electrons initiative, the New European Wind Atlas, and through international collaboration via IEA Wind Task 36 on the forecasting of wind power, which was launched in 2015. These mesoscale methods focus on improving the representation of the flow physics in the model code and are of most impact where there is not on-site data.

The use of taller towers or remote sensing to directly measure wind speeds at hub height or above will minimize uncertainty due to vertical extrapolation while decreasing the spacing of met towers; thus, increasing the availability of reference data on the site will reduce the uncertainty due to horizontal extrapolation.

Depending on the site conditions and the methods that are used, estimates of the wind resource at hub height are thought to have uncertainties from $1 \%-10 \%$ at different locations on the site. (See Section 4.2.) However, there are no known public data sets that can be used to show the true uncertainty in long-term wind resource estimates because there are no sites that are representative of wind development locations and that have been instrumented for long periods at heights from $80 \mathrm{~m}-100 \mathrm{~m}$ above ground with appropriate measurement equipment.

\subsubsection{Turbine Selection}

Turbine selection is the process by which one or more types of turbines are chosen for use in the plant design process (Table 6). The process is iterative and usually involves an evaluation of trade-offs among turbine performance and commercial considerations, including but not limited to turbine supply agreement costs and terms (e.g., warranty provisions), turbine load limitations, and manufacturer experience and reputation. The turbine selection process results in a preliminary gross energy estimate for several turbine models that can be used to inform negotiations and initial project pro forma scenarios. 
Table 6. Turbine Selection Activities

\begin{tabular}{|c|c|c|c|}
\hline Activity & Desired Outcome & Method & Uncertainties \\
\hline $\begin{array}{l}\text { Estimate IEC class } \\
\text { (by project sponsor } \\
\text { or OEM) }\end{array}$ & $\begin{array}{l}\text { Categorize locations on- } \\
\text { site according to their } \\
\text { IEC } 61400-1(2005) \\
\text { class. }\end{array}$ & $\begin{array}{l}\text { Quantify the } 50 \text {-year } \\
\text { return wind speed on- } \\
\text { site }\left(V_{\text {ref }}\right) \text {. } \\
\text { Quantify the } 95^{\text {th }} \\
\text { percentile of the } \\
\text { turbulence intensity at } \\
15 \mathrm{~m} / \mathrm{s}\left(I_{\text {ref }}\right) .\end{array}$ & $\begin{array}{l}\text { Accuracy of the } V_{r e f} \\
\text { estimate } \\
\text { Accuracy of the } I_{r e f} \\
\text { estimate }\end{array}$ \\
\hline $\begin{array}{l}\text { Perform loads } \\
\text { analysis (by OEM) }\end{array}$ & $\begin{array}{l}\text { Obtain offer from a wind } \\
\text { turbine OEM to provide a } \\
\text { warrantied wind turbine. }\end{array}$ & $\begin{array}{l}\text { The OEM performs } \\
\text { analysis following the } \\
\text { site suitability } \\
\text { assessment process } \\
\text { described in Chapter } 11 \\
\text { of IEC } 61400-1 \text { (2005). }\end{array}$ & $\begin{array}{l}\text { Accuracy of the } V_{r e f} \\
\text { estimate } \\
\text { Accuracy of the } I_{r e f} \\
\text { estimate } \\
\text { The OEM may not } \\
\text { always use all } \\
\text { atmospheric data. } \\
\text { Data from the wind } \\
\text { resource campaign may } \\
\text { be insufficient. }\end{array}$ \\
\hline $\begin{array}{l}\text { Perform power } \\
\text { analysis (by OEM) }\end{array}$ & $\begin{array}{l}\text { Obtain offer from a wind } \\
\text { turbine OEM to provide a } \\
\text { warrantied power curve. }\end{array}$ & $\begin{array}{l}\text { Perform coupled flow } \\
\text { modeling and turbine } \\
\text { performance } \\
\text { simulations. } \\
\text { These may result in } \\
\text { power curves for each } \\
\text { individual turbine } \\
\text { location. }\end{array}$ & $\begin{array}{l}\text { The proprietary } \\
\text { processes cannot be } \\
\text { tested. } \\
\text { The wind turbine power } \\
\text { curves have uncertainty }\end{array}$ \\
\hline $\begin{array}{l}\text { Estimate single- } \\
\text { turbine energy } \\
\text { capture (by project } \\
\text { sponsor or IE) }\end{array}$ & $\begin{array}{l}\text { Estimate gross energy } \\
\text { capture for each turbine } \\
\text { model, which can be } \\
\text { used to evaluate } \\
\text { financial viability. }\end{array}$ & $\begin{array}{l}\text { Perform a single-turbine } \\
\text { analysis using machine } \\
\text { power curve and } \\
\text { representative data. } \\
\text { Vet turbine selection } \\
\text { with energy estimate } \\
\text { from preliminary layouts. }\end{array}$ & $\begin{array}{l}\text { Preliminary estimate. } \\
\text { The method may over- } \\
\text { or underpredict plant } \\
\text { energy depending on } \\
\text { site layout. } \\
\text { It may not include wind } \\
\text { flow or wake modeling. } \\
\text { Turbine energy is } \\
\text { affected by a wide } \\
\text { range of atmospheric } \\
\text { conditions. }\end{array}$ \\
\hline $\begin{array}{l}\text { Select turbine(s) (by } \\
\text { project sponsor) }\end{array}$ & $\begin{array}{l}\text { Choose turbine(s) to use } \\
\text { in site layout } \\
\text { optimization. }\end{array}$ & $\begin{array}{l}\text { Compare performance } \\
\text { and commercial terms } \\
\text { among a subset of } \\
\text { turbine models. }\end{array}$ & $\begin{array}{l}\text { Turbine performance in } \\
\text { a wind power plant's } \\
\text { environment may be } \\
\text { different than predicted. }\end{array}$ \\
\hline
\end{tabular}

The project sponsor or IE produces the preliminary energy estimate by summing the energy from all turbines on-site and making a preliminary loss estimate using generic loss amounts. To do this, the energy from each turbine is estimated from the wind speed distribution at each turbine location and the turbine's power curve. First, the site wind speed data are analyzed to find the frequency of wind speeds in the range of 0.5 or 1 meter per second $(\mathrm{m} / \mathrm{s})$-wide bins in 1 year at 
each location (denoted $f\left(u_{i}\right)$ ). Then the power curve is used to find the expected power for that wind speed bin (denoted $P\left(u_{i}\right)$ ). The gross energy per turbine is then the sum of the power times the frequency of each bin (Figure 5).

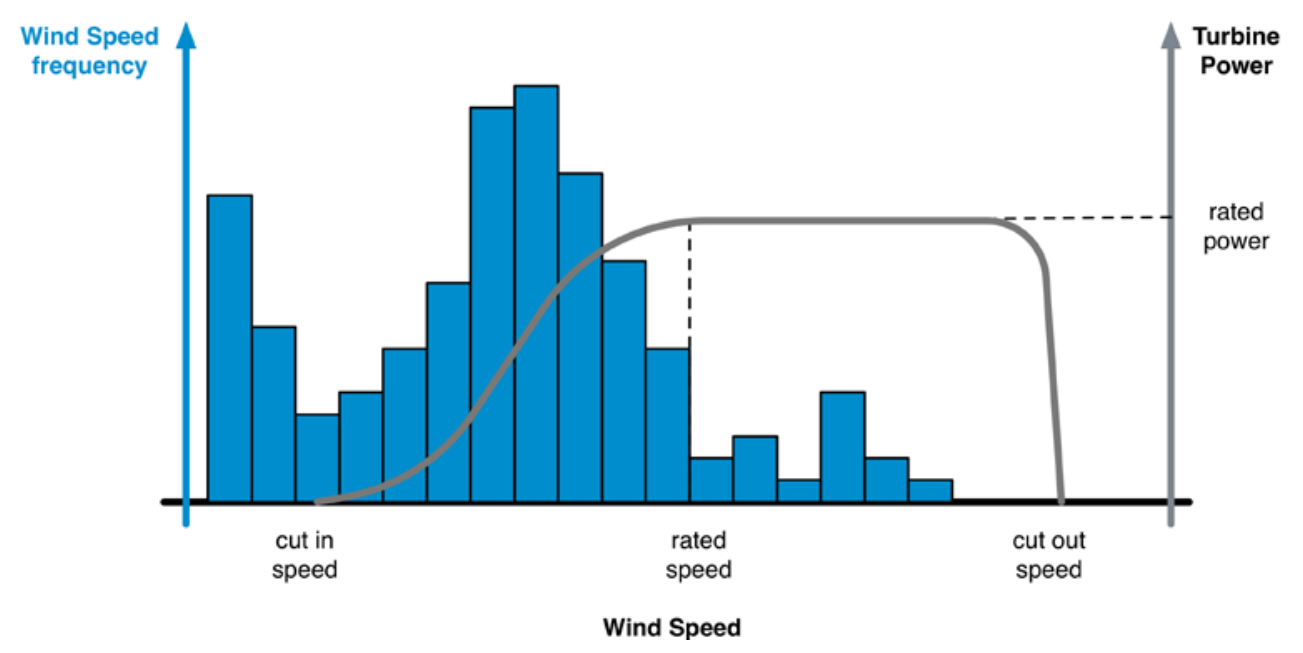

Figure 5. Binned wind speed for a single turbine together with the turbine power curve

Formally, the gross energy per turbine is as follows:

$$
\text { Gross energy estimate }=\sum_{i=1}^{i=n} P\left(u_{i}\right) \cdot f\left(u_{i}\right)
$$

If the wind speed frequency is given in hours and the power is given in kilowatts, the gross energy has units of kilowatt hours.

The turbine's power is adjusted to account for the effect of air density variation following the process described in IEC 61400-12-1 (2005) or using an OEM's density-adjusted power curves. This estimate is made for each turbine and then summed across the site to give the gross energy. Generic losses are then used to give a first net energy estimate for each of the possible choices of turbines on that site.

Estimating power from hub-height wind speed would be a reliable process if the hub height wind speed were always indicative of the energy in the wind and if the wind speeds were constant for a duration of 10 minutes. However, it is well known that the amount of energy in the wind can change for the same hub-height wind speed because wind speeds are not constant (turbulence) and they vary with height (shear). Power is not usually adjusted to account for shear; however, wind turbine OEMs may provide power curves at different reference turbulence intensities $\left(I_{r e f}\right)$.

In 2012, the Power Curve Working Group (an informal, international group of developers, consultants, turbine OEMs, and others) identified several factors that they considered key for turbine performance. These factors include turbulence and shear, directional shear (veer), other inflow conditions such as flow at an angle to horizontal, and changes in wind direction and angle. Changes in inflow are partly related to changes in the atmosphere from day to night, 
which is linked to atmospheric stability, but it is also related to changes in wind direction, seasonal variation, and even changes in global circulation patterns.

There has been considerable research into ways to predict turbine output that account for more than the hub-height wind speed, temperature, and pressure. Wagner et al. (2011) demonstrated the use of the rotor equivalent wind speed to capture the effect of shear on turbine power, and Choulkar et al. (2015) expanded the rotor equivalent wind speed to include the effect of directional veer and turbulence as well. The rotor equivalent wind speed approach requires wind speed and direction data across the rotor disk, which can be supplied only by taller towers or remote sensing; realistically, remote sensing is the only way to provide that data. Albers (2010) set out a method to account for the effect of turbulence on power by calculating the underlying "zero-turbulence" power curve and showed that power curves could be customized to any site's characteristics. Hedevang (2012) presents a comparison of several such methods, and Clifton and Wagner (2014) and Bulaevskaya et al. (2015) describe machine-learning approaches that can account for the effect of variables when the mechanism behind their effect is not clear.

Improving the way in which power curves are measured and used is the subject of much international collaboration. Experts from several countries are working together to create a third edition of the IEC wind turbine power performance testing standard (IEC 61400-12-1), which will include the methods proposed by Wagner et at. (2011) and Albers (2010) to account for the effects of turbulence and shear on power. Experts also share experience in working groups such as the Power Curve Working Group, and through organizations such as IEA Wind, the American Wind Energy Association, and the European Wind Energy Association.

\subsubsection{Site Optimization}

Site optimization is an iterative process that aims to design the layout of wind turbines, roads, and site electrical infrastructure against some goal according to the local wind resources and within the constraints imposed by the terrain, land agreements, and local regulations defining setback requirements (Figure 6 and Table 7). The process is usually driven by the distribution of wind speeds and directions that are outcomes from the horizontal and vertical extrapolation process.

Site optimization takes place only in the site development process. When the IE is preparing the preconstruction energy estimate report, the IE usually uses a site layout and plant infrastructure design that the sponsor or another engineer has developed. 


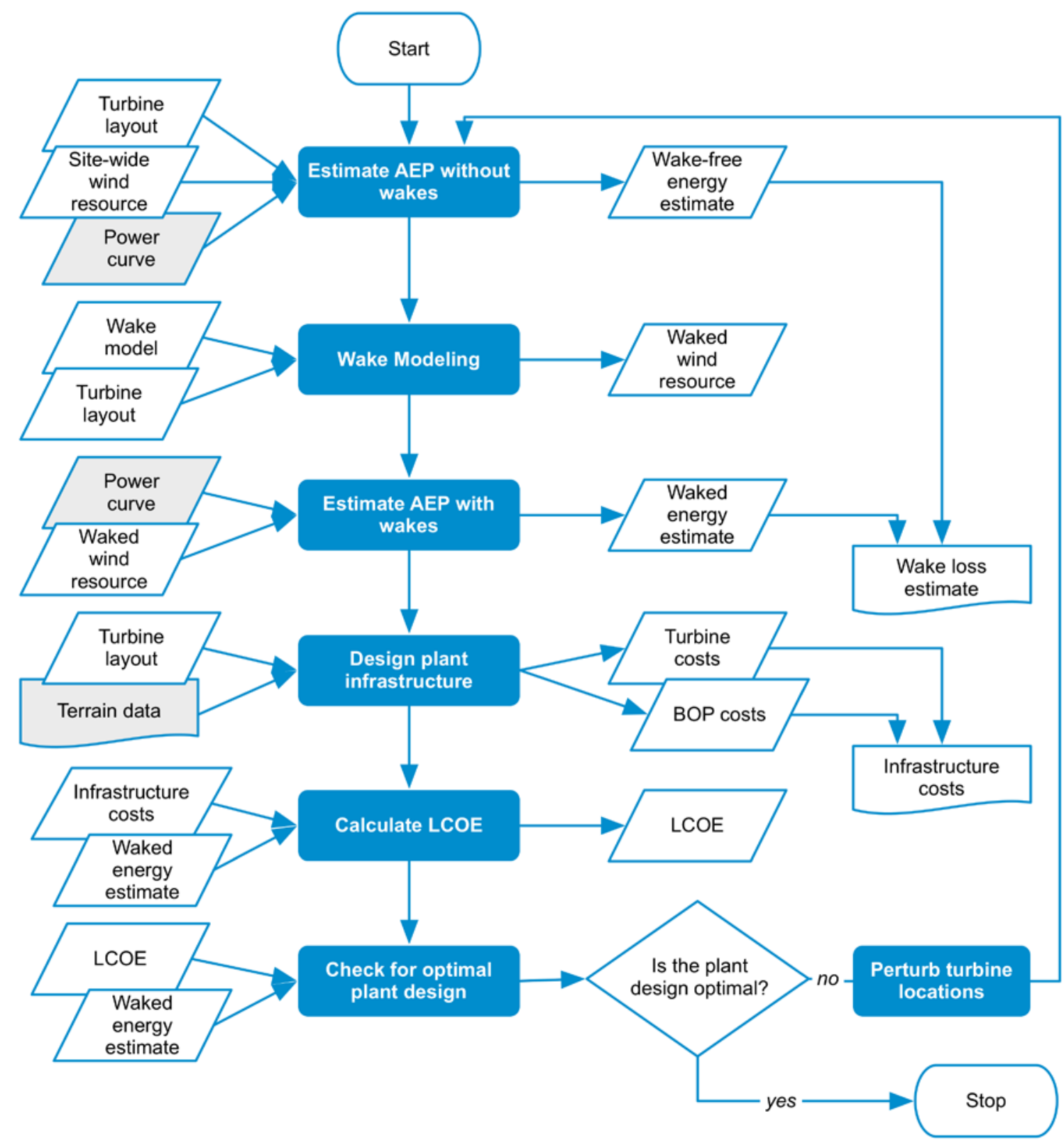

Figure 6. Site optimization process

The goal of optimization has historically been to maximize the energy capture of the plant while staying within constraints such as slope angle or distances to habitation; however, software tools have recently been developed that allow optimization with respect to total cost or LCOE. LCOE is best summarized as the net present value of all project expenditures divided by the net present value of energy production. The LCOE metric excludes policy incentives (e.g., renewable energy credits) and other revenue streams (e.g., capacity payments) that may be available to a wind project within a specific state or region. In reality, sponsors and investors are more concerned with the delivered energy price from a project (which includes policy incentives and other revenue streams) than with LCOE. LCOE is used in this document because it is more generic (i.e., independent of local market conditions) and provides a good proxy for price. 
Table 7. Site Optimization Activities

\begin{tabular}{|c|c|c|c|}
\hline Activity & Desired Outcome & Method & Uncertainties \\
\hline $\begin{array}{l}\text { Estimate energy } \\
\text { without wakes }\end{array}$ & $\begin{array}{l}\text { Obtain a wake-free } \\
\text { energy estimate. }\end{array}$ & $\begin{array}{l}\text { Use the wind turbine power } \\
\text { curve together with long-term } \\
\text { wind speed and direction } \\
\text { distribution data to estimate } \\
\text { annual energy capture. }\end{array}$ & $\begin{array}{l}\text { Uncertainties in energy are } \\
\text { from } 2 \%-5 \% \text {, depending on } \\
\text { uncertainties in wind } \\
\text { resource estimates and } \\
\text { turbine power curves. }\end{array}$ \\
\hline \multirow[t]{2}{*}{ Model wakes } & \multirow[t]{2}{*}{$\begin{array}{l}\text { Estimate the wind } \\
\text { resource at each } \\
\text { turbine location, } \\
\text { including slowdown } \\
\text { due to upwind } \\
\text { turbines. }\end{array}$} & \multirow{2}{*}{$\begin{array}{l}\text { Use a simple wake model } \\
\text { (e.g., Park, modified eddy } \\
\text { viscosity) to estimate the } \\
\text { wake from each turbine and } \\
\text { the effect on downwind } \\
\text { locations. } \\
\text { Assume each turbine seeks } \\
\text { to maximize its own energy } \\
\text { capture rather than being } \\
\text { down-rated by plant-level } \\
\text { control to increase a wind } \\
\text { power plant's overall energy } \\
\text { capture. }\end{array}$} & $\begin{array}{l}\text { Wake models that are used } \\
\text { in the optimization process } \\
\text { are typically very simple } \\
\text { and do not include the } \\
\text { effect of stability or terrain. } \\
\text { Uncertainties in wake loss } \\
\text { estimates may be as high } \\
\text { as } 50 \% \text { of the losses. }\end{array}$ \\
\hline & & & $\begin{array}{l}\text { Wake losses are from } 1 \%- \\
10 \% \text { of the plant's gross } \\
\text { energy, depending on site. }\end{array}$ \\
\hline $\begin{array}{l}\text { Estimate energy } \\
\text { with wakes }\end{array}$ & $\begin{array}{l}\text { Estimate energy } \\
\text { including the effect of } \\
\text { wakes on the wind } \\
\text { resource at each } \\
\text { turbine. }\end{array}$ & $\begin{array}{l}\text { Use the wind turbine power } \\
\text { curve together with waked } \\
\text { wind resource data to } \\
\text { estimate the annual energy } \\
\text { capture. }\end{array}$ & $\begin{array}{l}\text { Power models assume the } \\
\text { same power curve in and } \\
\text { out of the wake. }\end{array}$ \\
\hline \multirow[t]{3}{*}{$\begin{array}{l}\text { Design plant } \\
\text { infrastructure }\end{array}$} & \multirow{3}{*}{$\begin{array}{l}\text { Consider layouts of } \\
\text { roads, collection } \\
\text { lines, interconnection } \\
\text { points, substation, } \\
\text { operation and } \\
\text { maintenance (O\&M) } \\
\text { facility, and } \\
\text { transmission lines } \\
\text { (balance of plant). } \\
\text { Determine required } \\
\text { amount of fill or } \\
\text { number of borrow } \\
\text { pits. }\end{array}$} & $\begin{array}{l}\text { Use a combination of } \\
\text { automated layout tools and } \\
\text { desktop studies. } \\
\text { Estimate capital expenditure. }\end{array}$ & \multirow{3}{*}{$\begin{array}{l}\text { Cost estimates may not } \\
\text { fully consider the } \\
\text { interactions between } \\
\text { turbine layouts and } \\
\text { balance-of-plant costs. } \\
\text { Macroeconomic conditions } \\
\text { can fluctuate between } \\
\text { design and contracting, } \\
\text { changing actual costs. }\end{array}$} \\
\hline & & & \\
\hline & & & \\
\hline $\begin{array}{l}\text { Estimate } \\
\text { electrical loss }\end{array}$ & $\begin{array}{l}\text { Estimate electrical } \\
\text { loss. }\end{array}$ & $\begin{array}{l}\text { Perform a desktop study to } \\
\text { estimate losses between the } \\
\text { turbine and the point of } \\
\text { revenue metering, including } \\
\text { transformers, collection } \\
\text { wiring, substation, and } \\
\text { transmission. This could be } \\
\text { (1) a simple straight line } \\
\text { percentage assumption or } \\
\text { (2) a time-dependent } \\
\text { electrical loss analysis of } \\
\text { turbine circuits and the } \\
\text { collection system. }\end{array}$ & $\begin{array}{l}\text { Uncertainties are low. This } \\
\text { process generally uses } \\
\text { validated commercial } \\
\text { software products (e.g., } \\
\text { PSCAD). }\end{array}$ \\
\hline
\end{tabular}




\begin{tabular}{|c|c|c|c|}
\hline Activity & Desired Outcome & Method & Uncertainties \\
\hline \multirow[t]{2}{*}{ Calculate LCOE } & \multirow[t]{2}{*}{$\begin{array}{l}\text { Estimate the cost of } \\
\text { energy per kilowatt- } \\
\text { hour. }\end{array}$} & $\begin{array}{l}\text { Calculate the cost of } \\
\text { electricity (cost to build and } \\
\text { operate the plant divided by } \\
\text { the energy produced.) }\end{array}$ & $\begin{array}{l}\text { Cost models used in } \\
\text { optimization routines are } \\
\text { typically simplistic to reduce } \\
\text { calculation times. }\end{array}$ \\
\hline & & $\begin{array}{l}\text { O\&M cost models may be } \\
\text { very simple (e.g., } \$ 0.01 / \mathrm{kWh}) \text {. }\end{array}$ & $\begin{array}{l}\text { O\&M costs are highly } \\
\text { variable and may depend } \\
\text { on site wind resources and } \\
\text { environmental conditions. }\end{array}$ \\
\hline \multirow[t]{2}{*}{$\begin{array}{l}\text { Check for } \\
\text { optimal plant } \\
\text { design }\end{array}$} & \multirow[t]{2}{*}{$\begin{array}{l}\text { Determine optimum } \\
\text { plant layout. }\end{array}$} & \multirow{2}{*}{$\begin{array}{l}\text { Compare results from this } \\
\text { iteration (turbine locations) to } \\
\text { the previous iterations to test } \\
\text { for optimum layout using } \\
\text { whichever metric has been } \\
\text { chosen. }\end{array}$} & $\begin{array}{l}\text { Some optimization routines } \\
\text { find local minima in the } \\
\text { optimization function, which } \\
\text { may miss other, more } \\
\text { optimal layouts. }\end{array}$ \\
\hline & & & $\begin{array}{l}\text { Results may be impacted } \\
\text { by biases or uncertainties } \\
\text { introduced in other } \\
\text { activities, and may not be } \\
\text { optimal for the site. }\end{array}$ \\
\hline $\begin{array}{l}\text { Perturb turbine } \\
\text { locations }\end{array}$ & $\begin{array}{l}\text { Improve wind power } \\
\text { plant performance. }\end{array}$ & $\begin{array}{l}\text { Wind turbine locations are } \\
\text { randomly changed to see if } \\
\text { the plant performs better (in } \\
\text { terms of the optimization } \\
\text { criteria). }\end{array}$ & $\begin{array}{l}\text { Geotechnical conditions are } \\
\text { not always known in detail. } \\
\text { Automatically selected, } \\
\text { optimum locations are not } \\
\text { always suitable for turbines, } \\
\text { and a site survey may be } \\
\text { required before the final } \\
\text { turbine layout is chosen. }\end{array}$ \\
\hline
\end{tabular}

Site optimization is a computationally intensive process that may be repeated many thousands of times before the optimal solution is found. Therefore, simple (low-cost) models of turbine performance, wakes, and associated costs are used because these reduce the wall-clock time for the optimization to complete. This allows different scenarios to be tested, such as the effect of different types of wind turbines. However, these lower-cost models often oversimplify reality and can result in suboptimal plant designs. Some examples of the effects of these lower-cost models include:

- The turbine energy capture model will likely use the hub height wind speed to predict energy capture. Although some models have been updated to use rotor-equivalent wind speed or account for the effect of turbulence, almost all turbine performance models used in the site optimization process do not capture the effects of directional veer or rapidly changing conditions.

- The wake model may not capture the different wake structures that are thought to form in stable atmospheric conditions (typically nighttime) compared to unstable conditions (typically daytime). This can lead to considerable seasonal variations in model accuracy in different areas of the world because atmospheric stability impacts vary depending on terrain, location, and climate. 
- Plant infrastructure models may use simplified geotechnical data or simplified cost models. These may underestimate the real cost of plant infrastructure or result in unrealistic infrastructure designs.

- The energy production models that are used as inputs to the LCOE equation require information about turbine availability and curtailment. However, that information may be very low resolution or generic and not accurate for the combination of turbines, balance of plant, and site conditions.

Higher-fidelity modeling after the optimization process may reduce some of the uncertainties identified above. For example, a wake model that includes more physical processes might be used, or a more detailed turbine performance model could be used in place of a power curve. Likewise, it is possible to use more advanced infrastructure models rather than assume losses that are proportional to the length of transmission or distribution. However, these higher-fidelity models are inherently computationally expensive to run and are not always well validated. Also, it is important to match the fidelity of the models to each other, and to the data that are used as the optimization criteria. For example, there is little point in applying a computationally intensive flow model and a simplistic cost model if the goal is to optimize LCOE.

Recent research into site optimization includes the use of new optimization routines and multitarget optimization protocols (DuPont and Cagan 2012; Fleming et al. 2015). This research is aimed at allowing optimization on factors other than energy capture as well as speeding up the optimization process so that more complex wake or turbine performance models can be used. Such tools should enhance the ability of wind power plant designers to accurately weigh tradeoffs between capital expenditures and energy production, which could result in both more optimal plant layouts and reduced uncertainty.

Other areas of relevant research include plant-level controls wherein the energy capture from individual turbines may be regulated to maximize the energy capture of the plant as a whole. Computational models are being used to develop strategies to turn wakes away from downwind turbines by altering turbine yaw (Fleming et al. 2015) or to test tools such as forward-looking lidar to allow turbines to respond to incoming wakes. These approaches could potentially reduce or remove wake loses, but their effects on plant performance need to be considered in the plant optimization process.

\subsubsection{Plant Loss Estimation}

After the site layout has been optimized and the first energy estimate has been derived, the next step is to refine the estimates of energy loss within the plant to give a more accurate estimate of the energy that is delivered to the point of revenue metering. This step recognizes that the wind plant may be subject to losses that cannot be easily modeled during the optimization process and that the wind farm may have a few years of commissioning or teething trouble.

Efforts within the wind industry are underway to create a uniform framework of loss categories. This allows comparisons among projects. DNV KEMA, which frequently provides IE services, published a loss framework in 2013 in collaboration with nine other IEs (DNV KEMA 2013). Not all companies use the same framework, but often they use similar names for losses that may or may not have exactly the same breakdown in each category The desire to be able to compare projects prompted the founding of an IEC working group in 2013 to develop a new standard, 
tentatively called IEC 61400-15: Assessment of Wind Resource, Energy Yield, and Site Suitability Input Conditions for Wind Power Plants. In 2015, the IEC 61400-15 working group developed a list of major loss categories with associated subcategories. These categories are shown in Figure 7.

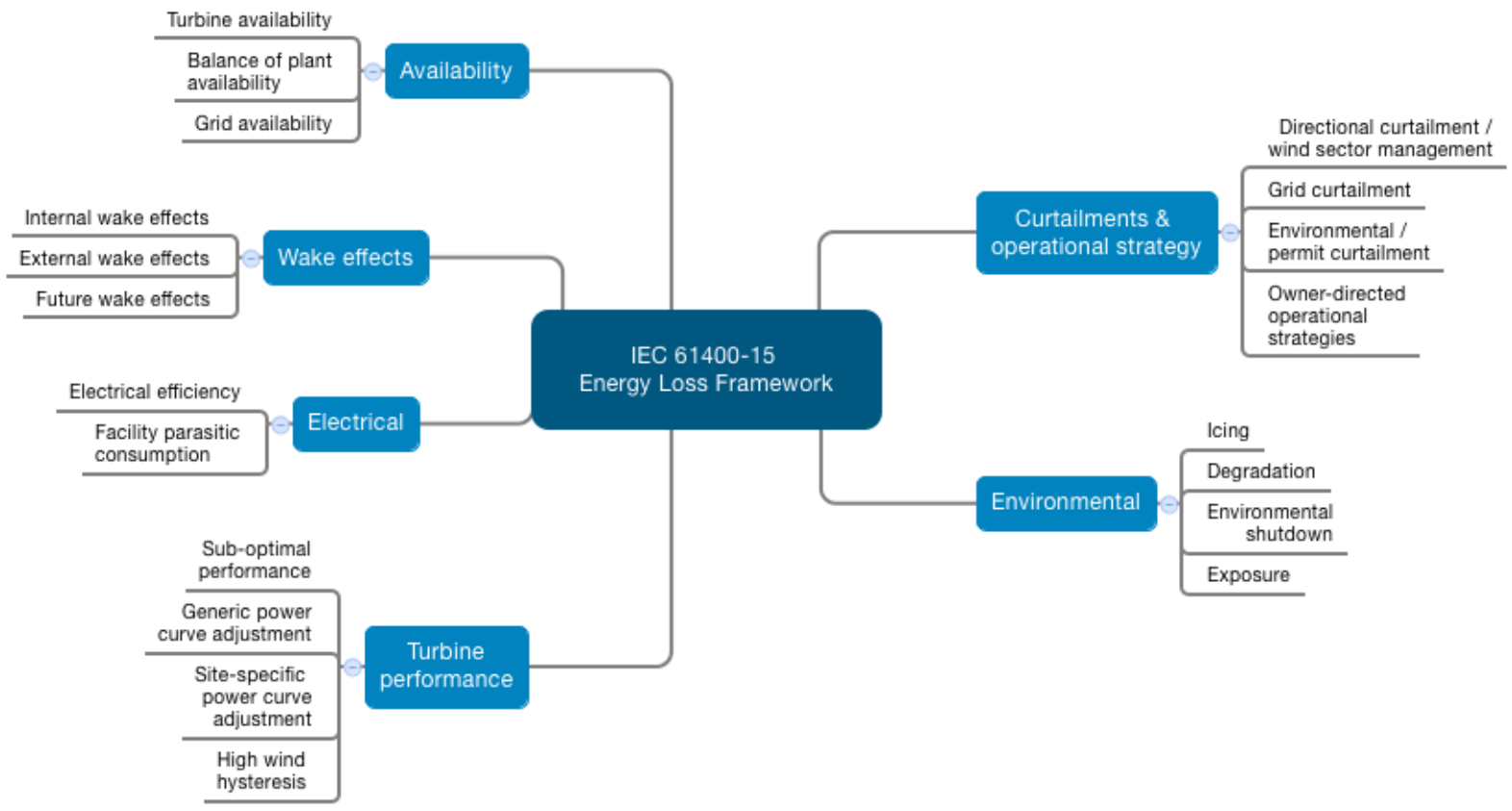

Figure 7. Loss categories proposed by the IEC 61400-15 working group

Version 1.0, 26 February 2015

Losses are estimated at different points in the wind plant preconstruction energy estimate process. For example, wake losses were estimated in the plant optimization process. Others, such as electrical losses, are estimated during the optimization process but then refined after the wind power plant layout has been finalized and the collection lines have been planned (Table 8).

A benefit of common loss categories is that losses can be identified, ranked, and valued throughout the entire wind industry, and the potential to address these losses through research and development can be evaluated. Further, placing a value on a loss allows for cost-benefit analysis at the plant level, wherein a project sponsor may choose to act to reduce losses; or at the industry level, wherein the wind energy community may choose to collaborate to address a large, complex problem.

A survey of recent estimates for different losses is provided in Section 4.1. 
Table 8. Loss Estimation Activities

\begin{tabular}{|c|c|c|c|}
\hline Activity & Desired Outcome & Method & Uncertainties \\
\hline $\begin{array}{l}\text { Estimate } \\
\text { availability }\end{array}$ & $\begin{array}{l}\text { Estimate annual } \\
\text { time-based or } \\
\text { energy-based } \\
\text { turbine and } \\
\text { balance of plant } \\
\text { availability. }\end{array}$ & $\begin{array}{l}\text { Perform a desktop study } \\
\text { to estimate the plant } \\
\text { availability on a yearly } \\
\text { basis using experience } \\
\text { from other plants or O\&M } \\
\text { models. } \\
\text { This can be a simple } \\
\text { straight-line percentage } \\
\text { assumption (energy } \\
\text { based) or informed with } \\
\text { environmental information } \\
\text { such as wind speed, } \\
\text { turbulence, temperature, } \\
\text { and air density, (time } \\
\text { based). }\end{array}$ & $\begin{array}{l}\text { This provides limited information } \\
\text { about component repair and } \\
\text { replacement rates, particularly for } \\
\text { new turbines or turbines used } \\
\text { outside their IEC design class. } \\
\text { The time needed to repair/replace } \\
\text { can vary depending on crane } \\
\text { availability and spare parts strategy. } \\
\text { The plant availability may vary } \\
\text { depending on the developer's O\&M } \\
\text { strategy and priorities. } \\
\text { Operating strategies for a wind } \\
\text { power plant may be different than } \\
\text { planned, including reduced } \\
\text { maintenance to minimize costs } \\
\text { toward the end of the plant life. }\end{array}$ \\
\hline $\begin{array}{l}\text { Determine } \\
\text { wake effects }\end{array}$ & \multicolumn{3}{|c|}{$\begin{array}{l}\text { This is calculated in the site optimization stage (Section 3.3.4), but it may be refined at } \\
\text { this stage. }\end{array}$} \\
\hline $\begin{array}{l}\text { Determine } \\
\text { turbine } \\
\text { performance }\end{array}$ & \multicolumn{3}{|c|}{$\begin{array}{l}\text { This is calculated in the site optimization stage (Section 3.3.4), but it may be refined at } \\
\text { this stage. }\end{array}$} \\
\hline $\begin{array}{l}\text { Estimate } \\
\text { electrical loss }\end{array}$ & \multicolumn{3}{|c|}{$\begin{array}{l}\text { This is calculated in the site optimization stage (Section 3.3.4), but it may be refined at } \\
\text { this stage. }\end{array}$} \\
\hline $\begin{array}{l}\text { Estimate } \\
\text { environmental } \\
\text { loss }\end{array}$ & $\begin{array}{l}\text { Estimate } \\
\text { annualized losses } \\
\text { from icing, blade } \\
\text { soiling, and out-of- } \\
\text { range atmospheric } \\
\text { variables. }\end{array}$ & $\begin{array}{l}\text { Perform a desktop study } \\
\text { to apply experience from } \\
\text { other sites to this site. }\end{array}$ & $\begin{array}{l}\text { Air temperature and icing are not } \\
\text { directly correlated. } \\
\text { Blade soiling is very dependent on } \\
\text { local land use and frequency of rain. } \\
\text { Turbine performance in out-of-range } \\
\text { conditions is not well defined. }\end{array}$ \\
\hline $\begin{array}{l}\text { Estimate } \\
\text { curtailment }\end{array}$ & $\begin{array}{l}\text { Estimate energy } \\
\text { losses due to grid, } \\
\text { environmental, or } \\
\text { operational } \\
\text { curtailment (i.e., } \\
\text { outside of } \\
\text { sponsor's control). } \\
\text { Estimate energy } \\
\text { losses due to } \\
\text { operational } \\
\text { strategy (i.e., within } \\
\text { sponsor's control). }\end{array}$ & $\begin{array}{l}\text { Perform a desktop study } \\
\text { to identify the risk of } \\
\text { curtailment due to } \\
\text { transmission constraints, } \\
\text { birds or bats, or grid } \\
\text { outages. }\end{array}$ & $\begin{array}{l}\text { The availability of transmission is } \\
\text { very dependent on the mix of } \\
\text { transmission on the grid. In areas } \\
\text { that have large stored hydro } \\
\text { capacity, wind may be curtailed to } \\
\text { allow water to move through the } \\
\text { system. This can be highly } \\
\text { dependent on weather. } \\
\text { Future changes in the electric } \\
\text { system (additional plants, } \\
\text { regulations) are difficult to predict. }\end{array}$ \\
\hline $\begin{array}{l}\text { Estimate } \\
\text { other losses }\end{array}$ & $\begin{array}{l}\text { Estimate losses } \\
\text { that may not be } \\
\text { captured through } \\
\text { other models. }\end{array}$ & $\begin{array}{l}\text { Perform an experience- } \\
\text { based assessment of } \\
\text { typical levels of losses } \\
\text { that are not assigned to } \\
\text { availability or curtailment. }\end{array}$ & $\begin{array}{l}\text { Uncertainties may be very high } \\
\text { depending on the amount of data to } \\
\text { which the developer or consultant } \\
\text { has access. } \\
\text { Loss categories are not } \\
\text { standardized. }\end{array}$ \\
\hline
\end{tabular}




\subsection{Uncertainty Analysis}

The estimates of energy capture and losses are all subject to a certain range of uncertainty. These uncertainties propagate through the energy estimate process in different ways, but can be combined to create a distribution of energy delivery over different timescales.

\subsubsection{What Is Uncertainty?}

Uncertainty is a measure of the random fluctuations of a repeated measurement, or the variability of the difference between predictions and observations of a process around the mean of those measurements or predictions.

Uncertainty is different from bias. Bias is the difference between the mean of lots of measurements or predictions and the actual value. Bias can therefore be removed through calibration or by modifying a prediction process.

\subsubsection{Measurement Uncertainty}

The meaning of uncertainty can be illustrated by considering a cup anemometer measurement.

A cup anemometer measures wind speed by converting fluctuating linear movement of air into rotation around a shaft. Those rotations are measured and converted into an electrical signal, which is then measured and converted back into a wind speed value using a transfer function.

The accuracy of a cup anemometer measurement is usually checked as part of a calibration process in a wind tunnel, wherein the anemometer is compared to a very accurate reference sensor. In an anemometer calibration, many measurements of the wind speed are made and compared to the reference using linear regression. This comparison allows the engineer to calculate a regression function that can be used to identify and remove any persistent bias relative to the reference device. It is inevitable that a small amount of error with respect to the reference device will remain, which is caused by the random variability of the measurement device.

The calibration and uncertainty evaluation process is partly described in standards such as EA4/02 (European Accreditation Laboratory Committee 2013), which is based on the Guide to the Expression of Uncertainty in Measurement (Working Group 1 of the Joint Committee for Guides in Metrology 2008).

If the anemometer is checked many times while the wind tunnel conditions stay the same and the value measured by the cup anemometer is counted in a large number of small bins, a bell-shaped distribution curve similar in shape to Figure 8 will be observed. This curve is known as a Gaussian distribution, and is typical of a measurement system. The distribution of those measurements forms a symmetric curve that can be described by a mean and standard deviation. If a measurement is made, it has the same chance of being above the mean as it has of being below the mean. Because bias is removed by calibrating the anemometer and because wind tunnel conditions are constant, the remaining error is the uncertainty of the cup anemometer. 


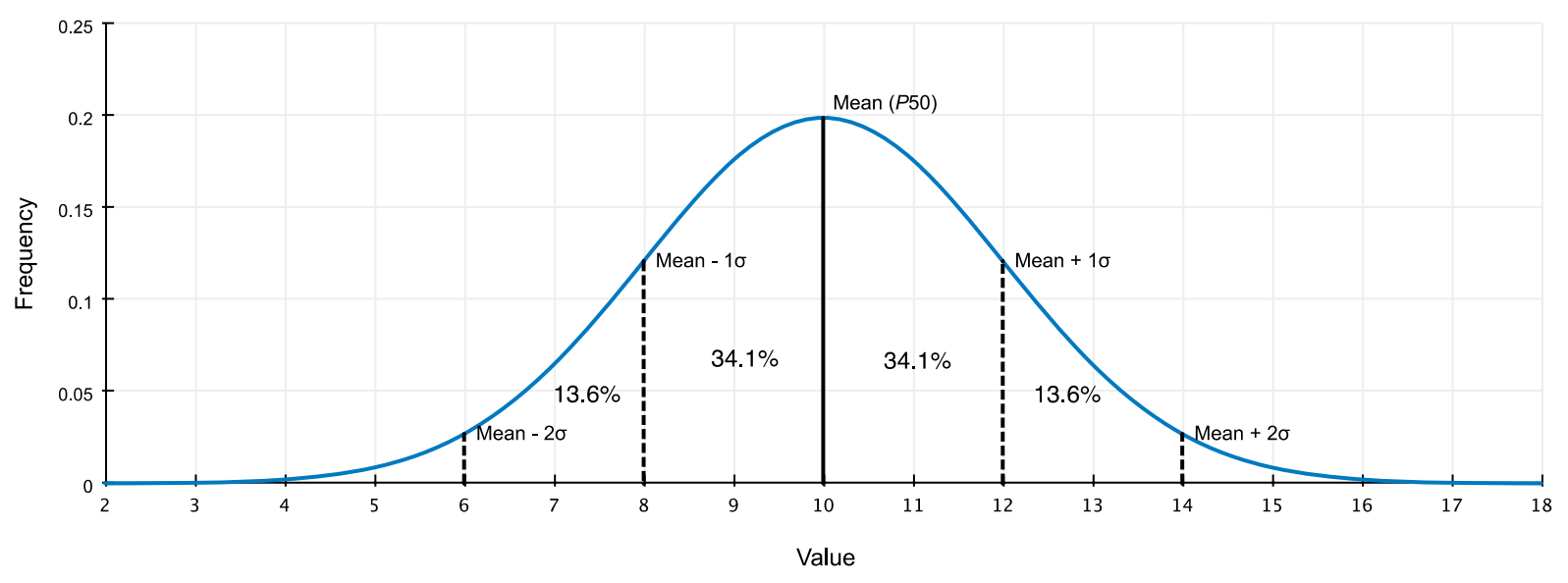

Figure 8. Example of a Gaussian distribution

The mean of the distribution is 10 , and the standard deviation is 2 . The percentage values are the percentage of observations that fall within that range.

An anemometer calibration report includes information about the uncertainty of the anemometer measurement; an example calibration report is shown in Figure 9.
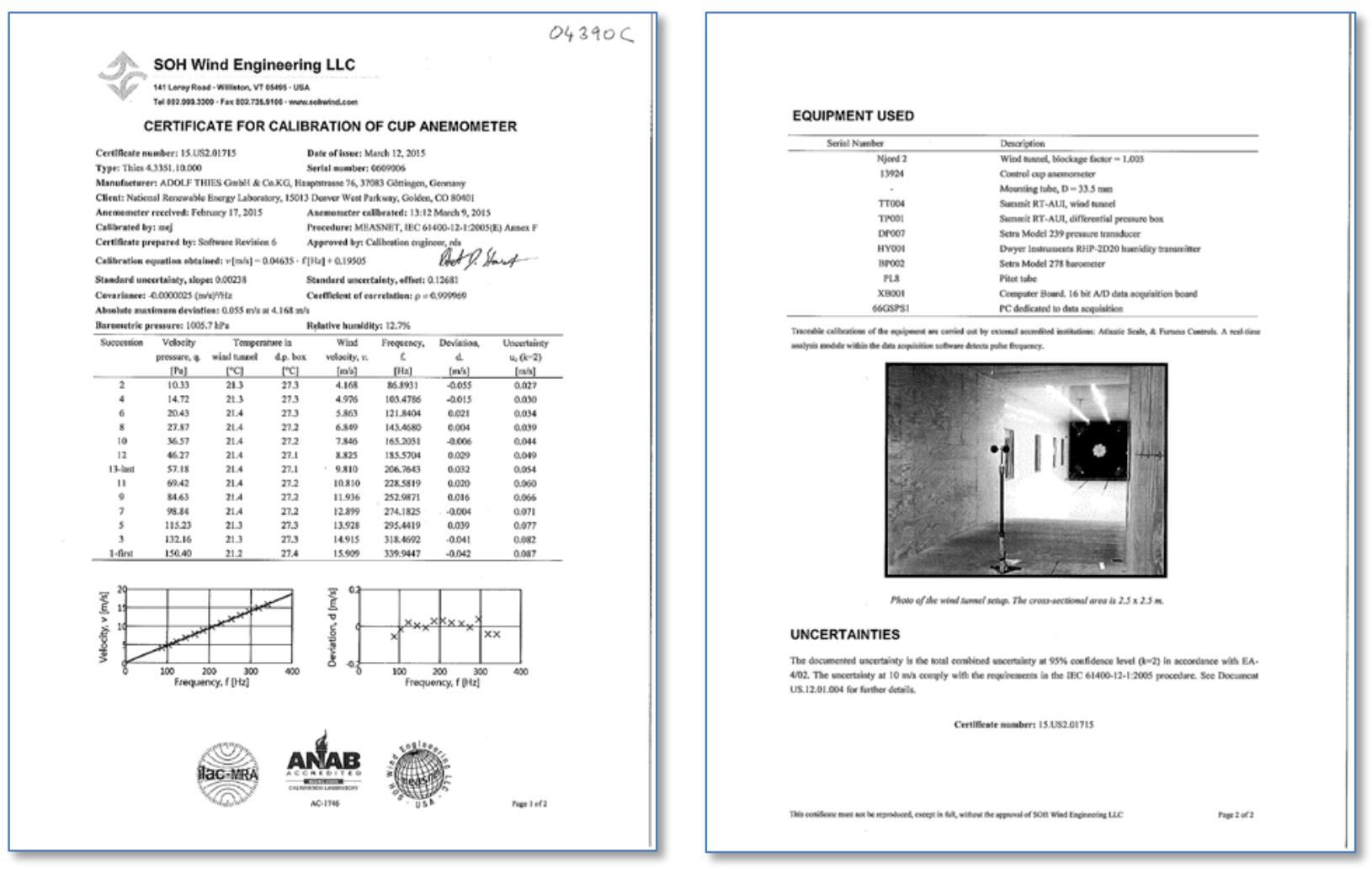

Figure 9. Calibration report for an anemometer

The anemometer calibration described in Figure 9 reports the total uncertainty as $0.044 \mathrm{~m} / \mathrm{s}$ at 10 $\mathrm{m} / \mathrm{s}$. The calibration report states, "the documented uncertainty is the total combined uncertainty at $95 \%$ confidence level $(k=2)$ in accordance with EA-4/02." This means that if the anemometer 
measures $10 \mathrm{~m} / \mathrm{s}$, there is a $95 \%$ certainty that the actual wind speed is in the range $9.956 \mathrm{~m} / \mathrm{s}-$ $10.044 \mathrm{~m} / \mathrm{s}$. According to the description given in EA-4/02, the use of $\mathrm{k}=2$ means that the reported uncertainty is actually an expanded uncertainty. The expanded uncertainty is $k$ times the standard uncertainty, which is the standard deviation of measurements due to random variation when conditions are constant. Thus, this anemometer's uncertainty is $0.022 \mathrm{~m} / \mathrm{s}$ at $10 \mathrm{~m} / \mathrm{s}$, or $0.22 \%$.

Uncertainty in measurements can be reduced by improving measurement methods.

\subsubsection{Model Uncertainty}

Model uncertainty is the standard deviation of multiple model predictions of the same process.

In practice, model uncertainty is defined slightly differently from measurement uncertainty. Most models used in the preconstruction energy yield assessment process are deterministic because for the same set of inputs they deliver the same output. An example of this is the power curve described in 3.3.3, wherein using the power curve several times with the same input conditions would give the same result and thus the model uncertainty would be zero if this approach were used.

Instead, model uncertainty in the context of the preconstruction energy yield assessment is measured by comparing the results from simulations to the available data. For example:

- To establish the uncertainty of the vertical extrapolation process, a comparison could be made between the extrapolated wind speeds and wind speed data from a remote sensing device. The standard deviation of the errors would be the uncertainty of this process.

- To establish the uncertainty of the wind model that is used for horizontal extrapolation, a model might be run for a site with $n$ observation locations using data from $n-1$ of those sites. This gives a total of $n-1$ combinations, wherein results from for the nth site would be compared to the observations for the $n$th site to give a mean error for that combination. This approach is often called the round-robin or k-folding approach. The uncertainty of the model over the whole site is then the standard deviation of the errors for each combination.

- To establish the uncertainty of the power curve, a comparison could be made of observed and predicted turbine power binned by wind speeds. The standard deviation of power in each wind speed bin could be the uncertainty of the power curve. Such a calculation would probably be performed by the wind turbine OEM outside of the preconstruction energy estimate process.

Uncertainties in modeling can be reduced by improving the way the model represents reality. Typically, a small amount of uncertainty is inevitable because measurements are hard to repeat or a model does not capture all of the physics of the actual process.

If a model consistently over- or underpredicts compared to observations, a calibration can be applied; however, instead of scaling results, most practitioners prefer to refine the model to account for new understanding. 


\subsubsection{Project Total Uncertainty}

There are many sources of uncertainty in a wind plant's preconstruction energy estimate. These sources are usually assumed to be uncorrelated from each other. If uncertainties are converted into percentages of net energy, the overall uncertainty in the energy estimate $\left(\sigma_{\text {Energy }}\right)$ can be calculated as the root of the sum of the squares of the different uncertainties. Formally, if there are $n$ sources of uncertainty, the total energy uncertainty is:

$$
\sigma_{\text {Energy }}=\sqrt[2]{\sum_{i=1}^{i=n} \sigma_{i}{ }^{2}}
$$

where $\sigma_{i}$ is one of the $n$ sources of uncertainty. If the uncertainties are correlated, then their covariances must be included. Positively correlated uncertainties would increase $\sigma_{\text {Energy }}$, whereas negatively correlated uncertainties would reduce $\sigma_{\text {Energy }}$. The amount of correlation between uncertainty sources and their importance for the total uncertainty is an ongoing research topic.

\subsubsection{Establishing P-factors from Uncertainties}

If total uncertainties are assumed to follow a Gaussian distribution, knowledge of the shape of the Gaussian distribution allows us to estimate the probability of exceeding a certain amount of energy. These values are typically the amount of energy that will be delivered to the point of revenue metering in $5 \%, 10 \%, 50 \%, 90 \%$, and $95 \%$ of a specific period, which are the $P 5, P 10$, ..., $P 95$ values for the project. Financial stakeholders can use these values in financial models to explore the implications of performance uncertainty on financial outcomes. (See Section 1.2.)

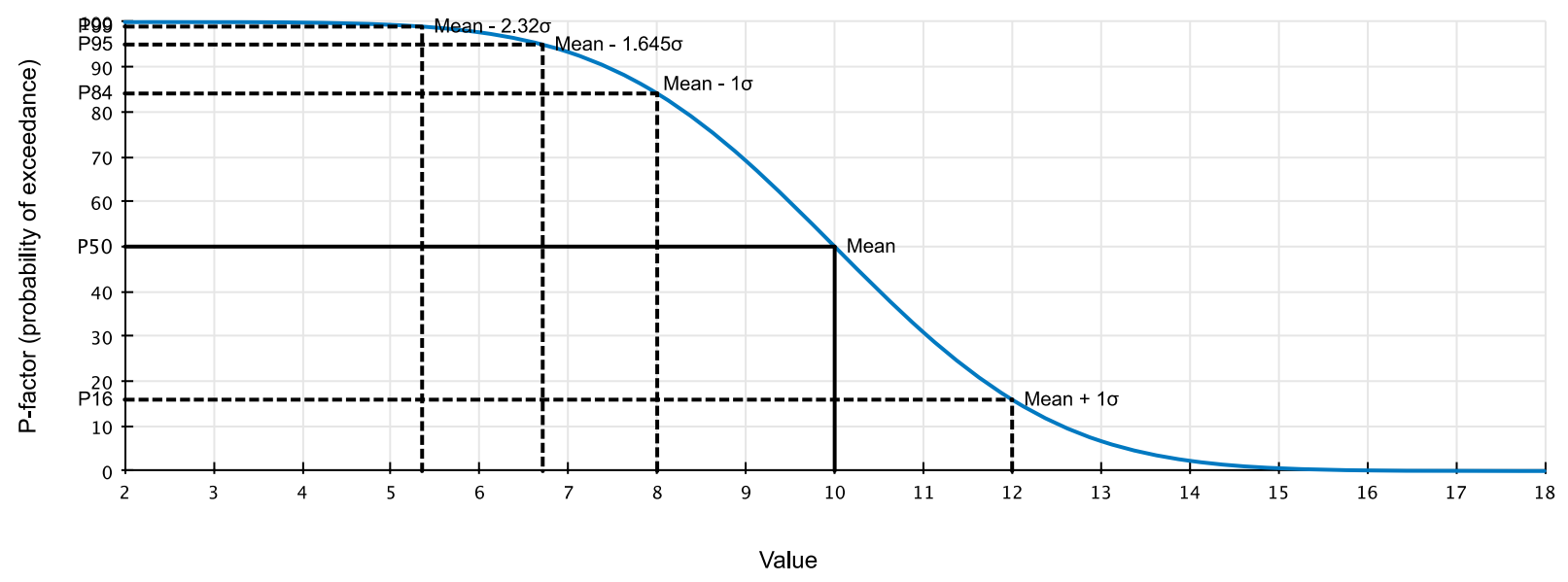

Figure 10. Example of the relationship between the mean and standard deviation and $P x x$ This figure uses the same distribution as that shown in Figure 8 (mean $=10$, standard deviation $=2)$.

The level of uncertainty surrounding the preconstruction energy estimate changes throughout the development process. In fact, the preconstruction energy estimation process is designed to reduce uncertainty about the energy estimate through on-site measurement, modeling, and verification activities. A project sponsor may repeat the uncertainty estimate many times by using the results to identify data that need to be refined (e.g., requiring an extension of the resource measurement campaign) or to identify models that are inadequate (e.g., the availability model may not include 
climatic effects). This process of continually refining uncertainty estimates cannot continue indefinitely, and it is subject to time and budget constraints.

The final preconstruction energy estimate that is used as the basis for structuring the financing package thus carries much less uncertainty than the preliminary energy estimate that is used in the prospecting phase. It is, however, subject to a degree of unavoidable uncertainty because of the fundamental challenge of predicting atmospheric conditions and the interaction between the wind power plant and the atmosphere during a 20-year-25-year period. If the value of the energy is high enough and the uncertainty is low enough, the plant may be an attractive opportunity. If the uncertainty is too high to justify the investment, sponsors may choose to collect more data to narrow the uncertainty or, in some cases, stop development activities.

\subsubsection{Uncertainty Frameworks}

As with losses, it is important to have commonly agreed-upon definitions of uncertainty among wind power plant development projects. As well as a loss framework, the IEC 61400-15 working group (see Section 3.3.5) created a first-draft community-consensus uncertainty framework (Figure 11). Like the loss framework, a standard uncertainty framework allows comparisons among different IEs and projects, enabling the detection of systematically high uncertainties that can be addressed at a project level by activities such as campaign extension or use of higher height measurements. This framework also facilitates targeted research and development coordinated among many organizations.

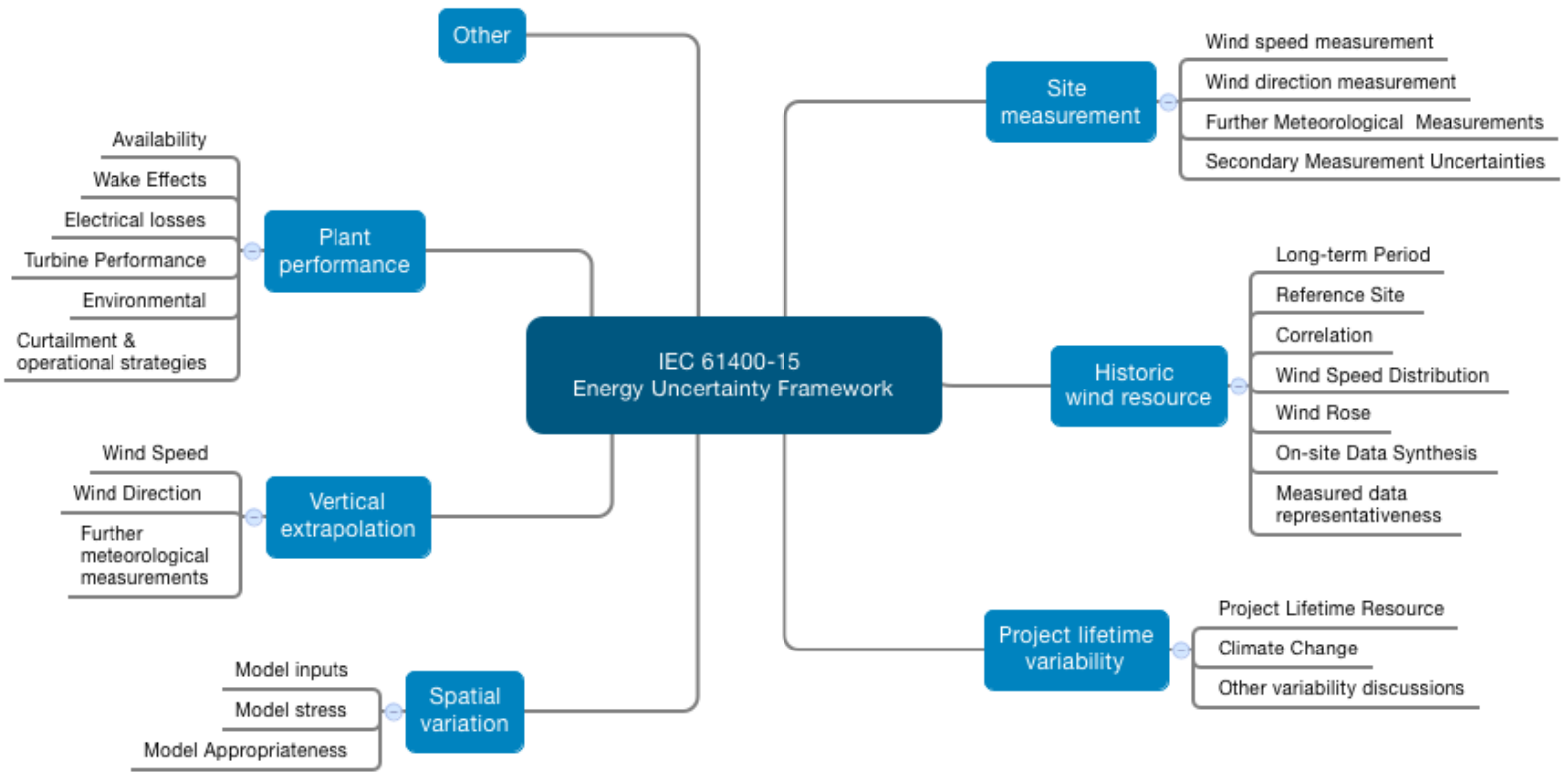

Figure 11. Uncertainty categories proposed by the IEC 61400-15 working group Version 1.0, 26 February 2015

The IEC 61400-15 draft uncertainty categories shown in Figure 11 arise at certain stages in the generic energy estimate process that is presented in this document (Figure 12). A survey of the values of uncertainties is presented in Section 4.2 . 


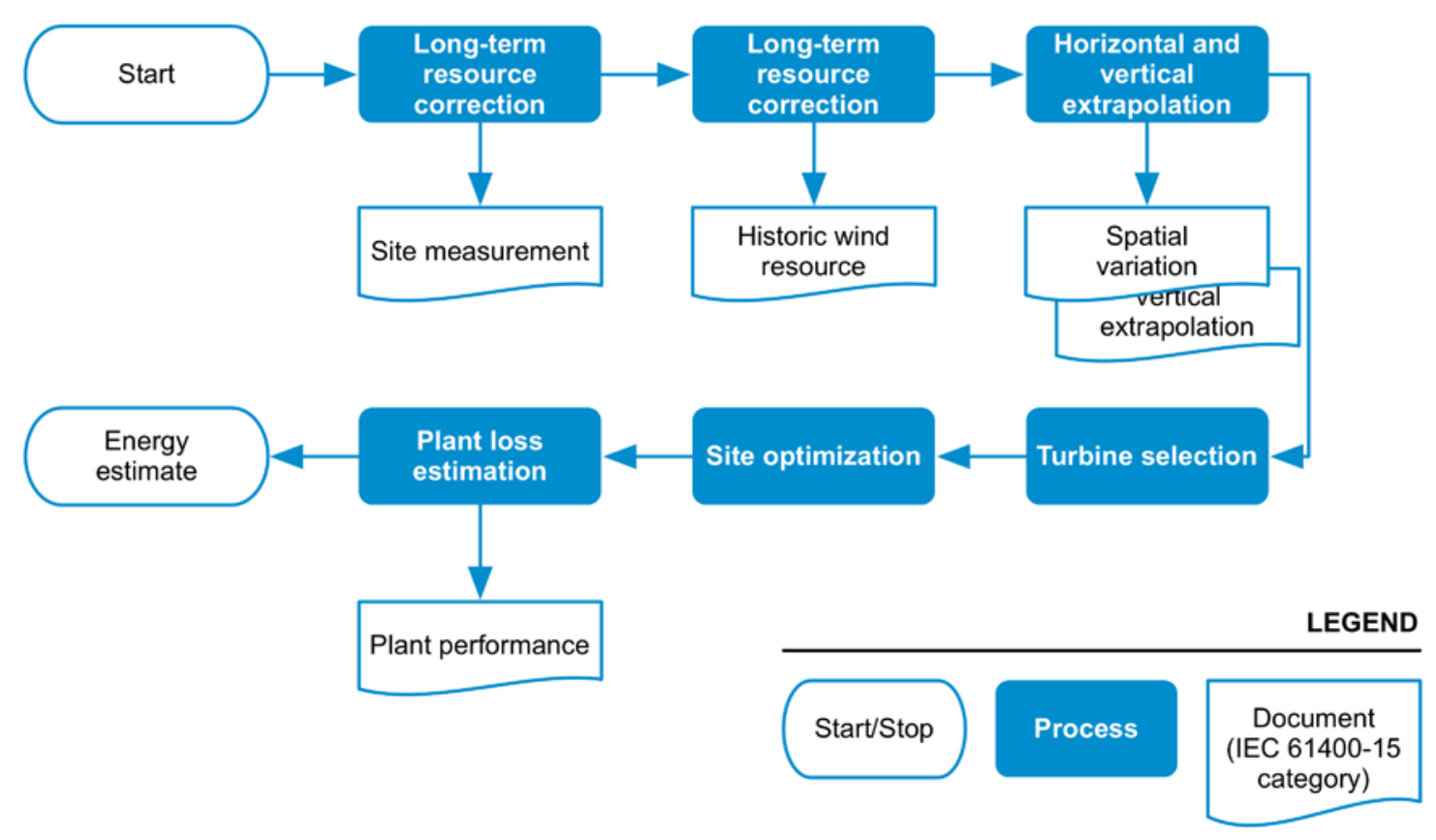

Figure 12. When uncertainties in the preconstruction energy estimate are created

Figure shows the stages at which uncertainty estimates are made, and how they map to IEC 61400-15 uncertainty categories

One challenge with the total project uncertainty calculation was introduced in Section 3.4.4: when adding a source of uncertainty in the uncertainty model without reducing the magnitude of the existing sources increases the apparent project uncertainty. Although this increase is appropriate if the source of uncertainty is genuinely new, there is a risk of double counting sources of uncertainty. A common uncertainty framework could help avoid this risk by providing clear guidance as to which uncertainty sources are accounted for under which categories.

The activities that take place to generate each uncertainty estimate are summarized in Table 9. 
Table 9. Uncertainty Estimation Activities

\begin{tabular}{|c|c|c|c|}
\hline Activity & Desired Outcome & Method & Uncertainties \\
\hline $\begin{array}{l}\text { Estimate site } \\
\text { measurement } \\
\text { uncertainty }\end{array}$ & $\begin{array}{l}\text { Estimate uncertainty } \\
\text { for all site } \\
\text { measurement } \\
\text { activities. }\end{array}$ & $\begin{array}{l}\text { Perform a desktop study } \\
\text { following IEC } 61400-12 \\
\text { (2005) for cup } \\
\text { anemometers. } \\
\text { Analyze pre- and post- } \\
\text { installation calibration of } \\
\text { cups, vanes, and other } \\
\text { devices. } \\
\text { Model tower wake and } \\
\text { slowdown. }\end{array}$ & $\begin{array}{l}\text { Information about the timing of } \\
\text { any calibration drift is unknown. } \\
\text { Met tower anemometer wake } \\
\text { models are not completely } \\
\text { validated. } \\
\text { The instruments' responses to } \\
\text { environmental factors are unclear } \\
\text { (rain, icing, etc.). }\end{array}$ \\
\hline $\begin{array}{l}\text { Estimate } \\
\text { spatial } \\
\text { variation } \\
\text { uncertainty }\end{array}$ & $\begin{array}{l}\text { Estimate the } \\
\text { uncertainty of the } \\
\text { wind speed at all } \\
\text { locations in the wind } \\
\text { power plant's } \\
\text { development area } \\
\text { due to spatial } \\
\text { extrapolation. }\end{array}$ & $\begin{array}{l}\text { Perform a desktop study. } \\
\text { Uncertainty is estimated } \\
\text { based on distance from } \\
\text { the nearest } \\
\text { measurement location } \\
\text { and terrain complexity. } \\
\text { Perform a field study } \\
\text { using remote sensing or } \\
\text { tower data from other } \\
\text { points to quantify model } \\
\text { uncertainty. }\end{array}$ & $\begin{array}{l}\text { Spatial variation can be validated } \\
\text { only at a few specific points. } \\
\text { This activity may not capture the } \\
\text { effect of changing atmospheric } \\
\text { stability or terrain on model } \\
\text { uncertainty. } \\
\text { It may not capture the effects of } \\
\text { phenomena that vary during short } \\
\text { periods (e.g., turbulence). }\end{array}$ \\
\hline $\begin{array}{l}\text { Estimate } \\
\text { vertical } \\
\text { extrapolation } \\
\text { uncertainty }\end{array}$ & $\begin{array}{l}\text { Estimate the } \\
\text { uncertainty of the } \\
\text { wind speed at all } \\
\text { points in the wind } \\
\text { power plant's } \\
\text { development area } \\
\text { due to vertical } \\
\text { extrapolation. }\end{array}$ & $\begin{array}{l}\text { Perform a desktop study } \\
\text { based on historical } \\
\text { experience with other } \\
\text { vertical extrapolations. } \\
\text { Perform a field study } \\
\text { using remote sensing or } \\
\text { tall towers to directly } \\
\text { measure hub-height wind } \\
\text { speed and compare to } \\
\text { wind speed predicted } \\
\text { from lower elevations. }\end{array}$ & $\begin{array}{l}\text { Sites may not be directly } \\
\text { comparable. } \\
\text { Seasonal or diurnal scaling may } \\
\text { change depending on regional } \\
\text { weather and climate conditions. } \\
\text { Uncertainty is dependent on } \\
\text { available data and the } \\
\text { extrapolation process. }\end{array}$ \\
\hline $\begin{array}{l}\text { Estimate plant } \\
\text { energy loss } \\
\text { uncertainty }\end{array}$ & $\begin{array}{l}\text { Estimate the } \\
\text { uncertainty of losses } \\
\text { in the plant. }\end{array}$ & $\begin{array}{l}\text { Perform desktop studies } \\
\text { using historic data or site } \\
\text { design data (electrical } \\
\text { systems). }\end{array}$ & $\begin{array}{l}\text { Uncertainties in losses can be } \\
\text { large. (See Table 8.) }\end{array}$ \\
\hline $\begin{array}{l}\text { Estimate } \\
\text { project lifetime } \\
\text { variability }\end{array}$ & $\begin{array}{l}\text { Estimate the effects } \\
\text { of plant lifetime and } \\
\text { climate change on the } \\
\text { energy capture. }\end{array}$ & $\begin{array}{l}\text { Perform a desktop study } \\
\text { exploring the variability of } \\
\text { the plant's energy that } \\
\text { can be delivered } \\
\text { depending on the } \\
\text { operational life of the } \\
\text { wind power plant. } \\
\text { Perform a desktop study } \\
\text { showing the sensitivity of } \\
\text { the wind resource to } \\
\text { climate variability (e.g., } \\
\text { El Niño). }\end{array}$ & $\begin{array}{l}\text { The sensitivity of winds to climate } \\
\text { change is not well understood. }\end{array}$ \\
\hline
\end{tabular}




\section{Ranges of Losses and Uncertainties}

Various studies have attempted to quantify the range of losses and uncertainties that occur in wind power plants and to quantify underperformance. This section presents a survey of recent work in this field. The information is organized according to the first-level loss and uncertainty categories proposed by IEC 61400-15.

\subsection{Losses}

The major loss categories proposed by IEC 61400-15 include availability, wake effects, electrical, turbine performance, environmental, and curtailment (Figure 7). This subsection presents the range of losses that are found in the literature and discusses how they could be reduced in the plant design stage or mitigated on an operating plant. The results are summarized in Table 10.

\subsubsection{Availability}

Availability is the probability that a wind plant could produce energy when required.

Availability can be defined in terms of time or energy. Time-based availability is the amount of time when a turbine could have worked, as a percentage of the total period, and it is part of the IEC 61400-26-1 standard (IEC 2011) for "Time-based availability for wind turbine generating systems." However, time-based availability ignores the fact that wind resources are intermittent, and thus turbine availability is not equally valuable from an energy production perspective. Therefore, the industry usually uses energy-based availability in the preconstruction energy estimate, which is defined as the amount of energy produced as a percentage of the total amount of energy that the wind plant could have captured if turbines were always ready to generate power. A standard for energy-based availability was developed as IEC 61400-26-2, "Productionbased availability for wind turbines," published in 2014.

Availability is driven by the interaction of the turbine with the local environment and the O\&M strategy of the wind plant operator. However, because there is a lack of models that can relate plant layout and local environment to turbine reliability, availability estimates for preconstruction energy estimates are usually based on experience with similar turbines in that region or similar operating environments. Publicly available data on availability are poor, leading to coarse availability estimates, but some project sponsors may have access to large historical databases that can be used to estimate availability with greater accuracy. Instead of historic estimates, values used in the preconstruction energy estimate may be based on contractual arrangements with an OEM because lower-than-planned availability may be mitigated through liquidated damages.

Public data about availability is limited and low resolution. Tavner, Xiang, and Spinato (2007) analyzed German and Danish wind turbine data from 1994-2004. They found a seasonal signal in turbine failures in Denmark, which they suggested was related to weather. Overall failure rates in German turbines were approximately 120 hours per year, implying more than $1.3 \%$ downtime per year, which is equivalent to more than $98 \%$ time-based availability or losses less than $2 \%$. This is higher availability than found by a later study of 102 wind farms in Germany by Spengemann and Borget (2008), who reported availability of 95\%-99\%. Analysis of an Irish wind farm in 2007 (Conroy, Deane, and Gallachóir 2011) showed that although the time-based 
availability was $97 \%$, which agreed with the industry estimates at the time (Graves et al. 2008), the energy-based availability was only $89 \%$. A study of 282 wind plants in the United Kingdom from 2002-2012 (Staffell and Green 2014) found that availability might not be constant over time, leading to a drop in plant energy production of $1 \%-2 \%$ compared to the previous year. Staffell and Green (2014) also found that more modern equipment may degrade less rapidly than older equipment. Overall, these results show that historic data from one location may not be a good guide for future availability at another.

The variability of availability with time and space has important implications. For example, new wind plants with new technology may be more reliable than older plants, but they may be financed assuming lower availability than they will ultimately achieve. In that case, the wind farm will produce more energy than expected and could have had lower financing costs if this had been recognized initially. Another implication is that the current approach to availability is simply not able to capture the interaction of wind plants and the local flow conditions; instead, there appears to be a need for availability (or reliability) models that link turbine technology to local flow conditions.

\subsubsection{Wake Effects}

Wake effects are the losses due to the reduced wind resource in a turbine wake. There is no standards-based way to estimate wake effect losses, but the industry approach is to model wind speeds at each location, calculate the turbine power output in that wind field, calculate the wakes from each turbine, then use the new wind speed to estimate power at each wind turbine location. The wake energy losses are the amount of power lost multiplied by time.

Wake losses vary depending on the wind resource and plant design. At one extreme, there are no wake losses for a single turbine. The opposite extreme occurs when wakes directly impinge on downstream turbines. The European Union-funded UpWind project showed that wake losses at the Horns Rev wind plant increased as the flow passed through a regular array of turbines, exceeding $30 \%$ by the third row when winds were perpendicular to the rows of turbines (Barthelmie et al. 2009). This is a worst-case scenario, and wind plant designers (and optimization tools) avoid designing wind plants to operate in this state for long periods of time. As a result of their high turbulence, wakes can also cause high turbine loading, which provides another incentive to design a wind plant to minimize wake-turbine interactions.

Annual losses due to wake interactions may be $0 \%$ for a plant where turbines are far apart and perpendicular to the winds, but it may be larger for sites where a large number of turbines are arranged close together and there are several wind directions. A summary of four comparative exercises presented at the European Wind Energy Association Wind Resource Assessment Workshop in 2015 suggested losses of between $6 \%-15 \%$ for four wind power plants but noted high uncertainty in those estimates (Mortensen, Nielsen, and Jørgensen 2015).

Wind farms are usually designed to maximize energy capture during their lifetimes, which is often associated with minimizing wake losses. Anecdotal evidence from discussions with IEs and wind plant developers suggests that current best practice is to design wind power plants with wake losses below $10 \%$. 
Adopting novel control strategies may reduce wake losses. It has been shown that it is possible to change the direction of turbine wakes by yawing wind turbines, which can decrease a wind plant's total energy losses (Gebraad et al. 2014; Fleming et al. 2014). Although this requires control at the level of the wind plant, this technique may give wind plant owners the capability to reduce losses compared to turbines that operate individually without regard to the rest of the wind plant.

\subsubsection{Electrical Losses}

Electrical losses from a wind farm are the energy losses inherent in energy transmission in collector lines, transformers, and other site equipment and transmission to the point of revenue metering. These transmission-related losses are therefore directly impacted by the site layout, cable runs, and electrical design. In addition to generating electricity, a wind power plant consumes electricity (e.g., in nacelle air conditioning and yawing turbines in low wind conditions). These losses are called parasitic losses.

A wind plant can be modeled as a combination of a wind turbine generator, a collector system, and a step-up transformer connected to the point of revenue metering by a transmission line (Western Electricity Coordinating Council Wind Generator Modeling Group 2008). Losses in each part of the wind plant are not independent; thus, losses have to be applied sequentially. For each megawatt-hour of energy that is generated in the drivetrain, a few percent are lost within the turbine itself; of the remaining energy, some more is lost in the collector system, and so on.

Electrical losses in the turbine depend on the wind resource and the local environment. Simulations by Colmenar-Santos et al. (2014) using a realistic turbine power curve and wind speed probability distribution functions suggest losses within the turbine itself of approximately $0.7 \%-2 \%$, although these losses are usually accounted for already within the turbine power curve. There are also losses between the turbine and the point of revenue metering. A modeling study of 17 wind plants reported in Brochu, Larose, and Gagon (2011) showed that wind plants had average collector system losses of approximately $2.3 \%$, although the magnitude of the losses depended on site-specific topology as well as the choice of underground or overhead collection systems. Transformer efficiencies are typically greater than $99 \%$, so transformer losses are less than $1 \%$. Losses in transmission are a function of the length of transmission, the voltage, and other line parameters (Western Electricity Coordinating Council Wind Generator Modeling Group 2008). Some of these parameters can be changed to optimize the relationship between losses and construction costs, so line losses are variable depending on design, but it is likely that they are less than 1\% for land-based wind farms. Analysis by Spengemann and Borget (2008) suggests overall electrical losses of approximately 3\% for approximately 100 wind plants in Germany. Losses for plants in the United States may be slightly larger than in Europe due to larger plant size and longer distances from plant substations to the point of revenue metering, but we have not been able to find any public data to test this.

Site electrical losses are not fixed on an operating plant. Although the infrastructure may stay the same, transmission losses vary with production, and parasitic losses change slightly from one year to another as environmental conditions change. 


\subsubsection{Turbine Performance}

Turbine performance losses represent the amount of energy that is not produced by a wind turbine at a given wind speed compared to the OEM power curve. Types of performance loss include the following:

- Turbine underperformance compared to the OEM power curve in ideal wind conditions. In some cases, a turbine may simply not perform as expected (e.g., due to load- or noisereducing control modes).

- Operation in nonstandard wind conditions. Nonstandard inflow conditions are those that differ from the OEM's design inflow conditions. Examples of nonstandard inflow conditions include high turbulence (Clifton et al. 2013b) and extreme shear associated with daytime or nighttime wind profiles (Wagner et al. 2011). Industry groups such as the Power Curve Working Group ${ }^{4}$ have suggested that factors such as directional veer across the turbine rotor, high variability of shear and veer, and high rates of change of flow characteristics with time could be important for wind turbine performance.

- High-wind speed hysteresis. Variable-speed, variable-pitch, horizontal-axis wind turbines feather their blades away from the wind at wind speeds above their rated wind speed and finally shut down at wind speeds between $25 \mathrm{~m} / \mathrm{s}-30 \mathrm{~m} / \mathrm{s}$ to reduce loads; this is called the cut-out wind speed. When a turbine shuts down because of high wind speeds, it continues to measure wind and then restarts if wind speeds are below a threshold for a certain length of time. Although the details of this high-wind speed hysteresis vary by manufacturer and control algorithm, the end effect is that at average wind speeds near the turbine's cut-out wind speed, the wind turbine energy capture is lower than would be expected. Performance at high wind speeds may be improved by modifying turbine control systems.

From the sources of underperformance listed above, it is clear that it is necessary to understand operating strategies and operating conditions to correctly predict turbine performance losses. For example, business processes that include real-time monitoring of turbine performance through SCADA data, as opposed to a monthly review, may reveal unexpected operating modes faster and thus reduce losses. Similarly, correctly accounting for the effect of inflow conditions on turbine performance is important, and it could provide a better prediction. For example, several studies have shown that changes of inflow conditions within typical atmospheric values may result in reduced performance of $1 \%-3 \%$ compared to expected wind turbine performance (Wagner et al. 2011). This deviation is very dependent on the conditions at the deployment site compared to the conditions used to derive the wind turbine power curve. This underperformance is not a given; for example, careful modeling of the turbine performance in realistic site conditions by the OEM could lead to more accurate power curves or potentially wind power functions that predict performance as a function of multiple parameters (Clifton et al. 2013a). Finally, turbine underperformance on existing sites could also be addressed through the use of lidar to "preview" incoming wind and adjust blade pitch or nacelle yaw to improve energy capture (Wang, Johnson, and Wright 2013).

\footnotetext{
${ }^{4}$ See www.pcwg.org.
} 


\subsubsection{Environmental Losses}

Environmental losses are those due to icing, blade and equipment degradation, environmental shutdown, and exposure. As with many other losses, these losses are therefore inherently controlled by site conditions.

Icing is the formation of ice on turbine blades or sensors, leading to full or partial loss of energy (compared to the same inflow wind speed without the presence of ice). Ice build up on blades or sensors may be occur during a range of weather conditions, including fog, freezing rain, or snow. Icing causes losses in energy production because of changes in the blade shape (reducing efficiency), loss of instrument data (preventing turbine operation), and site closures. Because of the different types of icing, the potential for ice formation and accretion is a complex function of atmospheric conditions including radiative heat transfer, temperature, humidity, pressure, precipitation, and wind speed. These are all highly localized conditions. Also, a rotating turbine will go through a different icing process than a stationary turbine. The actual energy losses depend on the profile and mass of ice on the blade (Davis et al. 2014; Homola et al. 2010; Jasinksi et al. 1998), when an operator or control system decides to shut down a turbine or plant, and how the turbine or wind plant is restarted after ice has formed.

Making accurate estimates of the amount of energy lost as a result of icing is therefore challenging. Ideally, a turbine OEM should be able to predict the energy losses for their turbines and the weather at a particular site; however, there is no widely agreed-upon best practice for this approach. Instead, the current industry best practice is to use the frequency of icing detected from anemometer wind speed data obtained during the site resource measurement campaign as a proxy for availability and lost performance (Baring-Gould et al. 2011).

For the purposes of this report, we can use climate conditions to assess the geographic distribution and frequency of icing. An analysis of freezing rain data from 1948 to 2000 by Changon and Karl (2003) can be used to provide a lower bound on the frequency of icing, noting that freezing rain is only one of several potential cases of ice formation. Changon and Karl (2003) showed that almost all areas of the United States east of the Rocky Mountains and west of the Cascade Mountains have more than 1 day of freezing rain per year $(<0.3 \%$ days), whereas. the northeastern region of the country experiences $3-6$ days of freezing rain per year $(1 \%-2 \%$ of days). Only southern Florida and southwestern California have no days of freezing rain on average. Icing could potentially also occur via ice accretion when temperatures are below $2{ }^{\circ} \mathrm{C}$ and there is humidity above $95 \%$ (Baring-Gould et al. 2011), or due to accretion of snow. U.S. climate data shows that almost all parts of the country experience 3 days with air temperatures below $2^{\circ} \mathrm{C}$, suggesting higher losses than due to freezing rain alone. This suggests a risk of icing losses of at least $1 \%$ across almost all of the United States. Some areas, such as the Northeast and Northwest, may experience higher icing losses because the increased risk of freezing rain is coupled with low temperatures and high frequency of snowfall. Therefore, losses due to icing of up to $5 \%$ in those areas could be expected. Overall, a minimum of $1 \%$ icing losses for the whole of the United States and up to $5 \%$ in the northeast has been confirmed in discussions with U.S. site owners, OEMs, and independent engineers.

Blade and equipment degradation includes two main effects: blade soiling and blade damage. Both processes depend on the timing and frequency of rain, the amount of dust in the air, and insects, and they may have more or less impact on airfoil performance depending on the blade 
surface treatment (Sareen, Sapre, and Selig 2014). Sareen, Sapre, and Selig (2014) extrapolated from their wind tunnel tests to show potential for $5 \%-25 \%$ annual losses, depending on the severity of damage and the wind climate at a site and ignoring blade cleaning by rain. Industry assumptions of $1 \%-2 \%$ soiling losses therefore appear reasonable, if blades are cleaned by rain or by hand and repaired as required. Blades can also suffer from leading-edge erosion by rain or dust, which reduces the aerodynamic performance of the blade. The size and amount of rain, the blade speed, influence erosion by rain, and thus experience with one turbine type or location may not be easily transferable to other locations.

Environmental shutdown includes effects such as high or low temperatures on the turbine, lightning, hail, and other environmental conditions in which it might not be safe to operate. Again, these are all inherently site dependent. Information about the frequency of high or low temperatures, hurricanes, tornadoes, or other severe weather can be obtained from organizations such as National Oceanic and Atmospheric Administration, and site-specific predictions can be made. Effects may range from multiple short shutdowns to a sustained shutdown in the event of damage to the turbine (captured in the turbine availability) or loss of grid connections (captured in the grid availability).

Areas that are prone to low-temperature shutdown include the northern U.S. plains and central Canada. In these areas, low temperatures may be associated with low wind speeds, and thus it is essential to consider the relationship between the wind resource and temperature rather than assume blanket losses.

Energy losses are likely to be less than $1 \%$ because equipment can be redesigned to mitigate high or low temperatures, and extreme weather is relatively rare. The financial implications of this are low because extreme weather can be mitigated through insurance.

Exposure includes changes to wind resources caused by factors such as tree growth or logging, residential or other building developments, among others. Tree growth, logging, or building developments change the surface roughness near the wind power plant and also upwind, which may reduce wind speeds across the wind turbine rotor disk for the same geostrophic (highaltitude) wind speed. Growing or mature trees can act as wind breaks; an area of reduced wind speeds may extend from 2-5 times the height of the trees upwind and up to 30 times the planting height downwind, depending on the density of the trees (Brandle, Zhou, and Hodges 2006). Usually the effect is constrained to the winds below the height of the trees, but there are areas of high turbulence downwind of the windbreak or above tree stands that extend a significant distance in the direction of the wind. Logging may lead to a significant increase in wind speeds above a cleared area because of the marked decrease in roughness between forest and bare ground, which could increase wind resources by $2 \%-3 \%$ at hub height. In many locations with managed forest, it is relatively simple to predict tree growth rates or logging from forestry plans and factor those effects into the preconstruction energy estimate. Predicting the rate and effect of building growth is harder, but because of a general trend toward urbanization it could be assumed that future rural developments will be slow and small and thus have minimal impacts on wind energy plants. 


\subsubsection{Curtailment}

Curtailment is the deliberate management of a wind plant to reduce the amount of energy compared to what is possible from the available resource. This may occur because of grid limitations, environmental or permitting requirements (e.g., to prevent bird or bat deaths or to prevent flicker), or deliberate operational strategies. Actions taken by the plant operator are challenging to capture in the preconstruction energy estimate unless the plant operator is very involved with the plant design process. Some market structures or energy trading strategies allow the wind power plant to play a different role in the market than purely variable generation on a power purchase agreement, which may result in energy losses but increase income.

Grid-driven curtailment can be predicted, to some extent, from operational histories of the transmission operator, but it is very dependent on weather, the other generators in the system, and the operating strategies of the balancing authority. In some areas, losses may be less than $1 \%$, but some plants in regions that have significant hydropower generation capacity have experienced unexpected curtailment when high winds combine with spring snowmelt.

Curtailment can be impacted by transmission availability; wind generation in the region of the Electric Reliability Council of Texas was curtailed by $17 \%$ at its peak in 2009 , but it was only $0.5 \%$ in 2014, partly as a result of building the Competitive Renewable Energy Zones transmission lines (Wiser and Bollinger 2015). In addition to expanding transmission capacity, curtailment can be managed through specific terms in power purchasing agreements and in some cases by reevaluating how wind is integrated into the grid. Bird, Cochran, and Wang (2014) found that curtailment was less than $4 \%$ for wind power plants in the United States, with many regions reporting negligible curtailment.

Curtailment to reduce environmental impact is often a condition of permitting. Currently, curtailment plans tend to be broad (e.g., switch off all summer nights). An example of this is the voluntary decision of operators in the northeastern United States to curtail for up to 120 summer nights per year (Bird, Cochran, and Wang 2014); however, as knowledge about bird and bat activity grows and detection technology improves, it may be possible to move from broad curtailment to micromanaging curtailment (e.g., based on algorithms or detection). These micromanagement approaches are intended to reduce bat deaths and reduce curtailment. At the time of writing, it is not clear how many wind plants have implemented micromanagement approaches.

\subsubsection{Summary of Losses}

The magnitude of losses are highly site specific and depend on a number of drivers, including regional environmental conditions, turbine technology selection, project size, and site layout philosophy, among others. These factors make it challenging to define "typical" losses for wind plants; therefore, the range of losses in individual categories for a new wind plant is shown in Table 10. A recent report estimated the losses from a typical 200-MW commercial project in the interior region of the United States at $15 \%$ with an additional $2 \%$ availability loss (Mone et al. 2015). 
Table 10. Summary of Losses in a Wind Plant

Values apply to wind plants designed and built from 2010-2015

\begin{tabular}{|c|c|c|c|}
\hline Loss Category & Range & Controlled By & Mitigation Actions \\
\hline Availability & $2 \%-5 \%$ & $\begin{array}{l}\text { Site operating conditions } \\
\text { Turbine installation date } \\
\text { Turbine age } \\
\text { Turbine lineage } \\
\text { Contractual agreements } \\
\text { with OEM }\end{array}$ & $\begin{array}{l}\text { Turbine selection and } \\
\text { contracting } \\
\text { Changes to O\&M practice } \\
\text { Enter long-term service } \\
\text { agreement with OEM or } \\
\text { third-party provider }\end{array}$ \\
\hline Wake effects & $0 \%-10 \%$ & $\begin{array}{l}\text { Site design } \\
\text { Wind rose } \\
\text { Turbulence intensity } \\
\text { Site control strategies } \\
\text { Wake model }\end{array}$ & $\begin{array}{l}\text { Best practice plant layout } \\
\text { optimization } \\
\text { Site control strategies } \\
\text { Advanced wake modeling } \\
\text { strategies (e.g., CFD or } \\
\text { LES) }\end{array}$ \\
\hline $\begin{array}{l}\text { Electrical } \\
\text { losses }\end{array}$ & $\begin{array}{l}\text { Collector system: } \\
1 \%-2 \% \\
\text { Substation: } \sim 0.5 \% \\
\text { Transmission: }<1 \%\end{array}$ & $\begin{array}{l}\text { Wind turbine design } \\
\text { Length of collectors } \\
\text { Transformer efficiency } \\
\text { Length of transmission, } \\
\text { line voltage } \\
\text { Weather conditions }\end{array}$ & $\begin{array}{l}\text { Best practice plant layout } \\
\text { optimization }\end{array}$ \\
\hline $\begin{array}{l}\text { Turbine } \\
\text { performance }\end{array}$ & $1 \%-3 \%$ & $\begin{array}{l}\text { Actual site operating } \\
\text { conditions compared to } \\
\text { generic operating } \\
\text { conditions }\end{array}$ & $\begin{array}{l}\text { Using actual or predicted } \\
\text { site conditions to generate } \\
\text { power curve } \\
\text { Use of feed-forward controls } \\
\text { to improve energy capture }\end{array}$ \\
\hline $\begin{array}{l}\text { Environmental } \\
\text { losses }\end{array}$ & $\begin{array}{l}\text { Icing: } 1 \%-5 \% \\
\text { Soiling and } \\
\text { erosion: } 1 \%-2 \% \\
\text { Environmental } \\
\text { shutdown: }<1 \% \\
\text { Exposure: } 0 \%-3 \% \\
\text { over time }\end{array}$ & $\begin{array}{l}\text { Geographic location } \\
\text { Weather conditions } \\
\text { O\&M strategies } \\
\text { Environmental and } \\
\text { socioeconomic policies }\end{array}$ & $\begin{array}{l}\text { Blade coatings } \\
\text { Active de-icing } \\
\text { Blade cleaning } \\
\text { Extending turbine operating } \\
\text { ranges-e.g., through low- } \\
\text { temperature packages }\end{array}$ \\
\hline Curtailment & $\begin{array}{l}\text { Grid driven: }<1 \% \\
\text { Permit driven: }<1 \% \\
\text { Overall: }<4 \%\end{array}$ & $\begin{array}{l}\text { Generation mix } \\
\text { Seasonal weather }\end{array}$ & $\begin{array}{l}\text { Power hedges, virtual power } \\
\text { purchase agreements, and } \\
\text { other risk allocation } \\
\text { Negotiation with balancing } \\
\text { authority } \\
\text { Cooperation with wildlife } \\
\text { experts } \\
\text { Litigation } \\
\text { Transmission development }\end{array}$ \\
\hline
\end{tabular}




\subsection{Uncertainties}

The final stage of the preconstruction energy yield assessment is to assess the uncertainty associated with the predicted energy yield.

The major uncertainty categories proposed by IEC 61400-15 include site measurements, spatial variation, vertical extrapolation, plant performance, historic wind resource, and project lifetime variability (Figure 11). This subsection presents the range of uncertainties that are found in the literature, and it discusses how they could be reduced in the plant design stage or mitigated in an operating plant. The results are summarized in Table 11.

\subsubsection{Site Measurements}

Site measurement uncertainties are associated with all measurement and characterization activities that contribute to the final energy yield assessment. These might include wind speed, wind direction, and other data described in Section 3.2.

In an uncertainty assessment, the choices of anemometer, mounting design, tower design, and data acquisition system information are all used to assess uncertainty. The uncertainty of the anemometers and temperature and pressure sensors that are used for site measurements is usually assessed using a calibration procedure carried out before those instruments are deployed. This calibration gives an estimate of the instrument performance under well-defined conditions. Temperature and pressure sensors have well-defined uncertainty, whereas anemometers have more complex responses to site conditions (Pedersen, Dahlberg, and Busche 2006). Anemometers are given a "class number" that predicts the deviation of the anemometer measurements. Performance also partly depends on the site complexity; a simple test is whether the site needs a site calibration according to Annex B of IEC 61400 (IEC 2005). On simple sites (no calibration required), an IEC Class 1 anemometer is expected to have an uncertainty of less than $1 \%$ at $10 \mathrm{~m} / \mathrm{s}$. On complex terrain sites where a site classification is required, the uncertainty of the same anemometers may increase to $3 \%-5 \%$ (Class 3 or greater). Because anemometer uncertainty can be estimated with ease from calibration results before the site measurements, anemometer uncertainty can be mitigated through the selection of a device specifically designed for complex flow situations, such as a three-dimensional sonic anemometer or a cup with a sine response to inflow angle. Anemometers are mounted on the end of booms on a tower. These booms can, depending on boom design, decelerate and deflect flow, which can lead to additional uncertainty of up to $2 \%$. Again, this can be mitigated through appropriate design. Data acquisition and storage systems also potentially add to the uncertainty through missing data, but this is usually a very small amount. The uncertainty assessment is usually carried out twice: once before measurements to give insight into the opportunity to reduce uncertainty and then again after the measurements to confirm the uncertainty. Overall, the typical uncertainty for an anemometer-based measurement campaign ranges from $1 \%-3 \%$ before horizontal and vertical extrapolation.

The uncertainty of wind speed and direction measurements from remote sensing varies. When remote sensing by lidar or sodar was first introduced in 2007-2008, the devices were unknown, and the data was ascribed high uncertainty values compared to cup anemometers. Efforts to codify best practices for installation and operation and more experience with the devices and data have led to a reduction in the uncertainty, meaning that in the best case in simple flows the 
uncertainty of data from a remote sensing device may be similar to data from cups and vanes. One challenge with remote sensing is the lower system availability compared to cups because the remote sensing device can sometimes be impacted by power losses or weather conditions and result in the loss of data. Therefore, although a single measurement from a remote sensing device may have similar uncertainty to a cup or vane, the overall data series from a remote sensing device may have fewer data points and thus be penalized with a higher uncertainty.

Measurement uncertainty could be reduced through the use of higher-accuracy instrumentation, such as IEC Class 1 anemometers in place of lower accuracy devices.

\subsubsection{Spatial Variation}

Uncertainty due to spatial variation arises from deviations of flow model results from reality. These uncertainties are a function of the type of flow model, the data that are available to drive the model, and the actual atmospheric conditions on-site.

Ways to assess uncertainty due to spatial variation were discussed in Section 3.4.3. Uncertainty due to spatial variation may range from $1 \%-2 \%$ for simple terrain in neutral conditions to more than $10 \%$ in very complex terrain. (See results from the Bolund Hill study reported in Bechmann et al. [2011] or a comparison of models reported in VanLuvanee et al. [2009]). These uncertainty ranges may also increase in flows in strongly stable or unstable conditions, depending on the flow model's ability to capture the effects of buoyancy (Paiva, Bodstein, and Menezes 2009). Likewise, high temporal variability associated with terrain-induced wakes can introduce uncertainty (Abiven, Palma, and O. Brady 2011). Uncertainty has also been modeled as a function of distance from the measurement tower (Clerc et al. 2012); although this method allows some estimate of uncertainty, it is not site or flow specific. The ability to use data from multiple towers to constrain flow model results is frequently cited as an opportunity for research and development that could offer significant uncertainty reduction.

Flow modeling may under- or overestimate the wind resource at points within a wind plant. Widespread overestimates of the wind resource from flow modeling would result in an overprediction of energy production, and therefore the wind plant's actual energy production would be lower than expected (i.e., toward the P95 value).

\subsubsection{Vertical Extrapolation}

Vertical extrapolation is the process of using data at one or more heights to predict wind speeds at the turbine rotor hub height or across the rotor disk. Therefore, uncertainty is $0 \%$ if data are available at the height of interest. When these data are not available, wind speed profiles such as the log law or power law profile (Stull 1988) are used to extrapolate data from lower elevations. These profiles assume that the wind speed measured lower down also applies higher up and may include some correction for atmospheric stability, which may also require more data, such as temperature differences. Depending on site conditions, extrapolation results in a combination of bias (persistent under- or overprediction) and uncertainty (standard deviation of errors).

The uncertainty of vertical extrapolation has typically been assessed using data from the limited number of tall towers that are available by comparing predictions from lower elevations to observations at the target height. Elkinton, Rogers, and McGowan (2006) found wind speed biases from $0 \%-6 \%$ depending on the site. Other studies frequently show that wind shear at 
lower elevations is not the same as the shear between the top of the measurements and the turbine hub height, which leads to uncertainty. Examples include wind profile measurements from 135-m towers reported by Clifton et al. (2013b) and remote sensing wind profile measurements from Wharton and Lundquist (2012) and Pichugina et al. (2011).

The uncertainty of vertical extrapolation can be reduced through the use of short-duration remote sensing or direct measurements of winds at hub height to confirm the accuracy of the vertical extrapolation. Alternatively, using taller met towers that reach hub height or remote sensing of winds for the duration of the resource measurement campaign can remove the uncertainty of vertical extrapolation.

\subsubsection{Plant Performance}

Plant performance uncertainty represents the uncertainty in the wind farm to convert the wind resource into energy that is delivered to the point of revenue metering. This includes turbine performance, electrical losses, wake losses, environmental effects, and curtailment.

Turbine performance uncertainty has historically been estimated from the spread in data obtained in power performance tests. This can be from $1 \%-2 \%$ in flat terrain if neutral conditions dominate, but it may be 3\%-4\% if the atmosphere is strongly stable or convective (Wharton and Lundquist 2012). Performance can also exhibit a bias if the turbine is tested at one site but deployed at another where conditions are quite different (Clifton et al. 2013a). The uncertainty of a wind plant's performance can be reduced through several actions. One opportunity is for the wind turbine OEM to supply a site-specific power curve that better represents the performance of the turbine on that site. This power curve could be derived from computer models or by selectively sampling power curve test data. Alternatively, a more representative transfer function could be created of the relationship between inflow conditions and power, but this would require more data about the inflow.

Electrical loss uncertainty is likely low because of the similarity of the balance of plant with other electrical systems. Brochu, Larose, and Gagon (2011) suggest that a simple model can get to within $1 \%$ of the actual losses of a wind plant, but this may depend on the actual complexity of the plant and how well the operating conditions are known.

Wake loss uncertainty arises because wake models do not perfectly capture the spread and effect of the wake through the wind power plant. A summary of four comparative exercises presented at the European Wind Energy Association Wind Resource Assessment Workshop in 2015 suggested uncertainty of between $13 \%-37 \%$ (based on the spread of a large number of model predictions), with the higher uncertainty being an anomaly (Mortensen, Nielsen, and Jørgensen 2015). These uncertainties were also approximately twice the predicted wake losses for each exercise. The current assumption in most research circles is that a more complex wake model is required to reduce uncertainty, but there is also evidence that a better choice of adjustable parameters in existing simple models may help reduce uncertainty.

Environmental effects are uncertain because the relationship between environmental conditions and a wind plant's energy output is not always clear, and there is annual variability in the frequency, severity, and impacts of environmental events such as extreme winds, icing, or temperature extremes. Anecdotal evidence suggests that the variability in the number of short- 
duration events per year (such as extreme winds or icing) can be high but that this also varies by location. So if losses due to environmental effects are forecast to be $1 \%$, the uncertainty may also be $1 \%$, but that uncertainty may be higher in areas that are more impacted by climate variability or by very local conditions. Options for mitigating this uncertainty include better models to link environmental conditions to turbine operation, but these models will be low impact without methods to better predict the winds during the 20-year life span of the plant. A more reliable solution would be to reduce the sensitivity of the turbine to environmental conditions, such as through the use of anti-icing technologies (Baring-Gould et al. 2011), although the installation of a cold weather package can increase turbine costs and parasitic load.

Curtailment uncertainty arises because the conditions that led to curtailment in one year will not always apply. Curtailment may vary because the system makeup changes or because the things that cause curtailment (e.g., bird and bat activity) are a function of weather. Also, because curtailment is imposed from outside the wind plant, curtailment may change as a result of human activity. For example, grid-driven curtailment in a constrained balancing authority is likely to be reduced through better planning (Bird, Cochran, and Wang 2014), whereas permit-driven curtailment is likely to be reduced through improved monitoring; although these are positive developments, they add uncertainty to the energy prediction. Uncertainty in curtailment varies from $1 \%-5 \%$ of installed wind capacity in the various reliability regions of the United States, with transmission-constrained regions showing the most curtailment. Curtailment can be mitigated and reduced through improved management, market integration, or increasing transmission capacity (Bird, Cochran, and Wang 2014). However, depending on the size of the development and the funds available for site development, these mitigation actions are typically implemented after construction.

\subsubsection{Historic Wind Resource}

Uncertainty in the long-term wind resource arises from the length of the reference site data, the reference site itself, the variability of the relationship between the reference site and the development site, and the representativeness of the site data. For example, a short reference time series from a site that has a poor correlation to a development site in complex terrain where there was only a short period of measurement will have a higher uncertainty than a site in flat terrain where long measurement periods are available for both the reference and development site. Also, the estimated historic wind resource can vary depending on the method that is used (Rogers, Rogers, and Manwell 2005). Reported uncertainty varies from $1 \%-6 \%$ when evaluated using training and test data sets. When test data do not exist, the jackknife method can be used to estimate uncertainty (Rogers, Rogers, and Manwell 2006), although this approach may underestimate uncertainty.

Uncertainty in the historic wind resource can be mitigated through a combination of longer time series from the reference site or the development site and the use of improved correlation models. For example, wind resources predicted using reanalysis data such as the ERA-interim or MERRA data sets may be better than predicted from data measured at surface stations, particularly in locations where surface stations are sparse (Carta, Velázquez, and Cabrera 2013; Zhang et al. 2015). 


\subsubsection{Project Lifetime Variability}

Project lifetime variability includes the lifetime resource, susceptibility to climate change, and other sources of variability. This is sometimes loosely termed the interannual variability [of wind resource]. Winds are inherently variable from one year to another, so this uncertainty can never be removed; however, knowing the magnitude of the variability in advance allows for an accurate financial model to be created, and thus it is essential that the interannual variability be well known.

Interannual variability can be estimated from long-term reference data or from reanalysis data as the standard deviation of the wind speed. Klink (2002) reports variation of the mean annual wind speed near ground level of approximately $5 \%$ of the long-term mean, whereas Pryor, Barthelmie, and Schoof (2006) report 8\%-14\% variability in northern Europe, with little variability in future years due to the effects of climate change. A similar effect was found in North America, where the overall change in wind energy production was expected to be less than 1\% from 2041-2062 compared to the period from 1979-2000 (Pryor and Barthelmie 2013). However, although the mean impact of climate change may not be large, the wind energy industry has noticed occasional "wind droughts" or years when performance was noticeably reduced, particularly in Texas, and it has drawn tentative conclusions about their relationship to climate variability indices such as El Niño (Oliver 2010; Clifton and Lundquist 2012).

The uncertainty of energy capture due to interannual variability may be challenging to mitigate. The use of reanalysis data sets coupled with forward-looking climate modeling may allow an IE to assess the sensitivity of a site to climate change. Also, a project sponsor may choose to reduce exposure by choosing geographically diverse sites for its wind portfolio.

\subsubsection{Summary of Uncertainties}

As with losses, uncertainties are highly site specific and depend on drivers such as site environmental conditions, turbine technology selection, project size, and site layout philosophy. The range of uncertainties in individual categories is shown in Table 11. 
Table 11. Summary of Uncertainties in Wind Plant Preconstruction Energy Estimates Values apply to wind plants designed and built from 2010-2015.

\begin{tabular}{|c|c|c|c|}
\hline $\begin{array}{l}\text { Uncertainty } \\
\text { Category }\end{array}$ & Range & Controlled By & Mitigation Actions \\
\hline $\begin{array}{l}\text { Site } \\
\text { measurements }\end{array}$ & $\begin{array}{l}\text { Anemometer: } \\
1 \%-2 \% \\
\text { Mounting: } 1 \%-2 \% \\
\text { Data systems: } \\
<0.5 \%\end{array}$ & $\begin{array}{l}\text { Choice of measurement } \\
\text { device } \\
\text { Mounting design } \\
\text { Flow complexity }\end{array}$ & $\begin{array}{l}\text { Using a device with better } \\
\text { calibration }\end{array}$ \\
\hline Spatial variation & $\begin{array}{l}\text { Simple terrain: } \\
1 \%-2 \% \\
\text { Complex terrain: } \\
>10 \%\end{array}$ & $\begin{array}{l}\text { Site complexity } \\
\text { Atmospheric conditions } \\
\text { Available validation data }\end{array}$ & $\begin{array}{l}\text { Higher spatial density of met } \\
\text { towers or remote sensing units } \\
\text { Optimization of tower locations } \\
\text { Research into using multiple } \\
\text { data sources }\end{array}$ \\
\hline $\begin{array}{l}\text { Vertical } \\
\text { extrapolation }\end{array}$ & $0 \%-6 \%$ & $\begin{array}{l}\text { Turbine hub height and } \\
\text { measurement heights } \\
\text { Boundary layer profile }\end{array}$ & $\begin{array}{l}\text { Direct measurement using } \\
\text { taller towers or remote sensing } \\
\text { More accurate boundary layer } \\
\text { profiles }\end{array}$ \\
\hline $\begin{array}{l}\text { Plant } \\
\text { performance }\end{array}$ & $\begin{array}{l}\text { Turbine } \\
\text { performance: } \\
0 \%-4 \% \\
\text { Electrical losses: } \\
1 \%-2 \% \\
\text { Wake losses: } \\
13 \%-35 \% \\
\text { (twice the predicted } \\
\text { losses) } \\
\text { Curtailment: } \\
1 \%-4 \%\end{array}$ & $\begin{array}{l}\text { Site conditions } \\
\text { Wind turbine power model } \\
\text { complexity } \\
\text { Wake model complexity } \\
\text { Generation management } \\
\text { Availability of transmission } \\
\text { Market integration }\end{array}$ & $\begin{array}{l}\text { Better information about inflow } \\
\text { conditions } \\
\text { Use of more complex power } \\
\text { performance models } \\
\text { Better selection of values in } \\
\text { wake model } \\
\text { Reduce turbine sensitivity to } \\
\text { environmental conditions } \\
\text { Anti-icing design } \\
\text { Generation management } \\
\text { Market Integration } \\
\text { Increased transmission } \\
\text { capacity }\end{array}$ \\
\hline $\begin{array}{l}\text { Historic wind } \\
\text { resource }\end{array}$ & $1 \%-6 \%$ & $\begin{array}{l}\text { Terrain complexity } \\
\text { Distance between reference } \\
\text { and development sites } \\
\text { Method }\end{array}$ & $\begin{array}{l}\text { Use of advanced methods } \\
\text { Use of reanalysis data sets as } \\
\text { reference data }\end{array}$ \\
\hline $\begin{array}{l}\text { Project lifetime } \\
\text { variability }\end{array}$ & $1 \%-10 \%$ & $\begin{array}{l}\text { Location } \\
\text { Climate change and } \\
\text { variability }\end{array}$ & $\begin{array}{l}\text { Use of reanalysis data and } \\
\text { climate models } \\
\text { Geographic diversity of the } \\
\text { sponsor's project portfolio }\end{array}$ \\
\hline
\end{tabular}




\section{Reporting}

The results of a preconstruction energy assessment are combined into a report. This preconstruction energy yield analysis is part of the package of information that the sponsor provides to the project financiers. The report therefore has to include a description of all steps and assumptions that have been taken and a clear summary of the expected energy production of the wind plant during the different timescales that are relevant to the project financiers. The authors of this technical report were provided with sample reports by major IEs; the example content presented here is a synthesis of several different reporting methodologies.

The content of a preconstruction energy yield analysis report varies depending on the exact process followed by the IE, but it contains the following information that is generated by the preconstruction energy estimate process:

- Site description

- Wind resource characteristics, including:

$\circ$ Wind measurements

- Estimation of long-term mean wind speed at mast height

- Extrapolation to hub height.

- Estimation of long-term energy production, including:

○ Loss estimate

$\circ$ Uncertainty analysis.

- Summary.

The way in which this information is typically reported is described in the following section. Most of this information is supplied as electronic files rather than printed, and therefore clear documentation of the information provided is also important. For this reason, the results of a preconstruction energy assessment are often delivered as an information pack rather than a single report.

\subsection{Site Description}

The site description includes information about the geographic characteristics of the site, such as maps, geographic information systems data, geotechnical information, and land lease areas. Information about the plant would also be provided, including type, counts, and locations of turbines and balance of plant equipment. Finally, the site description should also include information about the transmission interconnection. Most of this information is generated in the activities described in Section 3.

Often the site description and summary will be combined to give an overview of the project's energy production. An example summary table is shown in Table 12. 
Table 12. Example Summary Table of Energy Production

\begin{tabular}{|c|c|}
\hline Project name & Project name \\
\hline Project location & State \\
\hline Rated capacity & $\mathrm{XX} . \mathrm{X} \mathrm{MW}$ \\
\hline \multirow[t]{2}{*}{ Turbine model } & Turbine model X.X MW (X.X MW) \\
\hline & $\mathrm{XX}-\mathrm{m}$ rotor diameter, extra details as required \\
\hline Hub height & $\mathrm{XX} \mathrm{m}$ \\
\hline Number of turbines & $X X$ \\
\hline $\begin{array}{l}\text { Array-average freestream wind } \\
\text { speed }\end{array}$ & $X . X X \mathrm{~m} / \mathrm{s}$ \\
\hline $\begin{array}{l}\text { P50 gross annual production } \\
\text { (gross capacity factor) }\end{array}$ & $\begin{array}{l}\text { XXX.X GWh/yra } \\
(X X . X \%)\end{array}$ \\
\hline \multirow[t]{3}{*}{ Plant, wake, and total losses } & Plant - XX.X\% \\
\hline & Wake - XX.X \% \\
\hline & Total - XX.X \% \\
\hline $\begin{array}{l}\text { P50 net annual production } \\
\text { (P50 net capacity factor) }\end{array}$ & $\begin{array}{l}\text { XXX.X GWh/yr } \\
(X X . X \%)\end{array}$ \\
\hline $\begin{array}{l}\text { P95 net production (years } 2-10 \text { ) } \\
\text { (P95 net capacity factor) }\end{array}$ & $\begin{array}{l}\text { XX.X GWh/yr } \\
(X X . X \%)\end{array}$ \\
\hline $\begin{array}{l}\text { P99 net production (annual) } \\
\text { (P99 net capacity factor) }\end{array}$ & $\begin{array}{l}\text { XX.X GWh/yr } \\
(X X . X \%)\end{array}$ \\
\hline
\end{tabular}

${ }^{a} \mathrm{GWh} / \mathrm{yr}$ : gigawatt-hours per year

\subsection{Wind Resource Characteristics}

The preconstruction energy yield analysis report includes details of the wind resource characteristics on the site, including the measured wind data, the results of vertical and horizontal extrapolation, long-term resource estimation, and uncertainty estimates. This information may be rolled-up into a single wind plant mean wind speed and expected interannual variability. Increasingly, supporting data are also included in the preconstruction energy yield analysis. This supporting data adds confidence to the results by demonstrating good practices. This includes tower designs, equipment calibration certificates, tower inspection reports, reference site data records, reanalysis data, details of the methods used for horizontal and vertical extrapolation, and other activities described in Section 3.2 and Sections 3.3.1 to 3.3.4.

\subsection{Energy Production}

The key component of the preconstruction energy estimate report is the net amount of energy that would be delivered by the wind plant to the point of revenue metering.

Three different energy metrics are given in Table 12, including the net annual production, which is the mean amount of energy produced throughout 10 years; the $P 95$ from years $2-10$; and the $P 99$ in any year (a "lifetime" value). This information is likely to be provided in more detail in the information pack, such as on a turbine-by-turbine basis and at different Pxx levels. 
Table 13. Example Summary Energy Production and Capacity Factor Distribution

\begin{tabular}{lllllll}
\hline Metric & Year(s) & P50 & P75 & P90 & P95 & P99 \\
\hline Energy production (GWh/yr) & 1 & & & & & \\
\hline Capacity factor (\%) & 1 & & & & & \\
Average energy production (GWh/yr) & $2-10$ & & & & & \\
Average capacity factor (\%) & $2-10$ & & & & & \\
Energy production (GWh/yr) & Lifetime & & & & \\
Capacity factor (\%) & Lifetime & & & & \\
\hline
\end{tabular}

An IE's report includes a detailed description of the losses and uncertainties for the energy estimate. This information is derived from the activities described in Sections 3.3.5 and 3.4, and it usually includes a description of the methods that were used. The report may also refer to privileged internal documentation. As previously noted, there is not yet a standard definition for the losses and uncertainties. Therefore, in this document we use the proposed IEC 61400-15 loss and uncertainty categories.

Table 14 and Table 15 are examples of how those uncertainties and losses might be summarized. Both tables show features that may be specific to an IE's own process. For example, in Table 14 the example IE has assumed that the losses may be different in the first year of operation than in other years, representing teething issues in start-up and phasing of commissioning, whereas other IE's may break down losses by year. Similarly, Table 15 references uncertainties back to their effect on wind speed, which may not be relevant to all financiers.

Table 14. Example Summary of Loss Using Proposed IEC 61400-15 Categories

\begin{tabular}{|c|c|c|}
\hline & First Year & Long Term \\
\hline \multicolumn{3}{|l|}{ Availability (\%) } \\
\hline \multicolumn{3}{|l|}{ Wake effects (\%) } \\
\hline \multicolumn{3}{|l|}{ Electrical losses (\%) } \\
\hline \multicolumn{3}{|l|}{ Turbine performance (\%) } \\
\hline \multicolumn{3}{|l|}{ Environmental losses (\%) } \\
\hline \multicolumn{3}{|l|}{ Curtailment (\%) } \\
\hline Total energy losses (\%) & & \\
\hline
\end{tabular}


Table 15. Example Summary of Uncertainty Using Proposed IEC 61400-15 Categories

\begin{tabular}{lll|c}
\hline \multirow{2}{*}{ Uncertainty Sources } & \multicolumn{2}{c|}{ Wind Speed } & \multicolumn{2}{c}{ Energy Equivalent } \\
\cline { 2 - 4 } & $\%$ & m/s & \\
\hline Site measurements & & \\
Spatial variation & & \\
Vertical extrapolation & & \\
Historic wind resource & & \\
Project lifetime variability & & \\
Plant performance & N/A & N/A & \\
\hline Total energy uncertainty & & \\
\hline
\end{tabular}

Both Table 14 and Table 15 are highly condensed. It could be expected that an IE would deliver a report wherein the losses and uncertainties are broken down by category, allowing the project sponsor to see the major sources of losses or uncertainty. An IE may also choose to provide much of the above information in graphical form.

An increasingly important output from a preconstruction energy assessment is the so-called 12by-24 table (Table 16). This table shows the variability in energy in any year by hour and month, and it is used by some project sponsors to assess the value of energy production by time and understand the risk of seasonal losses due to icing or grid curtailment on revenue. Values in the 12-by-24 table could be $P 99, P 95$, or $P 50$ energy production values. For some applications, such as response to a utility's request for proposals, a similar 24-by-365 (hours by days) table (also known as an 8,760) might be provided at specific $P x x$ values to show energy production in each hour of a typical year. In some cases, specific years may be modeled to allow the project sponsor or offtaker to investigate synchronicity of the energy generation with load or market prices.

Table 16. Example 12-by-24 Table of Energy Production

\begin{tabular}{|c|c|c|c|c|c|c|}
\hline Hour & $\begin{array}{l}\text { Month } \\
\text { Jan. }\end{array}$ & Feb. & March & $\ldots$ & Nov. & Dec. \\
\hline \multicolumn{7}{|l|}{ 00:00-01:00 } \\
\hline \multicolumn{7}{|l|}{ 01:00-02:00 } \\
\hline \multicolumn{7}{|l|}{ 02:00-03:00 } \\
\hline \multicolumn{7}{|l|}{$\cdots$} \\
\hline \multicolumn{7}{|l|}{$22: 00-23: 00$} \\
\hline \multicolumn{7}{|l|}{$23: 00-00: 00$} \\
\hline Total energy & & & & & & \\
\hline
\end{tabular}




\section{Summary and Conclusions}

The wind industry estimates the annual energy production $(P 50)$ of prospective wind projects using a multistep preconstruction energy estimate process that is currently somewhat uniform (Figure 3 and Figure 4). Various stakeholders use the preconstruction energy estimate to make investment decisions and are thus heavily reliant on accurate estimates of energy, losses, and uncertainty. However, until recently there have been several different ways to quantify loss and uncertainty. In early 2015, an IEC 61400-15 working group drafted common loss categories (Section 3.3.5) as well as common uncertainty categories (Section 3.4). This document discusses the energy estimate process and shows how these losses and uncertainties are estimated.

Table 10 and Table 11 summarize the major losses and uncertainties found in a modern wind plant development. These are also shown in Figure 13 and Figure 14 (below), together with potential mitigation actions. Losses and uncertainties vary dramatically according to the site design, site terrain, availability of on-site data, and the methods that are used to calculate the energy yield.

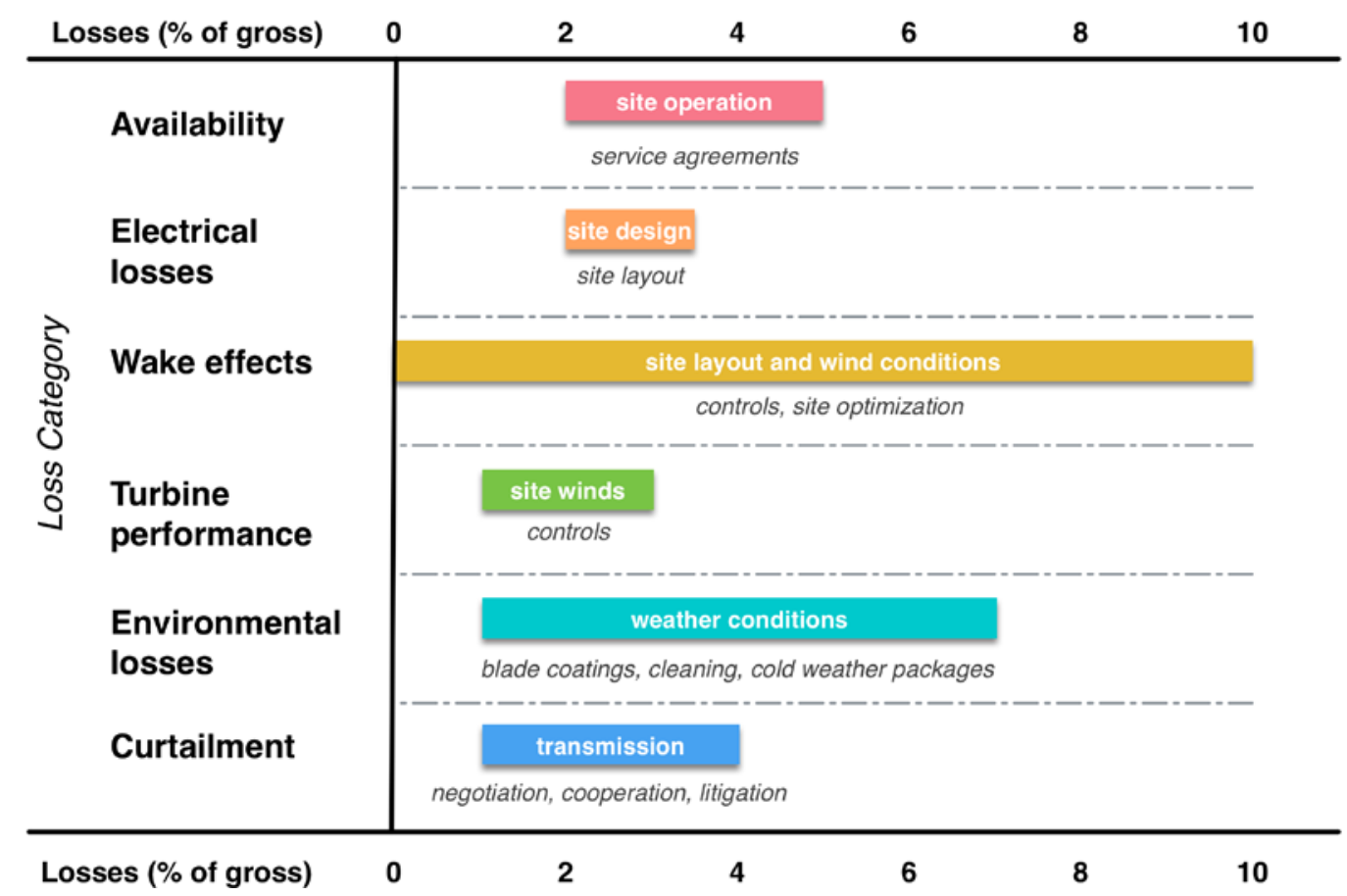

Figure 13. Range of energy losses in a wind plant's preconstruction energy estimate Controlling factors are shown in the bars; mitigation actions are shown beneath. Values apply to wind plants designed and built from 2010-2015 and are based on the literature survey in Section 4.

The range of operating conditions encountered by wind projects is very large. Therefore, it is difficult to assess how improvements in measurements or modeling might impact the wind industry. A solution may be to develop a set of baseline wind plant designs with well-defined uncertainties and losses and associated power take-off scenarios. These models can be used to assess the impact of reductions in uncertainty on the financial performance of a wind power plant. These baseline wind plant designs should represent realistic development projects, so their design would benefit from partnerships between research organizations and plant developers. 


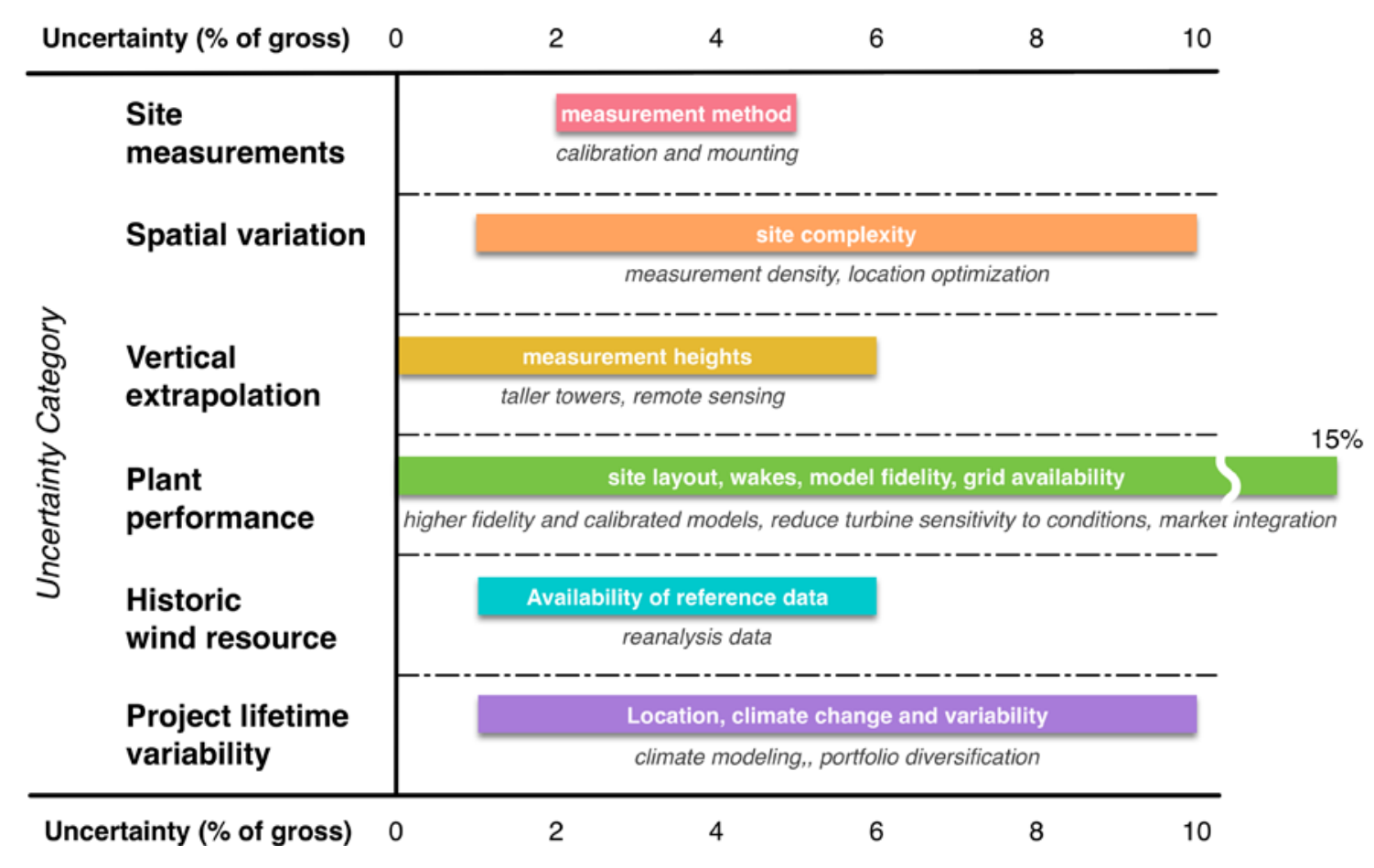

Figure 14. Range of energy uncertainties in a wind plant's preconstruction energy estimate Controlling factors are shown in the bars; mitigation actions are shown beneath. Values apply to wind plants designed and built in 2010-2015 and are based on the literature survey in Section 4.

The current sequential approach to estimating plant performance and then estimating losses impacts the accuracy of energy predictions and may lead to less-than-optimal wind farm designs. Current wake models are often simplistic and seldom include real atmospheric effects. The lack of detailed models of O\&M costs that can be used in the plant optimization process means that O\&M costs are only estimated later. Similarly, there is a lack of widely available reliability models that relate inflow to turbine failure rates. Together, these issues give rise to plant designs that may appear to optimize energy capture but fail to capture the negative effects of wakes on turbine performance and loads, which may increase O\&M costs and contribute to lower-thanexpected turbine availability because of high turbine loads.

Checking predictions against the actual performance of the wind plant and distinguishing among causes of variation in production is a major challenge. For this reason, there is a trend toward increasing sharing of specific data within the wind community. Examples include:

- O\&M data held in the Continuous Reliability Enhancement for Wind database operated by Sandia National Laboratories

- Drivetrain reliability data held by the Gearbox Reliability Collaborative, which is operated by the National Renewable Energy Laboratory

- Blade defect data held by the Blade Reliability Collaborative, which is operated by Sandia National Laboratories

- Wind turbine power performance data shared within the Power Curve Working Group 
- Experiences with wind resource data analysis shared within working groups affiliated with the American Wind Energy Association and European Wind Energy Association.

A next step in data sharing may be the formation of a confidential database that contains preconstruction energy estimates with data collected from the operating wind plant. An independent third party, who would only publish anonymized and aggregated information from the database, could hold the data. These data would enable preconstruction energy analysis to be compared to real performance information.

The broad range of uncertainties and losses and the dependency on site conditions that was shown in Figure 13, Figure 14, Table 10, and Table 11 suggests there is no one solution that will drastically reduce wind plant losses or uncertainty in wind plant performance during a wind plant's lifetime or from one year to another. However, some opportunities are clear:

- Improve data collection practices during wind resource measurement campaigns through the use of better tower instruments, more and/or taller towers on the development site, and by leveraging remote sensing.

- Improve the measuring and reporting of turbine power curves and provide energy capture models that characterize turbine performance across all atmospheric conditions.

- Improve the modeling of wake effects. This requires developing wake models that better capture the interaction of the turbines and atmosphere and include changing atmospheric conditions, and better models of the response of downwind turbines to wakes. Improved models should be coupled with investigations into ways to either reduce wakes or mitigate the effect of wakes on a farm.

- Improve reliability data sets and models to allow site-specific availability estimates.

- Move to time-based wind plant energy predictions. This would enable realistic accounting for seasonal performance variation due to icing or blade fouling, seasonal curtailment, and the creation of realistic generation profiles for power offtakers.

Current preconstruction energy estimates tend not to include a formal risk assessment. The loss uncertainty estimates may benefit from the use of a risk assessment to classify uncertainties according to the likelihood of risk and severity of risk. For example, grid curtailment may not be an issue at the initial stage of development of a wind plant, but it may be an issue as a region is developed, which may lead to an optimistic energy estimate. Although these risks may be hard to quantify and include in the preconstruction energy estimate, they may be important to the project sponsor. Documenting risks may allow for their later mitigation via contractual arrangements.

Improved preconstruction energy estimates would have positive impacts on wind power plant financing and deployment. This report has identified opportunities for high-impact, industryfocused research and development that would benefit from sharing experiences and data among the wind industry, government agencies, and academia, leading to reduced uncertainty and losses. Reducing losses increases the energy that a wind plant can deliver, thus increasing revenue. Reducing uncertainty about that energy offers the potential to bring in other capital sources that may be more risk averse and potentially offers the chance to reduce the cost of capital. Ultimately these steps could reduce the cost of energy supplied to the grid and support the deployment of wind energy in the United States and worldwide. 


\section{References}

Abiven, C., J. Palma, and O. Brady. 2011. "High-Frequency Field Measurements and TimeDependent Computational Modelling for Wind Turbine Siting." Journal of Wind Engineering and Industrial Aerodynamics 99:123-129.

Albers, A. 2010. "Turbulence and Shear Normalisation of Wind Turbine Power Curves." In European Wind Energy Conference and Exhibition 2010.

Baring-Gould, I., R. Cattin, M. Durstewitz, M. Hulkkonen, A. Krenn, T. Laakso, A. Lacroix, E. Peltol, G. Ronsten, L. Tallhaug, and T. Wallenius. 2011. Expert Group Study on Recommended Practices: 13-Wind Energy Projects in Cold Climates (Technical Report). Paris, France: International Energy Agency.

Barthelmie, R.J., K. Hansen, S.T. Frandsen, O. Rathmann, J.G. Schepers, W. Schlez, J. Phillips, K. Rados, A. Zervos, E.S. Politis, and P.K. Chaviaropoulos. 2009. "Modelling and Measuring Flow and Wind Turbine Wakes in Large Wind Farms Offshore.” Wind Energy 12(5):431-444. DOI: $\underline{10.1002 / \text { we. } 348 \text {. }}$

Bechmann, A., N. Sørensen, J. Berg, J. Mann, and P.-E. Réthoré. 2011. "The Bolund Experiment, Part II: Blind Comparison of Microscale Flow Models.” Boundary-Layer Meteorology 141:245-271. DOI:10.1007/s10546-011-9637-X.

Bird, L., J. Cochran, and X. Wang. 2014. Wind and Solar Energy Curtailment: Experience and Practices in the United States (Technical Report). NREL/TP-6A20-60983. Golden, CO: National Renewable Energy Laboratory.

Brandle, James R., X. Zhou, and L. Hodges. 2006. How Windbreaks Work (Technical Report). EC1763. Lincoln, NE: University of Nebraska-Lincoln Extension.

Brochu, J., C. Larose, and R. Gagon. 2011. "Generic Equivalent Collector System Parameters for Large Wind Power Plants.” IEEE Transactions on Energy Conversion 26(2).

Brower, M., M. Marcus, M. Taylor, D. Bernadett, M. Filippelli, P. Beaucage, E. Hale, K. Elsholz, J. Doane, M. Eberhard, J. Tensen, and D. Ryan, D. 2010. Wind Resource Assessment Handbook (Technical Report). 10-30. Albany, NY: New York State Energy Research and Development Authority.

Bulaevskaya, V., S. Wharton, A. Clifton, G. Qualley, and W.O. Miller. 2015. "Wind Power Curve Modeling in Complex Terrain Using Statistical Models." Journal of Renewable and Sustainable Energy 7(1):013103.

Carta, J.A., S. Velázquez, and P. Cabrera. 2013. "A Review of Measure-Correlate-Predict (MCP) Methods Used to Estimate Long-Term Wind Characteristics at a Target Site." Renewable and Sustainable Energy Reviews 27(0):362-400. 
Chagnon, S. and T.R. Karl. 2010. Temporal and Spatial Variations of Freezing Rain in the Contiguous United States: 1948-2000. Journal of Applied Meteorology, 42, 1302-1315, DOI: 10.1175/1520-0450(2003)042<1302:TASVOF $>2.0 . \mathrm{CO} ; 2$.

Choukulkar, A., Y. Pichugina, C. Clack, R. Calhoun, R. Banta, A. Brewer, and M. Hardesty. 2015. "A new formulation for rotor equivalent wind speed for wind resource assessment and wind power forecasting." Wind Energy. DOI: 10.1002/we.1929

Churchfield, M., S. Lee, J. Michalakes, and P. Moriarty. 2012. "A Numerical Study of the Effects of Atmospheric and Wake Turbulence on Wind Turbine Dynamics." Journal of Turbulence 13(14).

Clerc, A., M. Anderson, P. Stuart, and C. Habenicht. 2012. “A Systematic Method for Quantifying Wind Flow Modelling Uncertainty in Wind Resource Assessment." Journal of Wind Engineering and Industrial Aerodynamics 111(0):85-94.

Clifton, A., and J.K. Lundquist. 2012. "Data Clustering Reveals Climate Impacts on Local Wind Phenomena." Journal of Applied Meteorology and Climatology 51:1,547-1,557.

Clifton, A., and R. Wagner. 2014. "Accounting for the Effect of Turbulence on Wind Turbine Power Curves.” Journal of Physics: Conference Series 524(1):012109.

Clifton, A., D. Elliott, and M. Courtney. 2013. Ground-Based Vertically-Profiling Remote Sensing for Wind Resource Assessment:15-Expert Group Study on Recommended Practices (Technical Report). Paris, France: International Energy Agency. First Edition.

Clifton, A., L. Kilcher, J.K. Lundquist, and P. Fleming. 2013a. "Using Machine Learning to Predict Wind Turbine Power Output.” Environmental Research Letters 8(2):024009.

Clifton, A., S. Schreck, G. Scott, N.D. Kelley, and J.K. Lundquist. 2013b. "Turbine Inflow Characterization at the National Wind Technology Center." Journal of Solar Energy Engineering 135(3). DOI: $10.1115 / 1.4024068$

Colmenar-Santos, A., A. Campíez-Romero, L.A. Enríquez-Garcia, and C. Pérez-Molina. 2014. "Simplified Analysis of the Electric Power Losses for On-Shore Wind Farms Considering Weibull Distribution Parameters." Energies 7(11):6856-6885.

Conroy, N., J. Deane, and B.P.Ó. Gallachóir. 2011. "Wind Turbine Availability: Should It Be Time or Energy Based? A Case Study in Ireland.” Renewable Energy 36(11):2967-297.

Davis, N., A. Hahmann, N.-E. Clausen, and M. Zagar. 2014. "Icing Impacts on Wind Energy Production.” PhD diss., Danish Technical University.

DNV KEMA. 2013. Framework for the Categorisation of Losses and Uncertainty for Wind Energy Assessments (Technical Report). Chalfront, PA. http://www.dnv.nl/binaries/final\%20-

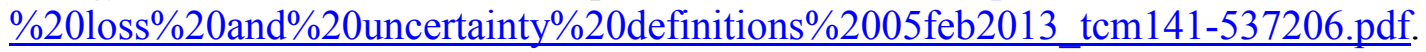


Draxl, C., A. Purkayastha, and Z. Parker. 2014. Wind Resource Assessment of Gujarat (India) (Technical Report). NREL/TP-5000-61741. Golden, CO: National Renewable Energy Laboratory.

Du Pont, B.L., and J. Cagan. 2012. "An Extended Pattern Search Approach to Wind Farm Layout Optimization.” Journal of Mechanical Design 134(8):081002-081002.

Elkinton, M., A. Rogers, and J. McGowan, 2006. "An Investigation of Wind-Shear Models and Experimental Data Trends for Different Terrains." Wind Engineering 30(4):341-350. DOI: $\underline{10.1260 / 030952406779295417}$

European Accreditation Laboratory Committee. 2013. Expression of the Uncertainty of Measurement in Calibration (Technical Report). EA-4/02. Paris, France.

Fleming, P.A., A. Ning, P.M.O. Gebraad, and K. Dykes. 2015. "Wind Plant System Engineering through Optimization of Layout and Yaw Control.” Wind Energy. DOI: 10.1002/we.1836.

Fleming, P.A., P.M. Gebraad, S. Lee, J.-W. van Wingerden, K. Johnson, M. Churchfield, J. Michalakes, P. Spalart, and P. Moriarty. 2014. "Evaluating Techniques for Redirecting Turbine Wakes Using SOWFA.” Renewable Energy 70(0):211-218.

Gebraad, P.M.O., F.W. Teeuwisse, J.W. van Wingerden, P.A. Fleming, S.D. Ruben, J.R. Marden, and L.Y. Pao. 2014. "Wind Plant Power Optimization through Yaw Control Using a Parametric Model for Wake Effects-A CFD Simulation Study." Wind Energy. DOI: $\underline{10.1002 / \text { we. } 1822}$

Graves, A.M., K. Harman, M. Wilkinson, and R. Walker. 2008. "Understanding Availability Trends of Operating Wind Farms." Paper presented at American Wind Energy Association WINDPOWER Conference and Exhibition, Houston, Texas, June.

Harper, J., Matthew D. Karcher, and Mark Bolinger. 2007. Wind Project Financing Structures: A Review and Comparative Analysis (Technical report). LBNL-63434. Berkeley, CA: Lawrence Berkeley National Laboratory.

Hamilton, B., M. Bielecki, C. Bloch, T. Decker, L. Frantzis, K. Midura, J. Paidipati, and F. Zhao. 2014. Offshore Wind Market and Economic Analysis 2014 Annual Market Assessment. Burlington, MA: Navigant Consulting, Inc. http://energy.gov/sites/prod/files/2014/09/f18/2014\%20Navigant $\% 20$ Offshore $\% 20 \mathrm{Wind} \% 20 \mathrm{Mar}$ ket $\% 20 \% 26 \% 20$ Economic $\% 20$ Analysis.pdf.

Hedevang, E. 2012. "Wind Turbine Power Curves Incorporating Turbulence Intensity." Wind Energy. DOI: $\underline{10.1002 / w e .1566}$

Homola, M.C., M.S. Virk, T. Wallenius, P.J. Nicklasson, and P.A. Sundsbø. 2010. "Effect of Atmospheric Temperature and Droplet Size Variation on Ice Accretion of Wind Turbine Blades." Journal of Wind Engineering and Industrial Aerodynamics 98(12) 724-729. DOI: 10.1016/j.jweia.2010.06.007. 
IEC. 2005. IEC 61400-1: Wind Turbines-Part 1: Design Requirements. Geneva, Switzerland: International Electrotechnical Commission. Third PPUB Edition.

IEC. 2011. IEC 61400-26-1: Wind Turbines-Part 26-1: Time-Based Availability for Wind Turbine Generating Systems. International Electrotechnical Commission, Geneva, Switzerland, First PPUB Edition.

Jasinski W.J., S.C. Noe, M.S. Selig, and M.B. Bragg. 1998. "Wind Turbine Performance Under Icing Conditions.” Journal of Solar Energy Engineering 120(1)60-65. DOI: 10.1115/1.2888048.

Klink, K. 2002. "Trends and Interannual Variability of Wind Speed Distributions in Minnesota." Journal of Climate 15(22):3311-3317. DOI: 10.1175/15200442(2002)015<3311:TAIVOW $>2.0 . \mathrm{CO} ; 2$.

Lackner, M.A., A.L. Rogers, J.F. Manwell, and J.G. McGowan. 2010. “A New Method for Improved Hub Height Mean Wind Speed Estimates Using Short-Term Hub Height Data.” Renewable Energy 35(10):2340-2347.

Mone, C., A. Smith, B. Maples, and M. Hand. 2015. 2013 Cost of Wind Energy Review (Technical Report). NREL/TP-5000-63267. Golden, CO: National Renewable Energy Laboratory.

Moriarty, Patrick, Javier Sanz Rodrigo, Pawel Gancarski, Matthew Chuchfield, Jonathan W. Naughton, Kurt S. Hansen, Ewan Machefaux, Eoghan Maguire, Francesco Castellani, Ludovico Terzi, Simon-Philippe Breton, and Yuko Ueda. 2014. "IEA-Task 31 WAKEBENCH: Towards a Protocol for Wind Farm Flow Model Evaluation. Part 2: Wind Farm Wake Models." J. Phys.: Conf. Ser. Journal of Physics: Conference Series 524: 012185. doi:10.1088/1742$6596 / 524 / 1 / 012185$.

Mortensen, N.G., M. Nielsen, and H.E. Jørgensen. 2015. “Offshore CREYAP Part 2: Final results." Paper presented at the 2015 European Wind Energy Association Resource Assessment Workshop, Helsinki.

Oliver, A. 2010. El Niño Southern Oscillation, Climate Indices and Their Relationship with Wind Speed in the Texas Panhandle (Technical Report). Broomfield, CO: Renewable Energy Systems Americas.

Paiva, L.M., G.C. Bodstein, and W.F. Menezes. 2009. "Numerical Simulation of Atmospheric Boundary Layer Flow over Isolated and Vegetated Hills Using RAMS." Journal of Wind Engineering and Industrial Aerodynamics 97(9-10):439-454. DOI:10.1016/j.jweia.2009.07.006

Pedersen, T.F., J.-Å. Dahlberg, and P. Busche. 2006. ACCUWIND-Classification of Five Cup Anemometers According to IEC 61400-12-1 (Technical Report). Risø-R-1556(EN). Roskilde, Denmark: Risø DTU National Laboratory.

Pichugina, Y.L., R.M. Banta, W.A. Brewer, S.P. Sandberg, and R.M. Hardesty. 2011. "Doppler Lidar-Based Wind-Profile Measurement System for Offshore Wind-Energy and Other Marine 
Boundary Layer Applications." Journal of Applied Meteorology and Climatology 51(2): 327349.

Pryor, S., and R. Barthelmie. 2013. "Assessing the Vulnerability of Wind Energy to Climate Change and Extreme Events." Climatic Change 121(1):79-91. DOI: 10.1007/s10584-013-0889y

Pryor, S., R. Barthelmie, and J. Schoof. 2006. "Inter-Annual Variability of Wind Indices across Europe." Wind Energy 9:27-38.

Rogers, A.L., J.W. Rogers, and J.F. Manwell. 2005. "Comparison of the Performance of Four Measure-Correlate-Predict Algorithms." Journal of Wind Engineering and Industrial Aerodynamics 93(3):243-264.

Rogers, A.L., J.W. Rogers, and J.F. Manwell. 2006. "Uncertainties in Results of MeasureCorrelate-Predict Analyses." Paper presented at the European Wind Energy Conference and Exhibition, Athens, Greece, February.

Rodrigo, Javier Sanz, Pawel Gancarski, Roberto Chavez Arroyo, Patrick Moriarty, Matthew Chuchfield, Jonathan W. Naughton, Kurt S. Hansen, Ewan Machefaux, Tilman Koblitz, Eoghan Maguire, Francesco Castellani, Ludovico Terzi, Simon-Philippe Breton, Yuko Ueda, John Prospathopoulos, Gregory S. Oxley, Carlos Peralta, Xiadong Zhang, and Björn Witha. 2014. "IEA-Task 31 WAKEBENCH: Towards a Protocol for Wind Farm Flow Model Evaluation. Part 1: Flow-over-terrain Models." J. Phys.: Conf. Ser. Journal of Physics: Conference Series 524: 012105. doi:10.1088/1742-6596/524/1/012105.

Sareen, A., C.A. Sapre, and M.S. Selig. 2014. "Effects of Leading Edge Erosion on Wind Turbine Blade Performance.” Wind Energy 17(10). DOI:10.1002/we.1649

Sempreviva, A., R. Barthelmie, and S. Pryor. 2008. "Review of Methodologies for Offshore Wind Resource Assessment in European Seas.” Surveys in Geophysics 29(6):471-497.

Spengemann, P., and V. Borget. 2008. "Review and Analysis of Wind Farm Operational Data Validation of the Predicted Energy Yield of Wind Farms Based on Real Energy Production Data." Presented at DEWEK, Bremen, Germany, November.

Staffell, I., and R. Green. 2014. "How Does Wind Farm Performance Decline with Age?" Renewable Energy 66(0):775-786. DOI: 10.1016/j.renene.2013.10.041

Stull, R. 1988. An Introduction to Boundary Layer Meteorology. Dordrecht, Netherlands: Kluwer Academic Publishers. Second Reprint 1989 Edition.

Tavner, P.J., J. Xiang, and F. Spinato. 2007. "Reliability Analysis for Wind Turbines." Wind Energy 10(1):1-18. DOI: $10.1002 /$ we.204

Tegen, S. 2015. "Wind Energy Deployment Process and Siting Tools" (Presentation). NREL/PR5000-63711. Golden, CO: National Renewable Energy Laboratory. http:/www.nrel.gov/docs/fy15osti/63711.pdf. 
Troen, I., and E. Peterson. 1989. European Wind Atlas. Roskilde, Denmark: Risø National Laboratory.

VanLuvanee, D.R., T. Rogers, G. Randall, A. Williamson, and T. Miller. 2009. "Comparison of WAsP, CFD, NWP and Analytical Methods for Estimating Site Wide Wind Speeds." Presented at the European Wind Energy Conference and Exhibition, Marseille, France.

Wagner, R., M. Courtney, J. Gottschall, and P. Lindelöw-Marsden. 2011. "Accounting for the Speed Shear in Wind Turbine Power Performance Measurement." Wind Energy 14(8):993-1004.

Walls, Elizabeth. 2015. "Continuum Wind Flow Model: Introduction to Model Theory and Case Study Review." Wind Engineering 39(3):271-298.

Wang, N., K. Johnson, and A. Wright. 2013. "Comparison of Strategies for Enhancing Energy Capture and Reducing Loads Using Lidar and Feedforward Control." IEEE Transactions on Control Systems Technology 21(4):1,129-1,142.

Western Electricity Coordinating Council Wind Generator Modeling Group. 2008. WECC Wind Power Plant Power Flow Modeling Guide (Technical Report). Salt Lake City, UT.

Wharton, S., and J.K. Lundquist. 2012. "Assessing Atmospheric Stability and Its Impacts on Rotor-Disk Wind Characteristics at an Onshore Wind Farm." Wind Energy 15:525-546. DOI: $10.1002 /$ we. 483 .

Wiser, R., and M. Bollinger. 2015. 2014 Market Technologies Report (Technical Report). DOE/GO- 102015-4702. Washington, D.C.: U.S. Department of Energy, Office of Energy Efficiency and Renewable Energy, Wind Program (EE- 4W). DOI: 10.2172/1220532.

Working Group 1 of the Joint Committee for Guides in Metrology. 2008. Evaluation of Measurement Data: Guide to the Expression of Uncertainty in Measurement (Technical Report). Sèvres, France: Bureau International des Poids et Mesures. Available from www.bipm.org.

Zhang, J., C. Draxl, T. Hopson, L. Delle Monache, E. Vanvyve, and B.-M. Hodge. 2015. "Comparison of Numerical Weather Prediction Based Deterministic and Probabilistic Wind Resource Assessment Methods." Applied Energy 156:528-541. DOI: 10.1016/j.apenergy.2015.07.059. 